\title{
Embodied technological change and patterns of investment in Austrian manufacturing
}

Citation for published version (APA):

Leitner, S. (2009). Embodied technological change and patterns of investment in Austrian manufacturing.

[Doctoral Thesis, Maastricht University]. Maastricht University. https://doi.org/10.26481/dis.20090312sl

Document status and date:

Published: 01/01/2009

DOI:

10.26481/dis.20090312sl

Document Version:

Publisher's PDF, also known as Version of record

\section{Please check the document version of this publication:}

- A submitted manuscript is the version of the article upon submission and before peer-review. There can be important differences between the submitted version and the official published version of record.

People interested in the research are advised to contact the author for the final version of the publication, or visit the DOI to the publisher's website.

- The final author version and the galley proof are versions of the publication after peer review.

- The final published version features the final layout of the paper including the volume, issue and page numbers.

Link to publication

\footnotetext{
General rights rights.

- You may freely distribute the URL identifying the publication in the public portal. please follow below link for the End User Agreement:

www.umlib.nl/taverne-license

Take down policy

If you believe that this document breaches copyright please contact us at:

repository@maastrichtuniversity.nl

providing details and we will investigate your claim.
}

Copyright and moral rights for the publications made accessible in the public portal are retained by the authors and/or other copyright owners and it is a condition of accessing publications that users recognise and abide by the legal requirements associated with these

- Users may download and print one copy of any publication from the public portal for the purpose of private study or research.

- You may not further distribute the material or use it for any profit-making activity or commercial gain

If the publication is distributed under the terms of Article $25 \mathrm{fa}$ of the Dutch Copyright Act, indicated by the "Taverne" license above, 
Embodied Technological Change and Patterns of Investment in Austrian Manufacturing 
(c) Sandra M, Leitner, Maastricht 2009

ISBN 978-90-5278-815-9

Universitaire Pers Maastricht 


\title{
Embodied Technological Change and \\ Patterns of Investment in \\ Austrian Manufacturing
}

\author{
PROEFSCHRIFT
}

ter verkrijging van de graad van doctor aan de Universiteit Maastricht, op gezag van de Rector Magnificus, Prof. Mr. G.P.M.F. Mols

volgens het besluit van het College van Decanen,

in het openbaar te verdedigen

op donderdag 12 maart 2009 om 14.00 uur

door

Sandra M. Leitner

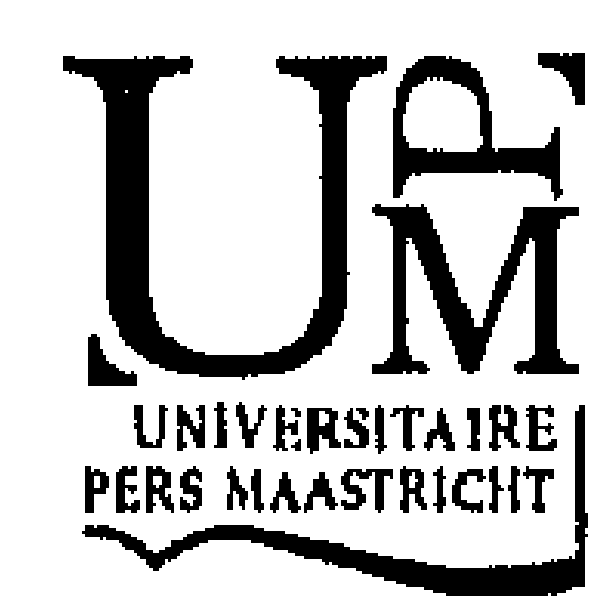




\section{Promotor}

Prof. Dr. Pierre Mohnen

\section{Beoordelingscommissie}

Prof. Dr. Bart Verspagen (voorzitter)

Prof. Dr. Michael Landesmann (Johannes Kepler University Linz, Austria)

Prof. Dr. Gerard Pfann 


\section{Acknowledgements}

First of all I would like to thank my supervisor and promoter Dr. Pierre Mohnen for his invaluable comments and his incredible eye for details. I am particularly thankful for his patience when due to diverse circumstances priorities shifted and progress came to an end. His endless optimism and continuous encouragement made this endeavor a less arduous one.

This is also a great opportunity to thank Dr. Michael Landesmann who has been pivotal to my entire academic career. He has been motivating and encouraging, but most of all, he has been enlightening. His enthusiasm and profound knowledge deeply inspired and stimulated me in my academic pursuit. He never had a simple answer to my questions but always provided me with a list of references instead.

I would like to thank the Department of Economics at Johannes Kepler University, especially my former colleagues at the Institute for Economic Theory and Quantitative Economics for their expertise and encouragement. I am particularly indebted to Dr. Reiner Buchegger for his invaluable input and continuous support.

I am very grateful to Corien Gijsbers who made UNU-MERIT a warm and joyful place and to Eveline in de Braek for her invaluable administrative support. Special thanks to Bas Straathof for translating the abstract into Dutch.

Special thanks to my dearest friends Jose Maria D. Caparas, Ma. Teresa S. Dueñas, Victoria Kravtsova and Doris Weichselbaumer for their understanding, trust, inspiration, incessant support and humor.

Finally, and most importantly, I would like to thank my family. My sister Monja has always been my greatest inspiration. Her endless support and encouragement were pivotal for my academic pursuit. I also thank my brother-in-law Stefan whose continuous support and understanding greatly facilitated my professional life. I also wish to thank my nephew Lion and my nieces Lucia, Leyla and Laetitia for constantly reminding me to never stop asking questions. 


\section{Table of Contents}

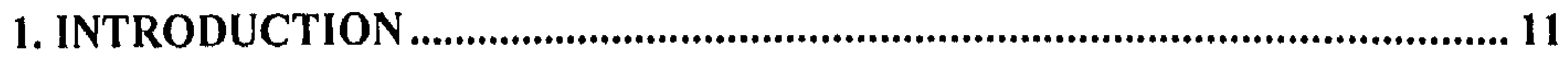

I. EMBODIED TECHNOLOGICAL CHANGE............................................ 11

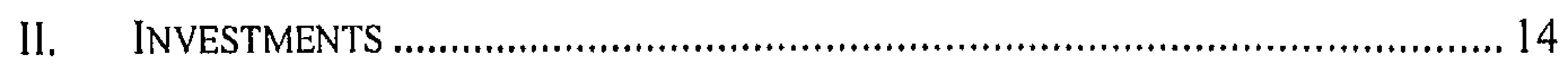

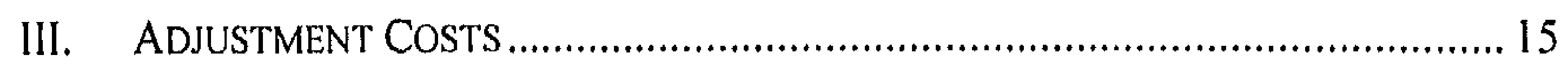

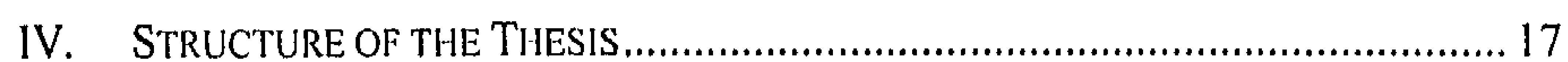

\section{THE AUSTRIAN BUSINESS CYCLE - A ROLE FOR TECHNOLOGY} SHOCKS?

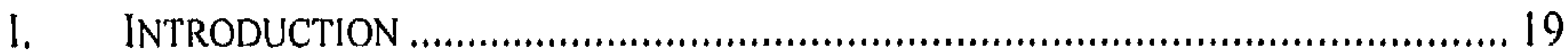

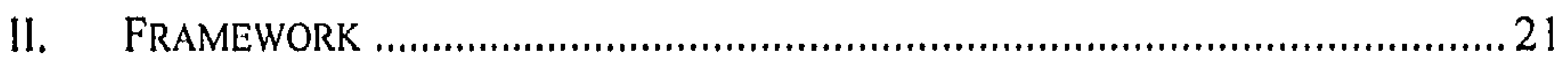

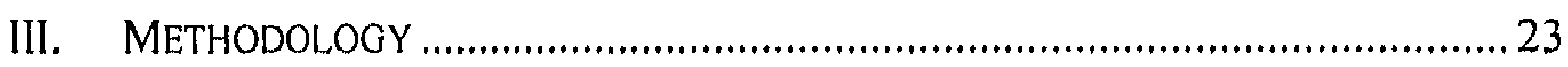

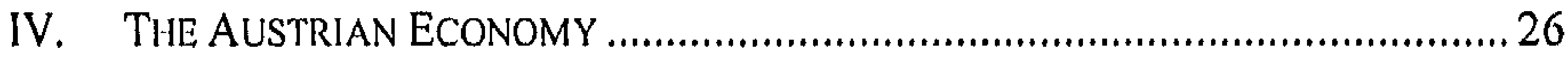

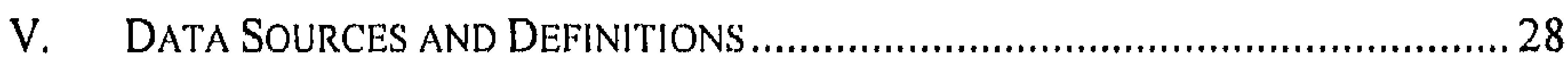

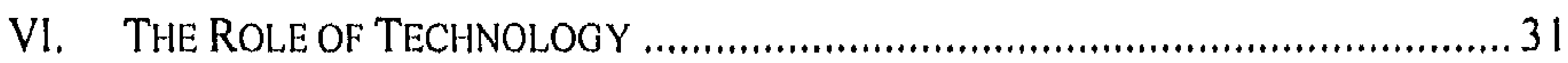

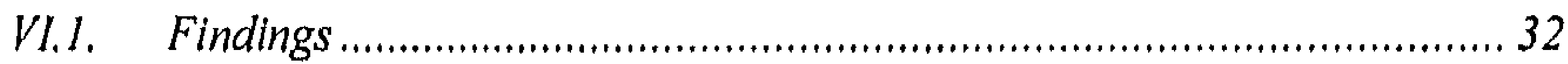

VI.1.1 Impulse-Response Functions............................................................. 32

VI.1.2 Discussion of the Hours Response ....................................................... 34

VI.I.3 The Role of Technology for the Variation in Monthly Hours Worked

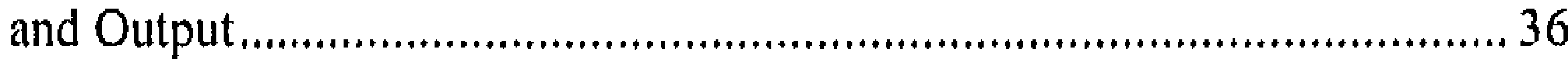

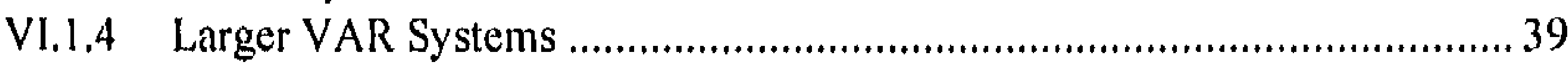

VII. EXOGENEITY OF IDENTIFIED TECHNOLOGY SHOCKS ............................... 42

VIII. SUMMARY AND CONCLUSION ......................................................... 43

3. INTERRELATEDNESS, DYNAMIC FACTOR ADJUSTMENT PATTERNS AND FIRM HETEROGENEITY IN AUSTRIAN MANUFACTURING ...... 53

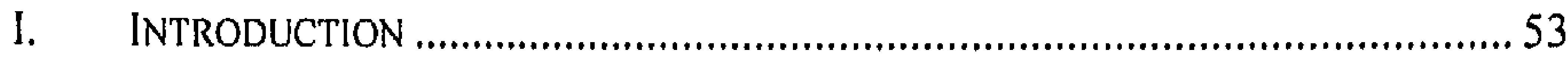

II. RELATED RECENT LITERATURE ...................................................... 55

III. INPUT SPIKES AND INTERRELATEDNESS ........................................... 57

III.1. Data and Descriptive Statistics.................................................... 57

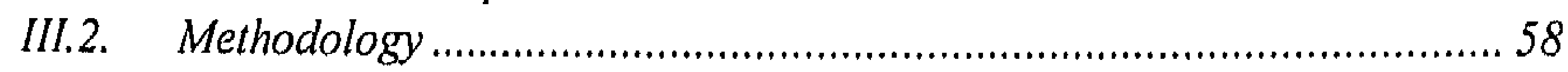

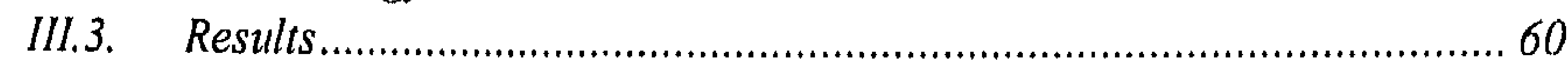

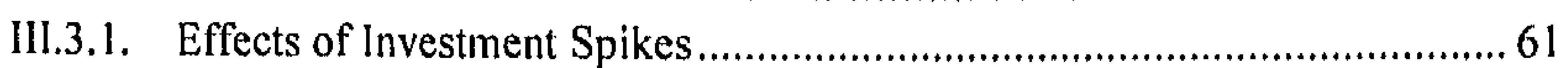

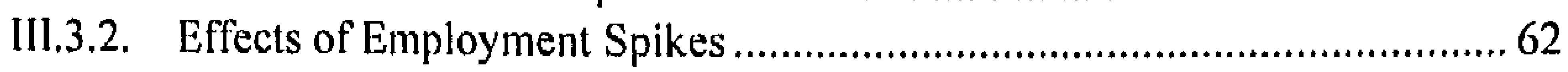

III.3.3. Effects of Non-Production Labor Spikes.............................................63

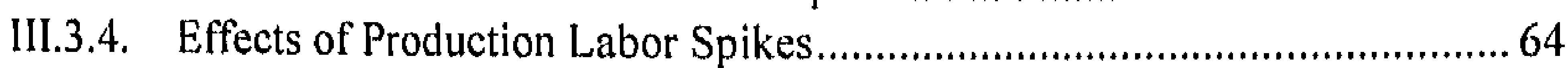

III.4. Performance Spike Effects ...................................................6 65

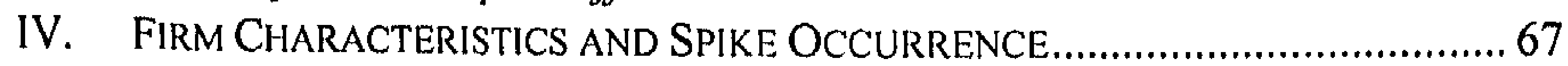

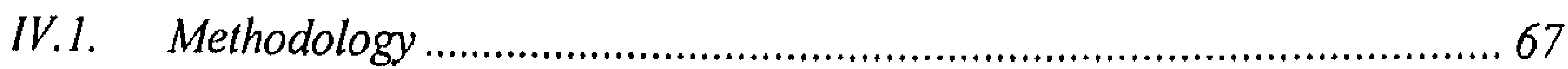

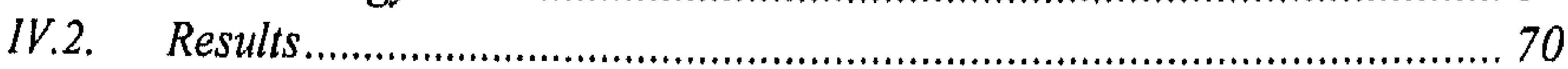

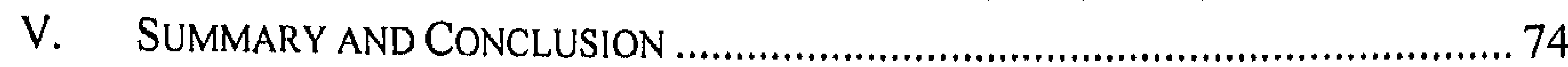




\section{THE NATURE OF CAPITAL ADJUSTMENT COSTS IN AUSTRIAN}

MANUFACTURING

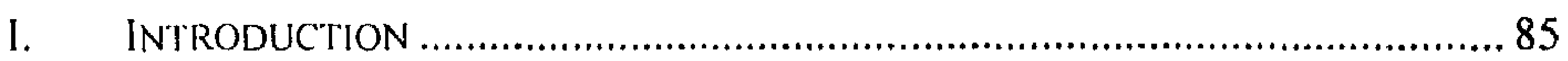

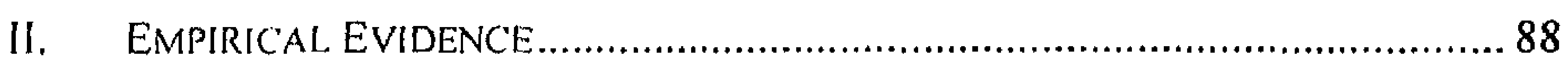

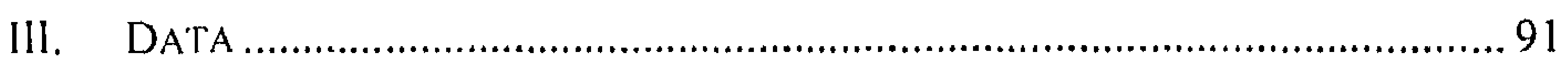

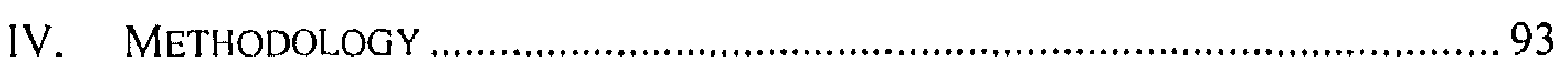

IV.1 Case 1: Convex Adjustment Costs only .......................................... 95

IV.2 Case 2: Nonconvex Adjustment Costs only ...................................... 95

IV.3 Case 3: Convex and Nonconvex Adjustment Costs and Investment Irreversibilities ................................................................96

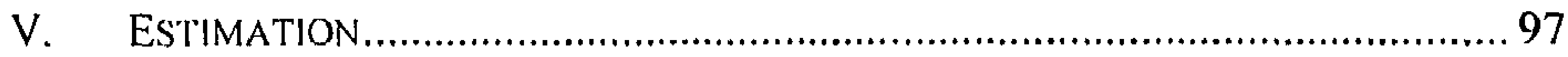

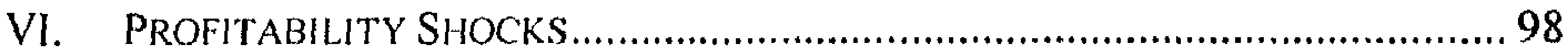

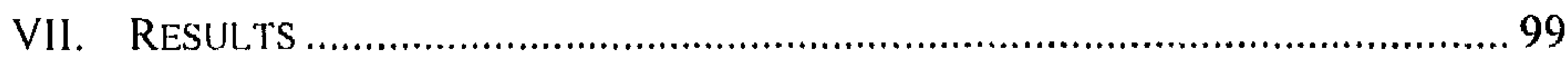

VIII. SUMMARY AND CONCIUSION …....................................................... 100

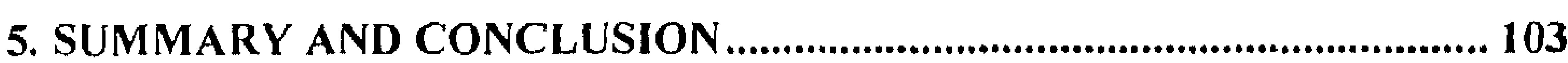

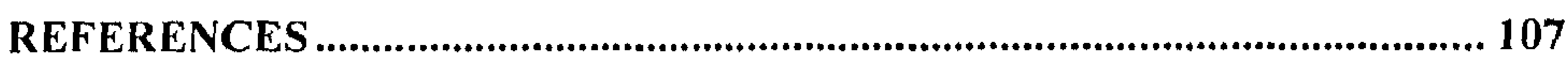

NEDERLANDSE SAMENVATTING ........................................................... 11 


\section{List of Tables}

TABLE 1: CONTRIBUtions of EMBODIED TECHNOLOGY TO BUSINESS CyCLE

CONTRIBUTIONS OF OUTPUT AND HOURS WORKED.

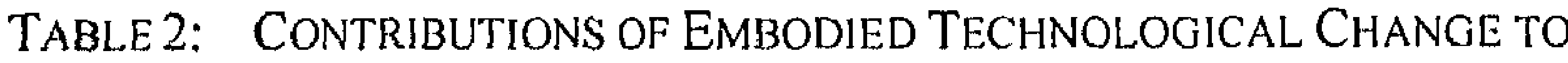

ECONOMIC GROWTH .

TABLE 3: COHESION RESULTS FOR DIFFERENT OPENNESS INDICATORS .................. 38

TABLE 4: EXOGENEITY TEST - P-VALUES ..................................................... 42

TABLE 5: STATIONARITY TESTS FOR THE SUBPERIOD: 1977:1 TO 2005:4 ...............44 44

TABLE 6: STRUCTURAL VECTOR AUTOREGRESSION RESULTS WITH THE REAL TRADE BALANCE AS OPENNESS INDICATOR: 1977:1 TO 2005:4 ............... 45

TABLE 7: UNCONDITIONAL CORRELATION ..................................................... 46

TABLE 8: ABSOLUTE FREQUENCY OF SPIKY INPUT ADJUSTMENTS .......................... 59

TABLE 9: SUMMARY STATISTICS OF ANALYZED INPUT SPIKES ............................ 60

TABLE 10: EFFECTS OF PREVIOUS, CURRENT OR FUTURE ABSOLUTE OR RELATIVE INVESTMENT SPIKES

TABle 1 1: EfFects of Previous, Current or Future Positive or NEGATIVE EMPLOYMENT SPIKES

Table 12: Effects of Previous, Current or Future Positive or Negntive NON-PRODUCTION LABOR SPIKES

TABle 13: EFfects of Previous, CURRENT OR Future Positive or NEGATIVE PRODUCTION LABOR SPIKES

TABLE 14: RESUlTS FOR OUTPUT, LABOR PRODUCTIVITY AND PROFITS .................66 66

TABLE 15: REGRESSION RESULTS - FIXED EFFECTS LOGIT FOR 3-YEAR WINDOW .... 71

TABLE 16: EXPECTED AND ACTUAL EFFECTS OF EXPLANATORY VARIABLES...........73

TABLE 17: INDUSTRY SERVICE LIVES OF MACHINERY AND EQUIPMENT (EXCLUDING VEHICLES) ............................................................. 78

TABLE 18: CONTEMPORANEOUS CORRELATION OF INPUT FACTORS ...................... 81

TABLE 19: SUMMARY STATISTICS .............................................................. 81

TABLE 20: REGRESSION RESULTS - FIXED EFFECTS LOGIT FOR ALL RELEVANT OBSERVATIONS.

TABLE 21: MOMENTS OF INVESTMENT RATE

TABLE 22: CHARACTERIZATION OF INPUT ADJUSTMENT RATES ........................... 92

TABLE 23: MEAN INVESTMENT ADJUSTMENT RATES BY RANK ............................. 93

TABLE 24: PARAMETER VAlUES USED IN THE SIMULATION ................................... 99

TABLE 25: Simulated MOMENTS AND STRUCTURAL COST PARAMETER VALUES 100

TABLE 26: CROSS COUNTRY COMPARISON OF INVESTMENT RATE CHARACTERISTICS . 102

TABLE 27: CROSS COUNTRY COMPARISON OF RESULTS 


\section{List of Figures}

FIGURE 1: RELATIVE PRICE OF EQUIPMENT ................................................... 12

FIGURE 2: REAL GDP PER CAPITA AND REAL GDP PER HOUR IN US-\$ ..................26

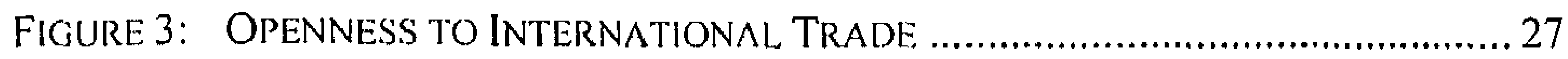

FIGURE 4: MACRO-LEVEL AND INDUSTRY BUSINESS CYCLES ................................29

FIGURE 5: VARIABLES IN THE MODELS ......................................................... 30

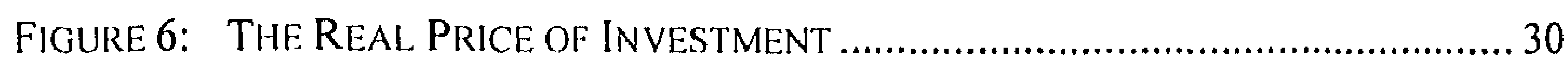

FIgURE 7: THE REAL PRICE OF INVESTMENT OVER THE BUSINESS CYCLE............... 31

FIGURE 8: STRUCTURAL IMPULSE-RESPONSE FUNCTIONS TO STRUCTURAL TECHNOLOGY SHOCKS

FIGURE 9: COHESION OF TECHNOLOGY RELATED VARIATIONS TO OVERALL VARIATIONS IN MONTIILY HOURS WORKED AND OUTPUT WITH TIIE REAL TRADE BALANCE AS OPENNESS INDICATOR (3 LAGS).

FIGURE 10: COHESION OF TECHNOLOGY RELATED VARIATIONS TO OVERALL VARIATIONS IN MONTHLY HOURS WORKED AND OUTPUT WITH THE REAL TRADE BALANCE AS OPENNESS INDICATOR; 6-VARIABLE SPECIFICATION WITH 4 LAGS.

FIGURE 11: COHESION OF TECHNOLOGY RELATED VARIATIONS TO OVERALL VARIATIONS IN MONTHLY HOURS WORKED AND OUTPUT WITH THE REAL TRADE BAL.ANCE AS OPENNESS INDICATOR; 7-VARIABLE SPECIFICATION WITH 5 LAGS,

FIGURE 12: STRUCTURAL IMPULSE-RESPONSE FUNCTIONS TO STRUCTURAL TECHNOLOGY SHOCKS WITH THE TERMS OF TRADE AS OPENNESS INDICATOR (4-VARJABLE SPECIFICATION)...

FIgURE 13: STRUCTURAL IMPULSE-RESPONSE FUNCTIONS TO STRUCTURAL TECHNOLOGY SHOCKS WITH REAL OPENNESS AS OPENNESS INDICATOR (4-VARIABLE SPECIFICATION)

FIGURE 14: ADDITIONAL VARIABLES

FIGURE 15: STRUCTURAL IMPULSE-RESPONSE FUNCTIONS TO STRUCTURAL TECHNOL OGY SHOCKS WITH THE REAL TRADE BALANCE AS OPENNESS INIDICATOR (7-VARIABLE SPECIFICATION). 50

FigurE 16: COHESION OF TECHNOLOGY RELATED VARIATIONS TO OVERALL VARIATIONS IN MONTHLY HOURS WORKED AND OUTPUT WITH THE TERMS OF TRADE AS OPENNESS INDICATOR

FIGURE 17: COHESION OF TECHINOLOGY RELATED VARIATIONS TO OVERALL VARIATIONS IN MONTHLY HOURS WORKED AND OUTPUT WITH REAL OPENNESS AS OPENNESS INDICATOR

FIGURE 18: DISTRIBUTIONS OF RELEVANT INPUT VARIABLES... 80 


\section{Introduction}

\section{Embodied Technological Change}

Historically, the idea that much of technological progress is embodied in new capital equipment with streams of new and more efficient generations of capital vintages continuously replacing obsolete capital is an old and highly disputed one. It dates back as far as Smith's Wealth of Nations (1776) and culminated in the famous embodiment controversy between Jorgenson and Solow in the 1960s.

Basically, which form of technological change dominates is decisive for our understanding of the exact transmission mechanism of technological change to productivity and output growth. In that respect, investment activities are crucial if technological change is embodied in new equipment but irrelevant if technological change is disembodied in nature. And only if entrepreneurs invest in and install leading-edge production technologies will the embodied productivity-enhancing effect fully take effect. On the contrary, disembodied technological change equally affects the productivity of all inputs in production and therefore unfolds independently of any purposeful investment activities'.

Surprisingly, even though the last century witnessed the development of many unparalleled new IT-related durable goods like computers, robots, television or cellular phones, economic studies were unable to detect the obvious. And it was not until Gordon (1990) that the widely held view that a significant amount of quality change remains unmeasured in official statistics was confirmed. His quality-adjusted price indices for 22 types of equipment and their components became a widely used alternative to the standard National Income and Product Accounts (NIPA) price indices. They demonstrated that in the U.S. between 1947 and 1983, embodied technological change grew at an annual average rate of 2.6 percent (Figure 1).

Thereafter, economic studies based on Gordon's equipment price series fundamentally changed economists' understanding of what really drives long-term economic growth or short-term cyclical variations in aggregate output.

Beginning with Greenwood et al. (1997) and Cummings and Violante (2002), quality-adjusted price indices found explicit application and empirical evidence was increasingly put forward which suggested that investment specific technological change, and not neutral technological change, is the major driver of economic growth. Both studies emphasize that about 60 percent of U.S. growth in per capita

\footnotetext{
' Symonymously, embodied technological change is also referred to as investment-specific technological change while disembodied technological change is also referred to as neutral technological change. Throughout, the terms embodied or investment specific technological change and disembodied or neutral technological change will be used interchangeably.
} 
output between 1954 and 2000 can be attributed to investment specific technological change. Furthermore, Cummings and Violante (2002) demonstrate that up to 1975, investment specific technological change grew at an annual rate of 3 percent but accelerated to 5 percent thereafter.

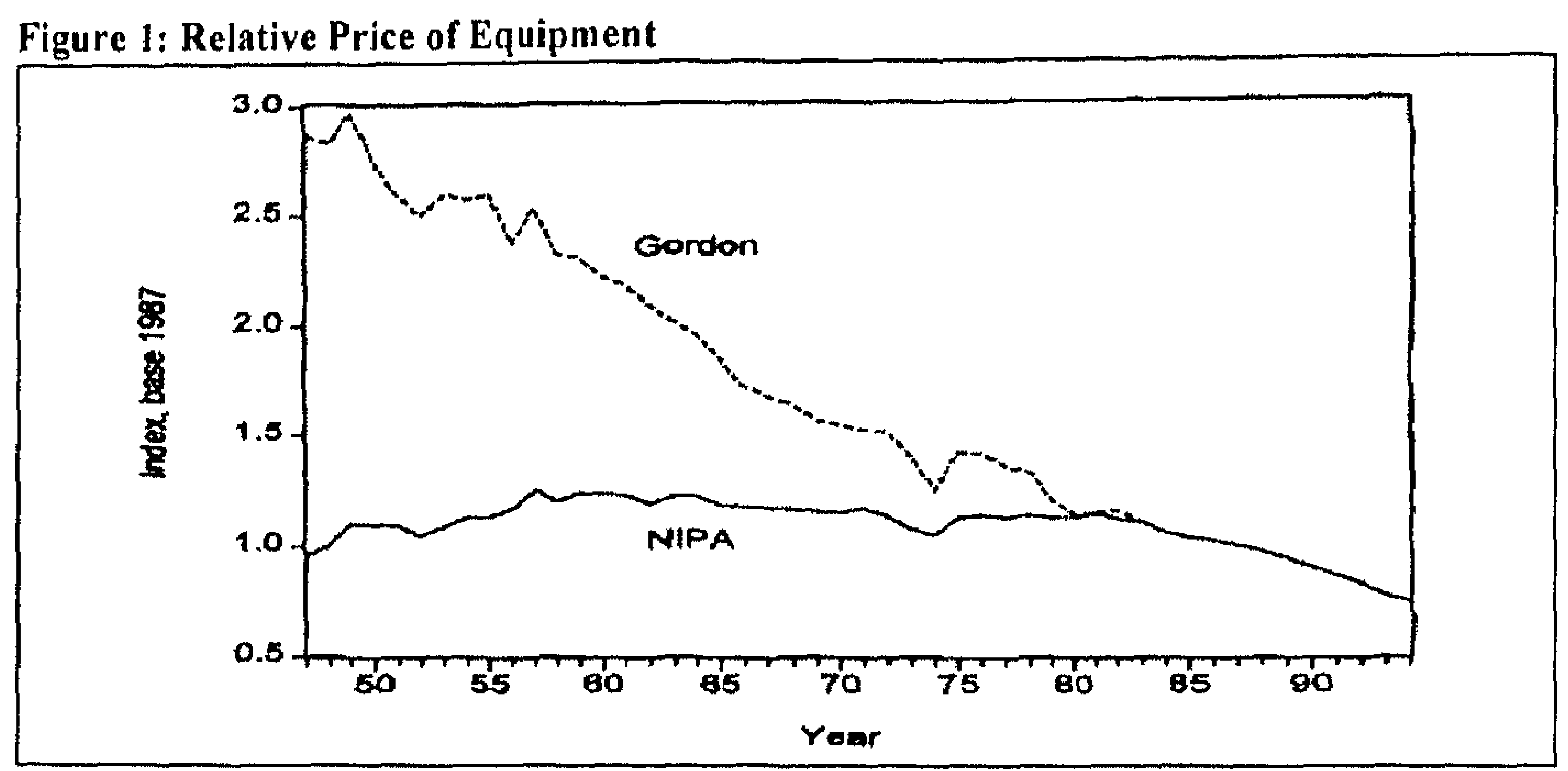

Source: Hercowitz (1998)

Recently embodied technological change is also put to test for its role in explaining recurring business cycle fluctuations in aggregate output and productivity observable in modern economies (see Table 1 for an overview of alternative results).

Once investment specific technological change, as captured by Gordon's equipment price series, is explicitly accounted for, overall technological change is identified as the prime source of U.S. business cycle fluctuations in output and hours worked. Additionally, relative to embodied technological change, disembodied technological change is found to be of negligible importance only.

Fisher (2002) first emphasizes the significance of embodied technology shocks for business cycles and shows that in the U.S. both embodied and disembodied technology shocks together explain between 40 and 76 percent of overall variations in output and between 52 and 64 percent of business cycle variations in hours worked. Moreover, embodied technology shocks alone account for the greater part of cyclical variations: up to 44 percent in output and up to 54 percent in hours worked.

His split-sample analysis later demonstrates that over time, from 1955-1979 to 1982-2000, the contributions of investment specific technology to variations in output and hours worked have changed such that output becalne more responsive while hours worked became less responsive to investment specific technology (Fisher, 2006).

Gambetti (2005) applies a trivariate time-varying coefficients Bayesian Vector Autoregression approach and stresses that in the U.S. both embodied and disembodied technology shocks together explain about 34 to 55 percent of total business cycle volatility of output and hours worked. Again, embodied technology alone accounts 
for the majority of fluctuations in output (22 to 33 percent) and hours worked (21 to 34 percent).

However, Khan and Tsoukalas (2006) show that in contrast to the U.S. technology is of minor importance for UK business cycles. Investment specific technology shocks only explain between 2 and 15 percent of overall observed fluctuations in output and hours worked.

Table 1: Contributions of Embodied Technology to Business Cycle Contributions of Output and Hours Worked

\begin{tabular}{|l|l|l|l|l|}
\hline Authors & Country & Sample Period & \multicolumn{2}{|c|}{$\begin{array}{c}\text { Explained by Embodied } \\
\text { Technology }\end{array}$} \\
& & & A. Output & B. Hours \\
\hline Fisher (2006) & US & $1955: 1-1979: 4$ & $42 \%$ & $47 \%$ \\
Gambetti (2005) & US & $1982: 3-2000: 4$ & $67 \%$ & $36 \%$ \\
Fisher (2002) & US & $1954: 4-2003: 3$ & $22-33 \%$ & $21-34 \%$ \\
Greenwood et al. (2000) & US & $1955: 1-2000: 4$ & $34-44 \%$ & $48-54 \%$ \\
Khan and Tsoukalas (2006) & US & $1954-1990$ & $30 \%$ & \\
\hline
\end{tabular}

These results were in striking contrast to the then widely held view on the dominant source of business cycles: Until then, the consensus prevailed which strongly underscored the significance of neutral technological change for business cycle fluctuations. Inferences were drawn from parametric versions of standard growth models, specified and simulated to test the model's validity by evaluating as to how well the simulated data can resemble the actual data.

Moreover, at the turn of the century, Gali (1999) heavily challenged the realbusiness-cycle interpretation of business cycles that attaches a central role to technology as source of cyclical variations in output or hours. Specifically, his simple reduced-form structural vector autoregression approach that only accounts for neutral technology demonstrates that, between 1948 and 1994, neutral technology shocks only play a secondary role in explaining cyclical variations in hours in the U.S. However, empirical findings of Fisher (2002), which were later confirmed by Gambetti (2005) and Fisher (2006), show that inferences drawn by Galí (1999) are very specific to his assumption of just neutral technology affecting variations in hours. He emphasizes that once investment specific technology shocks are also accounted for, technology shocks become crucial in determining business cycles.

However, Gordon's (1990) quality-adjusted prices also came under heavy criticism for their likely understatement of true embodied technological change for his price indices only cover a subset of all types of equipment, disregarding some potentially crucial kinds of quality changes (Gordon, 1996; Gort and Wall, 1998).

Alternative approaches or modified price indices reconfirm the decisive role of embodied technological change for economic growth: embodied technology growth rates for the U.S. are found to range between 9.5 and 32.6 percent (Hobijn et al., 2002) or between 8 and 17 percent (Sakellaris and Wilson, 2004) (Table 2). 
Table 2: Contributions of Embodied Technological Change to Economic Growth

\begin{tabular}{|l|c|c|l|}
\hline Authors & Country & Sample Period & \multicolumn{1}{|c|}{$\begin{array}{c}\text { Rate of Embodied } \\
\text { Technology }\end{array}$} \\
\hline Sakellaris and Wilson (2004) & US & $1972-1996$ & $8-17 \%$ \\
Hobijn et al. (2002) & US & $1960-1996$ & $\begin{array}{l}9.5-32.6 \% ; \\
\end{array}$ \\
Cummings and Violante (2002), & US & $1948-2000$ & $4 \%$ \\
with Gordon's prices & US & $1975-2000$ & $5 \%$ \\
Hobijn (2000) & US & $1947-2000$ & $4 \%$ \\
\hline
\end{tabular}

Hence, with embodied technological change as prime engine of macroeconomic phenomena like growth and business cycle fluctuations, investment activities in new and more efficient leading-edge capital vintages as carriers of embodied technology become the key transmission mechanism from technological change to changes in productivity and output. In this regard, it becomes vital to improve the understanding of investment strategies and to shed light on investment patterns of entrepreneurs, the 'heroic men of practical action' (Schumpeter, 1934).

\section{Investments}

Recently, numerous firm level studies have disclosed that irrespective of country, industry or capital good considered, firm level investments proceed in jumps with periods of close to zero investment activities being superseded by periods of rather heated investments. Specifically, the majority of firm investment activities is found to be concentrated in three years only with immense variation across firms. The degree of lumpiness also varies across capital goods considered with more sporadic investment adjustments attributed to buildings and vehicles as compared to machinery. Finally, firm characteristics also matter for firm investment patterns in that smaller or younger plants and plants that undergo changes in organizational structure or switch industries show lumpier investment patterns.

Moreover, factor inputs are strongly dynamically interrelated. Particularly, in the light of radical capital adoption, supplementary factor input adjustments of strategic complements or substitutes are called for. Conclusive empirical evidence highlights that capital and labor are strategic complements supporting the view that investment dynamics are also crucial for labor market dynamics and outcomes. Employment changes are found to be significantly higher in the year of as well as in the years preceding and succeeding any investment spike. Typically, early employment adjustments ahead of any investment spikes are attributed to preparatory training activities to enhance employees' absorptive capacity in the light of future major changes in capital stocks and production processes (Letterie et al., 2004). Furthermore, Sakellaris (2004) highlights for the U.S. that capital, production and nonproduction labor are strategic complements. Furthermore, production labor appears to be the more flexible labor input since major adjustments are accomplished in one 
year only while adjustments in non-production labor are spread out over a couple of years.

Major capital adjustments also come at an immediate though only temporary cost. In the course of retooling, smooth and routinized production processes are disrupted when workers' assignments are rearranged and tasks are reassigned and restructured. And it takes time for new and smooth production routines to develop and learning-by-doing effects to unfold in higher and increasing productivities. Nilsen et al. (2006) and Sakellaris (2004) show that positive or negative investment spikes are accompanied by almost proportional changes in sales and output. Effects on productivity are less clear-cut since productivity is found to either drop significantly (Huggett and Ospina, 2001; Sakellaris, 2004) or remain unresponsive at all (Nilsen et al., 2006).

Finally, drastic capital adjustments also call for optimal timing. In that respect, Caballero et al. (1994) advocate the 'pit-stop idea of recessions' and suggest a bunching of investments in economic recessions. Given temporary disruption costs of retooling and reorganization activities in terms of output, sales or productivity losses, opportunity costs associated with said rearrangements are relatively low in economic downturns. On the contrary, Cooper et al. (1999) define a machine replacement problem and demonstrate that in case of persistent exogenous shocks coupled with predominantly fixed adjustment costs, input adjustment activities should be procyclical. Alternatively, Klenow (1997) stresses the role of learning effects for the procyclical behavior of investment activities and technology adoption. He emphasizes that due to higher production rates during economic booms, high learning rates emerge quickly which materialize in higher productivity levels. Empirical results are inconclusive however. For example, Cooper and Haltiwanger (1993) find countercyclical replacement while Doms and Dunne (1998), Cooper et al. (1999) and Süssmuth (2003) disclose a procyclical pattern of large investment episodes.

The sluggish or lumpy nature of capital adjustment patterns is typically attributed to the existence of non-negligible fixed costs associated with investments that generate costs over and above capital prices (Nickell, 1978). Specifically, in addition to reported temporary declines in firm output and productivity following the disruption of routinized production processes, firms also incur fixed costs related to plant or organizational restructuring or worker retraining.

\section{Adjustment Costs}

The size and structure of said adjustment costs determine the evolution of firm capital stocks and, given capital-labor complementarities, also firm labor stocks and the size and the timing (see Cooper et al., 1999) of investment projects.

Traditionally, partly inspired by observed smooth aggregate investment patterns and lacking firm level evidence, the representative firm was assumed to face strictly convex adjustment costs. Convex adjustment costs render the realization of smaller investment projects affordable, inducing firms to split and spread out any sizeable 
investment projects over several periods, generating a pattern of frequent and small investment activities.

Under linear adjustment costs, the size of the investment project becomes irrelevant for the adjustment decision. However, since any profit maximizing firm delays capital stock adjustments until additional profits of adjustment offset the costs incurred, some discontinuity emerges in the adjustment pattern.

Finally, under fixed or, synonymously, nonconvex adjustment costs, manifested in temporary losses in output, productivity and profitability, any investments become costly activities irrespective of their size, giving rise to empirically observed infrequent and sizeable investments.

Furthermore, adjustment frictions also emerge in case of prevailing irreversibilities. As pointed out by Arrow (1968), resale prices of capital may be considerably lower than purchase prices of capital, or in the extreme case, may even be zero, so that investments are constrained to be non-negative. A low frequency of negative investment activities is compatible with the prevalence of irreversibilities.

While a plentitude of empirical analyses emphasizes the lumpy, infrequent, asymmetric and nonlinear nature of investment activities, invalidating the assumption of pure convex adjustment costs, only recently attempts were made to explicitly specify the nature of adjustment costs in terms of convex, nonconvex costs as well as irreversibilities.

The very few studies concur that it is not one single adjustment cost component that solely determines observed firm level adjustment patterns but the combination of all adjustment cost components, though the exact composition of adjustment costs and magnitudes differ across countries studied.

In that respect, Cooper and Haltiwanger (2006) identify considerable mean disruption costs of 20.4 percent and mean fixed costs of 4 percent of installed capital but only a negligible role for irreversibilities to prevail in U.S. manufacturing. Contreras (2006) also accounts for capital-labor complementarities and emphasizes the significance of congestion effects in Colombian manufacturing such that joint adjustment of capital and labor is more expensive than the adjustment of only one of the two factors. Furthermore, probably due to lacking or insufficient second hand capital goods markets, irreversibilities are key in determining investment activities in Columbian manufacturing.

Finally, infrequent and lumpy investment episodes in Spanish and Greek manufacturing lead Sánchez-Mangas (2002) and Lapatinas (2007), respectively, to specify discrete models with irreversibilities and nonconvex capital adjustment costs. Sánchez-Mangas (2002) finds that irrespective of firm size, fixed costs of adjustment dominate. He furthermore highlights the firm-size dimension of adjustment costs. Specifically, small firms face considerably higher fixed costs than medium sized or large ones: small firms are found to face fixed adjustment costs of 23 percent of installed capital while medium sized firms and large firms only face fixed costs of 1.1 percent and 0.24 percent, respectively. Similarly, due to the negligible prevalence of negative capital adjustment episodes, Lapatinas (2007) also specifies a discrete capital adjustment model and discovers sizeable fixed costs of investments to prevail 
in Greek manufacturing. Specifically, he shows that firms face fixed costs of 15.57 percent of installed capital in case of capital adjustments.

\section{Structure of the Thesis}

This thesis contributes to recent discussions on issues related to embodied technological change and investment patterns and analyzes the small and open economy of Austria. It comprises five chapters.

Specifically, in chapter 2, light is shed on embodied and disembodied technology as potential crucial determinants of business cycles in an economy lagging behind the technological frontier commonly viewed as being determined by the U.S. Given the unprecedented development in national productivity as captured by real GDP in hours that almost led to a complete catch-up with U.S. national productivity levels, technological change appears to have been critical for Austrian productivity developments. Hence, a strong overall role for business cycle fluctuations is expected. The analysis is conducted for the period 1977:1 to 2005:4.

Furthermore, since investment activities are found to represent an important determinant of Austrian business cycles, chapter 3 seeks to identify input adjustment patterns, dynamics and disruption costs for a set of firm groups operating in Austrian manufacturing. The analysis focuses on the period covering 1982 to 1991, since lacking data availability renders the analysis of more recent micro-level data impossible. Furthermore, binding legal restrictions on data confidentiality make individual firm observations unavailable and groups of similar-sized firms are analyzed instead. The strongly regulated Austrian labor market aimed at helping to achieve a higher level of employment under socially acceptable and fair conditions renders labor less flexible and more costly to adjust downwards since relatively restrictive firing rules are in place. Paired with non-negligible capital-labor complementarities, binding labor market rules and regulations are expected to have repercussions on investment patterns also.

Finally, lumpy and erratic equipment investment patterns in Austrian manufacturing are reckoned to arise from non-negligible adjustment frictions. Chapter 4 addresses the nature of underlying adjustment costs in terms of convex and nonconvex adjustment costs for a scenario of perfect irreversibilities arising from deficient information on disinvestment of machinery and equipment.

Chapter 5 provides a detailed summary and discussion of the results of the previous three chapters. 


\section{The Austrian Business Cycle - A Role for Technology Shocks?}

Whether technology represents a major driver of observed business cycles has been an ongoing debate for over two decades. While simulations of parameterized versions of stochastic growth models point at technology as a dominant contributor, more recent applications of structural vector autoregression methods cast serious doubt on the role of technology for business cycle variations. In all these studies neutral technology shocks refer to aggregate, sector-neutral productivity shocks, while investment specific technology shocks relate to productivity-enhancing shocks to technology embodied in capital goods which necessitate investments to unfold and affect output.

Specifically, Gali (1999) shows that between 1948 and 1994 aggregate neutral technology shocks played a secondary role only in explaining the cyclical variation of output and total hours worked in the U.S. On the other hand, Fisher (2006), Christiano et al. (2003) and Gambetti (2005) explicitly calculate the contribution of variations in U.S. output and hours worked due to different technology shocks to the variables' overall variations, while Khan and Tsoukalas (2006) provide comparable measures for the UK.

Depending on different model specifications, Christiano et al. (2003) identify the role of neutral technology shocks only for observed business cycle variations in output and hours worked that are found to account for 64 to 1.3 percent of business cycle variations in output and for 33 to 4.1 percent of cyclical variations in hours worked ${ }^{2}$.

According to Fisher (2006), who first emphasizes the importance of investment specific technology shocks for observed business cycle variations, investment specific and neutral technology shocks together explain between 40 and 76 percent of overall variations in output and between 52 and 64 percent of business cycle variations in hours worked, depending on the model specification. Neutral technology shocks alone, however, only account for 9 to 28 percent of variations in output and 4 percent of variations in hours worked.

In the same vein, applying a trivariate time-varying coefficients Bayesian Vector Autoregression approach, Gambetti (2005) stresses that depending on the particular

\footnotetext{
${ }^{2}$ The role of technology is significantly more pronounced in level specification models as compared to models specified in terms of first differences. Under the level specification scheme contributions of output and hours worked to overall cyclical variations show dramatic reductions once the inflation rate, the Federal Funds rate or consumption and investment are included. While, under difference specification, the contribution of variations in hours worked only negligibly falls after inclusion of additional variables, the contribution of output drastically falls from 11 to 2 percent only.
} 
specification chosen, investment specific and neutral technology shocks together explain about 34 to 55 percent of total business cycle volatility of output and hours worked. Neutral technology shocks alone only account for 10 to 21 percent of output fluctuations and for 11 to 22 percent of variations in hours worked.

Finally, and in contrast to results obtained for U.S. business cycles, Khan and Tsoukalas (2006) show that technology only has a negligible role in shaping UK business cycles. The contribution of neutral technology shocks is similar in magnitude to those derived for the U.S. and amounts to between 8 and 25 percent. However, the effects of investment specific technology shocks are significantly smaller and only explain between 2 and 15 percent of observed fluctuations in output and hours worked.

With the exception of results for UK business cycles, all results point at the secondary role neutral technology shocks play for observed business cycles and the necessity to also include investment specific technology shocks to better capture the overall role of technology for observed business cycle variations.

This paper identifies the role of technological change for observed business cycles of the small and open economy of Austria. Given past economic records on national productivity developments it is expected that overall technology should be vital for Austrian business cycles. Furthermore, as a small and exceptionally open economy with high-technology products dominating its trade portfolio, investment specific technology should have a major impact.

Methodologically, this paper takes an alternative approach for identifying the role of technology: In contrast to the variance based measure derived from filtered output and hours worked as obtained by Christiano at al (2003), Fisher (2006), Gambetti (2005) or Khan and Tsoukalas (2006) and in order to evade adverse and spurious effects of filtering, a spectral analysis is conducted. The analysis therefore totally dispenses of the need to pre-filter data to extract and identify the businesscycle component. The contributions of either technology shocks to actual variations in hours worked and output can then be identified at different frequencies: the very short run, the medium-run typically associated with business cycles of between 1.5 and 8 years and the long run connected to long run growth. As a frequency dependent measure, cohesion (Croux et al., 2001) is derived to determine dynamic correlations of simulated data with actual data.

A key variable in the underlying model is the price for a newly produced unit of equipment, expressed in terms of consumption goods. Proxied by the ratio of the equipment investment deflator to the total consumption deflator, the index captures investment specific technological change. Neutral technological change affects the investment and consumption sector symmetrically, so that relative prices as captured by the real price of investment remain unchanged and only labor productivity is affected in the long run. However, investment-specific technological change affects both, the real price of investment and long-run labor productivity.

Methodologically, a structural vector autoregression approach is applied to capture the roles of both investment specific and neutral technology shocks for business cycle variations in output and hours worked. In order to do so, it is assumed that (1) 
investment specific and neutral technology shocks are the only shocks affecting labor productivity in the long run and that (2) only investment specific technology shocks have permanent effects on the real price of investment. Once the structural neutral and investment specific technology shocks are identified, their individual as well as mutual effects on variations in output and hours worked are simulated accordingly. To identify the role of technology related variations in output and hours worked, cohesion, as a frequency dependent dynamic correlation coefficient, is calculated based on unfiltered data.

The results show that technology plays a decisive role in explaining cyclical variations in output but is of moderate importance for determining business cycle variations in hours worked in the sub-aggregate of Industry. Hence, observed strong variations in output are not accompanied by equally strong variations in hours. Furthermore, partly due to the inferior proxy for investment specific technology shocks, a decomposition of the overall effect into a component explained by investment specific technology shocks and a component explained by neutral technology shocks emphasizes the dominant role neutral technology shocks play. The application of the frequency-dependent dynamic correlation coefficient also allows for the identification of the role of either technology shocks for other than business cycle frequencies. It highlights that for variations in both hours and output, the impact of neutral technology shocks increases over time which points at learning effects to increasingly unfold and take effect. On the contrary, investment specific technology shocks have the strongest effect on variations in output in the very short run only.

The remainder of the paper is organized as follows: the next section outlines the underlying theoretical framework applied to the empirical analysis. Section III discusses the methodologies of the vector autoregression and the structural vector autoregression to help identify the contribution of different technology shocks to business cycles. Section IV highlights why the Austrian economy is an interesting economy to study and what roles to expect for both technology shocks, while section $\mathrm{V}$ discusses data coverage and data sources used. The findings are presented and discussed in section VI, while section VII tests whether technology shocks are indeed capturing variations in technology. Finally, section VIII concludes.

\section{Framework}

The model is adopted from Fisher (2006) where due to the absence of market imperfections, a social planner chooses consumption $C_{t}$, investment $X_{t}$, hours worked $H_{1}$ and next period's capital stock $K_{l+1}$ according to the following maximization problem:

$\max E_{0} \sum_{t=0}^{\infty} \beta^{t} U\left(C_{t}, H_{t}\right)$ 
subject to

$$
\begin{array}{ll}
Y_{1}=C_{1}+X_{1} \leq A_{1} K_{1}^{\alpha} H_{1}^{1-\alpha} & \text { with: } \alpha \in(0,1) \\
K_{t+1} \leq(1-\delta) K_{1}+V_{1} X_{t} & \text { with: } K_{0} \text { given and } \delta \in(0,1)
\end{array}
$$

and

$$
\begin{array}{ll}
A_{t}=\exp \left(\gamma+C_{a}(L) \varepsilon_{a t}\right) A_{t-1} & \text { with: } \gamma \geq 0 \\
V_{t}=\exp \left(u+C_{v}(L) \varepsilon_{u}\right) V_{t-1} & \text { with: } v \geq 0
\end{array}
$$

By definition, the production function implies constant returns to scale so that scale economies cannot erroneously be interpreted as technology shocks. $A_{1}$ and $V_{1}$ are the levels of neutral and investment specific technology, respectively, and $C_{a}$ and $C_{u}$ are square summable polynomials in the lag operator L. $\varepsilon_{u \prime \prime}$ and $\varepsilon_{u x}$ are white noise innovations interpreted as exogenous neutral and investment specific technology shocks, respectively, with $E\left(\varepsilon_{a t}\right)=E\left(\varepsilon_{u}\right)=0$ and diagonal covariance matrices specified by $E\left(\varepsilon_{a l} \varepsilon_{a l}^{\prime}\right)=\Sigma_{a t}$ and $E\left(\varepsilon_{u t} \varepsilon_{u x}^{\prime}\right)=\Sigma_{u}$. The two stochastic technology processes imply that the logs of $A_{l}$ and $V_{l}$ follow a random walk with drifts $\gamma$ and $v$ so that shocks to technology can have permanent effects.

The long run implications of the model can be identified by considering its balanced growth properties with output, consumption, investment and the stock of capital displaying similar average growth rates over sufficiently long time horizons and constant hours worked per capita.

Given the above specification of the resource constraint (2), consumption, investment, output and labor productivity all grow at the same rate $g=g_{C}=g_{X}=g_{Y}=g_{Y / H}$, while the accumulation equation for capital (3) points at the capital stock to grow at a higher rate $g_{K}=v g$, provided $u>1$. Finally, the specification of the production function (2) implies that $g=\gamma g_{K}^{\alpha}$. Hours worked are stationary. Thus, the following restrictions are imposed on balanced growth: $g=\gamma^{1 /(1-\alpha)} v^{\alpha /(1-\alpha) 3}$.

Stationarity is guaranteed if all variables grow at a constant rate. Hence, with $\hat{x}=x_{1} / g$ and $x_{1}=C_{1}, X_{1}, Y_{1}, Y_{1} / H_{1}$, consumption, investment, output and labor productivity all grow at $(\gamma+\alpha \nu) /(1-\alpha)$ and with $\hat{k}_{t}=k_{t} / g_{K}$, the capital stock grows at $g_{K}=(\gamma+v) /(1-\alpha)$.

\footnotetext{
${ }^{3}$ With stationarity in hours worked, total output grows at: $g_{Y}=g=\gamma\left(\operatorname{vg} g_{X}\right)^{\alpha}$. With $g_{Y}=g_{X}=g$, output grows at the rate $g=\gamma(\lg )^{\alpha}$ which is equivalent to $g^{1-\alpha}=\gamma v^{\alpha}$ and results in: $g=\gamma^{1 / 1-\alpha} v^{\alpha / 1-\alpha}$.
} 
Additionally, any shocks to the neutral or investment specific technology level (i.e. $\varepsilon_{\iota t}$ or $\varepsilon_{v t}$ ) have permanent effects while leaving hours worked unaffected in the long-run. Hence, labor productivity is affected by both types of technology shocks.

Since according to equation (2) investment and consumption goods can be traded on a one-for-one basis, the real price of one unit of investment good is given by the number of consumption goods that need to be given up in order to get one additional unit of the investment good which is $1 / V_{1}$. Hence, only a shock to the investment specific technology level captured by $\varepsilon_{u}$ can have any permanent effect on the real price of investment.

These long term implications of investment specific and neutral technology shocks help determine and specify the structural vector autoregression system that will be discussed next.

\section{Methodology}

Vector Autoregressions (VARs hereafter) are multivariate, linear representations of a vector of observables on its own lags and possibly lags of other variables (as trend or constant).

Consider the following $\operatorname{VAR}(\mathrm{p})$ representation without exogenous variables or a constant term

$y_{1}=A_{1} y_{t-1}+A_{2} y_{t-2}+\ldots+A_{p} y_{t-p}+u_{t}$

where $y_{1}=\left(y_{1}, \ldots, y_{K_{1}}\right)^{\prime}$ is a $(K \times 1)$ random vector, the $A_{i}{ }^{\prime} s$ are fixed $(K \times K)$ matrices of parameters and $u_{l}$ is a $(K \times 1)$ vector of white noise disturbances with zero mean and covariance $\Sigma_{u}$, i.e. $u_{t} \sim\left(0, \Sigma_{u}=E\left(u_{t} u_{t}^{\prime}\right)\right)$.

Above process has the following lag operator notation:

$$
A(L) y_{1}=u_{1} \quad \text { with } A(L)=I_{K}-A_{1} L-\ldots-A_{p} L^{p}
$$

If the process is stable, i.e. all eigenvalues of $A_{i}$ have modulus less than 1 , Lütkepohl (2005) shows that the VAR(p) process has the following Moving Average (MA) representation, where $y_{t}$ is expressed in terms of past and present disturbance terms 


$$
\begin{array}{ll}
y_{t}=\sum_{i=0}^{\infty} \Phi_{i} u_{t-1} & \text { with } \quad \Phi_{l}=I_{K} \quad \text { if: } i=0 \quad \text { and } \\
\Phi_{1}=\sum_{j=1}^{i} \Phi_{i-,} A_{J} & \text { if: } i=1,2,3, \ldots \ldots
\end{array}
$$

Since the coefficient matrices $A_{j}$ 's are absolutely summable, so are the $\Phi_{i}{ }^{\prime} s$. The $\Phi$, $s$ as coefficients of the MA representation are the impulse-response functions at horizon $i$, where the $x, y$ element of $\Phi_{i}$ gives the effect of a one-time one-unit increase in an error term to variable $y$ on variable $x$ after $i$ periods holding everything else constant. Formally, this is expressed as

$$
\Phi_{t, x y}=\frac{\partial y_{x, t+i}}{\partial u_{y, t}} \quad \text { with } y_{x} \in y_{t}=\left(y_{l t}, \ldots, y_{K t}\right)^{\prime}
$$

Additionally, the long-term effect of such a one-time one-unit shock after $m$ periods is the sum of all individual impulse-responses per period: $\sum_{i=0}^{m} \Phi_{i, x y}$.

However, results from above MA representation are not attributable to single economically-interpretable shocks but to all shocks correlated with the responding variable if the components of $u_{t}$ are instantaneously correlated. Hence, in order to disentangle observed shocks and attribute them to single sources, a structural VAR (SVAR hereafter) with structural assumptions leading to unique impulse-responses is applied. With reference to the above discussion of the theoretical framework the structural assumptions are: (1) only investment specific technological shocks affect the real price of investment in the long run and (2) both, investment specific and neutral technology shocks have permanent effects on labor productivity.

In order to impose these structural long term restrictions, Shapiro and Watson (1988) suggest entering the other control variables in double-differences in the estimation. Specifically, assume the following trivariate case in which the real price of investment $p_{l}$, labor productivity $x_{t}$ and hours worked $n_{t}$ are difference stationary and functions of their current and lagged values:

$$
\begin{aligned}
& \Delta p_{t}=\sum_{j=1}^{m} \alpha_{m p, j} \Delta p_{t-j}+\sum_{j=0}^{m} \alpha_{p x, j} \Delta x_{t-j}+\sum_{j=0}^{m} \alpha_{m m_{, j}} \Delta n_{t-j}+v_{l} \\
& \Delta x_{t}=\sum_{j=1}^{m} \alpha_{x p, j} \Delta p_{t-j}+\sum_{j=1}^{m} \alpha_{x x_{i}, j} \Delta x_{t-j}+\sum_{j=0}^{m} \alpha_{x m_{, j}, \Delta n_{t-j}+a_{t}} \\
& \Delta n_{l}=\sum_{j=1}^{m} \alpha_{n p, j} \Delta p_{t-j}+\sum_{j=1}^{m} \alpha_{n x, j} \Delta x_{t-j}+\sum_{j=1}^{m} \alpha_{l m, l} \Delta n_{t-j}+\varepsilon_{n t}
\end{aligned}
$$


Assuming that only investment specific technology shocks affect the real price of investment in the long-run, requires the long-term multipliers of $\Delta x$, and $\Delta n_{t}$ to be zero and the coefficient of its lags to sum to zero. Hence, the above specification for the real price of investment becomes

$\Delta p_{l}=\sum_{j=1}^{m} \alpha_{m p, j} \Delta p_{t-j}+\sum_{j=0}^{m-1} \alpha_{p x_{, j}} \Delta^{2} x_{t-j}+\sum_{j=0}^{m-1} \alpha_{m, j} \Delta^{2} n_{t-j}+v_{l}$

and labor productivity and hours worked enter in double-differences ${ }^{4}$. Since current values of $\Delta^{2} x$, and $\Delta^{2} n_{1}$ are correlated with the error term $v_{1}$, the equation must be estimated using instrumental variables, with lags one through $m$ of $\Delta p_{1}, \Delta r_{1}$ and $\Delta n_{l}$ as instruments. The estimates of the error term $v_{t}, \hat{v}_{t}$, represent the estimates of the structural investment specific technology shocks.

Similarly, the equation for labor productivity is specified as

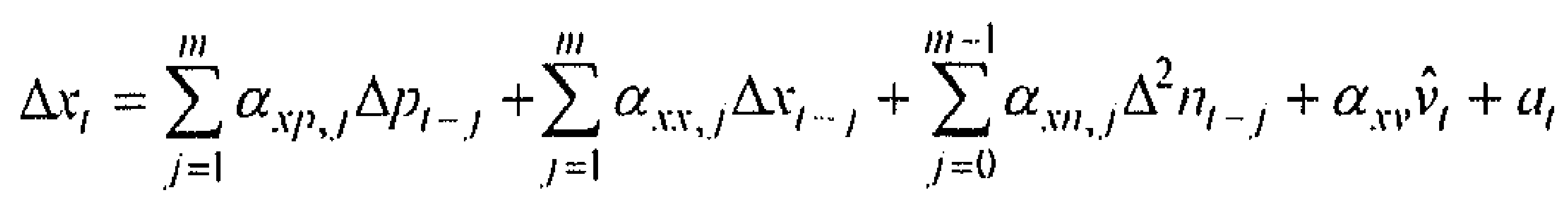

where differences of $\Delta n$, are included to impose the long term constraint that only investment specific and neutral technology shocks permanently affect labor productivity. The equation must again be estimated using instrumental variables with lags one through $m$ of $\Delta p_{1}, \Delta r_{1}$ and $\Delta n_{1}$ as instruments and $\hat{v}_{l}$, the estimated residual from the real price of investment equation, as additional independent variable. The estimates of the error term $a_{1}, \hat{a}_{t}$, represent the estimates of the structural neutral technology shocks.

In the absence of long term structural assumptions for hours worked, the above equation remains unaltered except for the inclusion of the two error terms of the real price of investment equation and the labor productivity equation as additional independent variables:

$$
\Delta n_{t}=\sum_{l=1}^{m} \alpha_{n p, l} \Delta p_{t-, j}+\sum_{j=1}^{m} \alpha_{m,, j} \Delta r_{t-l}+\sum_{j=1}^{m} \alpha_{m m, j} \Delta n_{t-l}+\alpha_{m,} \hat{v}_{t}+\alpha_{m l} \hat{a}_{t}+\varepsilon_{m}
$$

To isolate the contribution of technology shocks to observed business cycles, the procedure is as follows: first, based on a pre-specified number of lags derived from different information criteria a VAR is estimated and the matrices of parameters are

\footnotetext{
t For a detailed discussion refer to the methodological appendix.
} 
calculated. Second, an SVAR with long-run restrictions on the real price of investment and labor productivity is estimated to isolate the structural shock terms $\hat{v}_{1}$ and $\hat{a}_{1}$. A simulation with the estimated structural technology shock vectors $\hat{v}_{1}$ and $\hat{a}_{1}$ replacing the error vectors in the VAR on the one hand, and zero non-technology shocks on the other is applied to derive the dynamic response of the real price of investment, labor productivity, output and hours worked to the structural neutral and investment specific technology shocks only. The number of lags specified by different information criteria is used to initialize the simulation. Instead of filtering the data to extract the business cycle components of all data of interest and in order to avoid spurious effects of filtering, the dynamic correlation coefficient "cohesion" is calculated. Dynamic correlation between technology-related variations in output and hours worked on the one hand, and in original output and hours worked on the other are identified at typical business cycle frequencies.

\section{The Austrian Economy}

Austria is considered an economically stable small and open economy with relatively low inflation and unemployment rates and satisfactory GDP growth records.

Figure 2: Real GDP per Capita and real GDP per Hour in US-\$
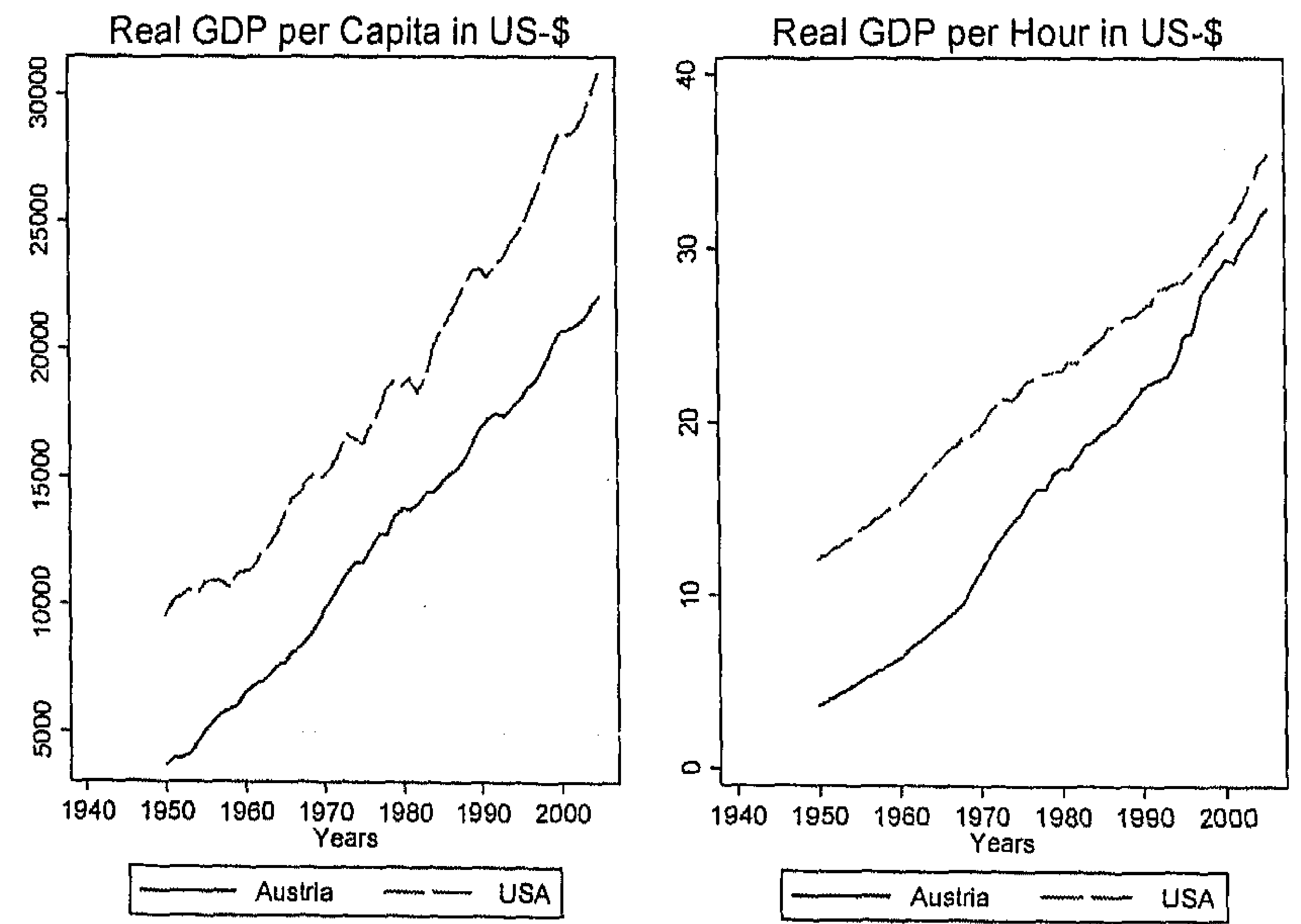

Source: Groningen Growth and Development Centre and the Conference Board, Total Economy Database 
In contrast to the U.S. economy, however, Austria lags behind and starting in the early 1980s even reveals diverging real GDP per capita levels with average annual growth rates of 2.14 percent and 2.08 percent between 1980 and 2000 for the U.S. and Austria, respectively (Figure 2). In terms of national productivity, as captured by real GDP per hours, starting in the late 1960s, Austrian real GDP per hour slowly converged to the U.S. level. The per-hour gap almost vanished in the late $1990 \mathrm{~s}$ before it started to diverge again in 2000 (Figure 2).

Endogenous and evolutionary growth theories stress the importance of technological change and purposeful entrepreneurial innovative activities for determining productivity improvements and long-term economic growth. And while the U.S. persistently outperforms Austria in terms of GDP per capita levels and growth rates, between 1970 and 2000, Austrian national productivity almost entirely caught up with the U.S. level. In that respect, during the last three decades, technological change appears to have been of crucial importance for Austrian productivity developments and a strong overall role for its business cycles is expected.

Figure 3: Openness to International Trade

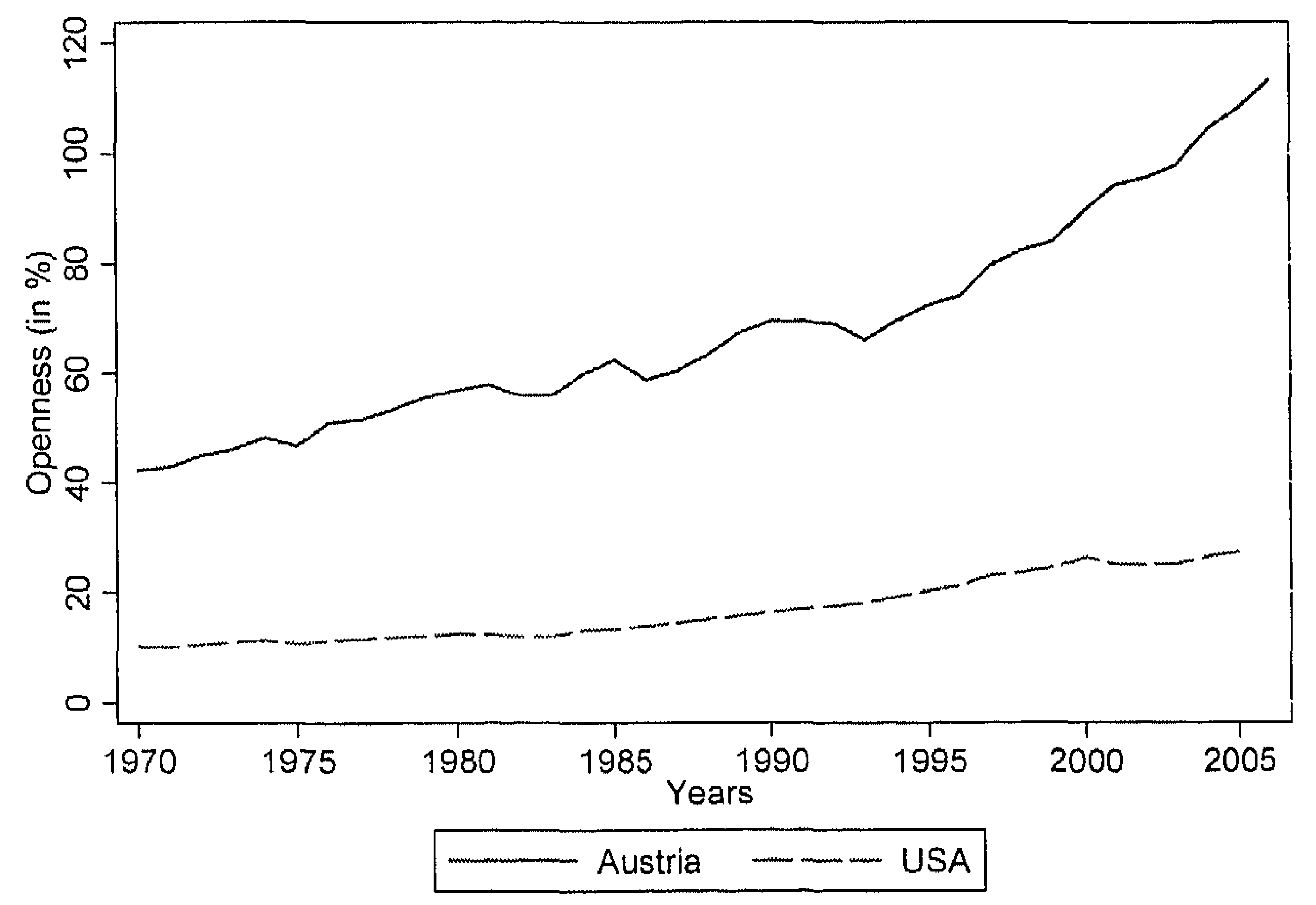

Source: Quarterly' National Accounts, OECD

Openness is defined as the ratio of the sum of exports and imports to overall GDP.

Austria is very outward-oriented and open to international business relations in order to compensate for its technological or endowment-specific shortcomings.

At the end of the 1970s openness, as defined by the ratio of the sum of export and imports to overall GDP, reached about 60 percent. A decade later, 70 percent of the Austrian GDP was either exported or imported, while at the turn of the century, 
openness approached 90 percent until it finally crossed the 100 percent line in 2004 (Figure 3). The Euro-area represents the most prominent region of destination or source of trade. Austria exports about 70 percent of its GDP to countries within the Euro-area and imports about 80 percent of its GDP from this region, with Germany, Italy, the U.S, Switzerland, France and Great Britain as its main trading partners. Its main export and import products are Machinery and Equipment, Motor Vehicles and Parts, Chemical Products, Wood Products and Furniture and Textiles.

The strong multilateral trade flows imply that apart from purely domestic economic factors, EU-specific economic conditions and shocks in general, and those of the main trading partners in particular, also impact on domestic economic performance. More specifically, given that trade serves as a vehicle to internationally diffuse knowledge and leading-edge technologies embodied in machinery, the intense trade integration in general and the dominance of high-technology products in the overall national trade portfolio in particular suggest that investment specific technology should dominate the overall technology impact on Austrian business cycles.

\section{Data Sources and Definitions}

All data series are quarterly. Monthly hours worked are seasonally adjusted by means of a three-lag moving average smoothing procedure to eliminate the prevailing seasonal root identified by the Hylleberg, Engle, Granger and Yoo (1990) seasonal root test. Data are either taken from the Quarterly National Accounts, the Main Economic Indicators or the Economic Outlook administered by the Austrian Institute of Economic Research (WIFO).

The real price of investment is calculated as the ratio of the equipment investment deflator to the total consumption deflator. Nominal and real quarterly equipment investment series are available only for the period 1988:1 to 2006:2 within the European Standard Accounts 1995 (ESA 1995) accounting approach, while one of the preceding accounting schemes, the System of National Accounts 1968 (SNA 1968), only gathered information on quarterly gross fixed capital formation. Hence, due to the high and significant correlation between nominal and real gross fixed capital investment expenditures and its subgroup of real and nominal equipment investment expenditures between 1988:1 and 2006:2, (both, in levels and in growth rates), quarterly growth rates of gross fixed capital formation were applied to interpolate the time series of nominal and real equipment investments to $1965: 1$, starting from 1987:4.

Labor productivity in Industry is available for the period 1965:1 to $2005: 4$ and is defined as the sector's total real GDP divided by hours worked per wage earner and apprentice in Industry.

The hours measure is hours worked by wage earners and apprentices in Industry, excluding Construction and is available between 1965:1 and 2005:4.

Labor productivity and hours worked are not available at the macro-level, however. But given the high and positive correlation (0.873) between Industry and 
macro-level real GDP growth rates at business cycle frequencies and the suggested central role of Industry performance for the overall macroeconomic performance, dynamics in Industry (NACE C, D and E) are subject to the analysis (Figure 4). Business cycle variations in Industry strongly resemble cyclical variations at the macroeconomic level but exhibit higher volatility in terms of the measured standard deviation of 0.0061 at the level of the Industry versus 0.0031 at the macroeconomic level.

Finally, the real trade balance is captured by the difference between real exports and real imports.

Figure 5 displays the basic variables in the model.

Figure 4: Macro-level and Industry Business Cycles

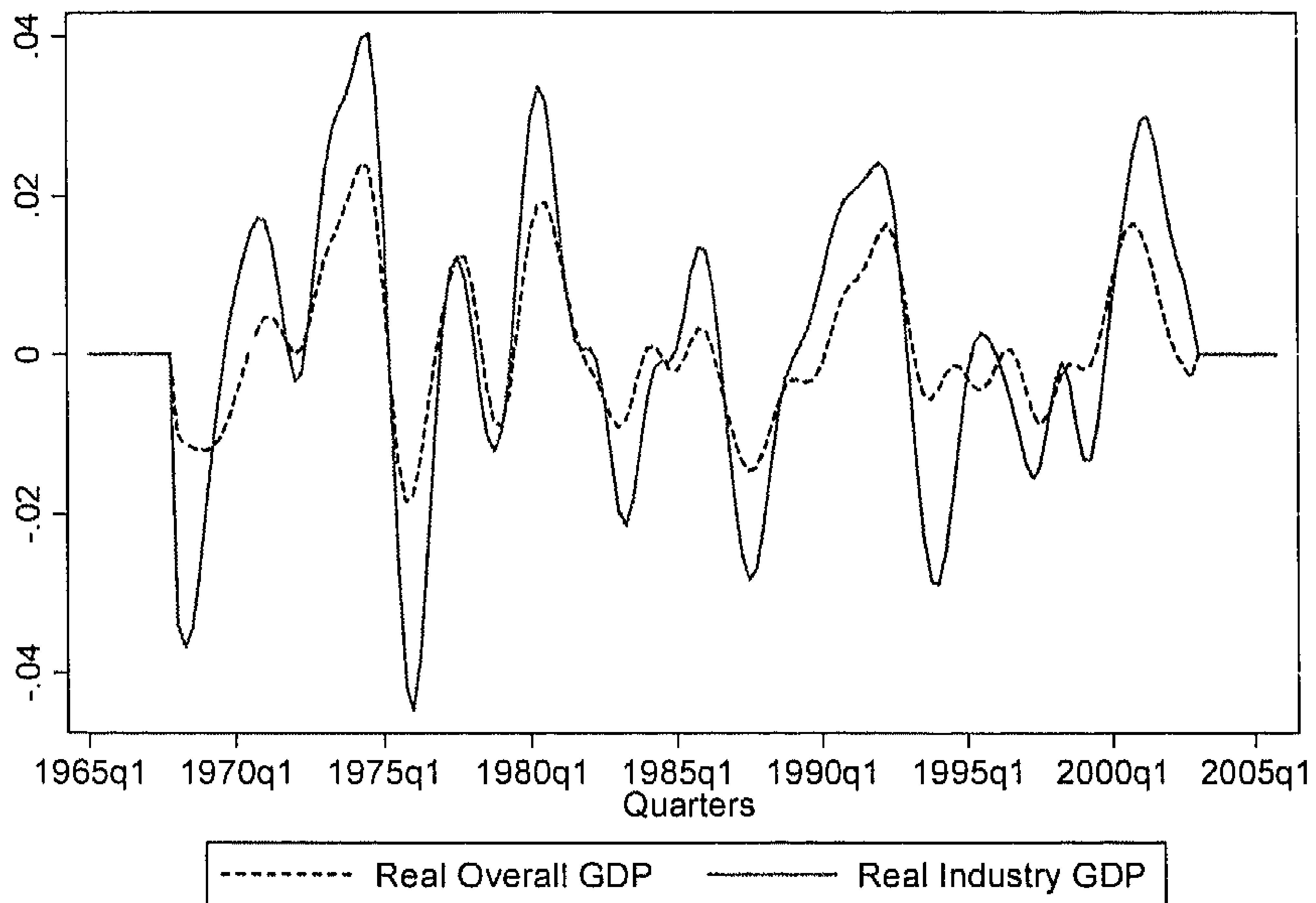

Source: Quarterly National Accoumts, OECD

Austrian equipment deflators are not explicitly quality-adjusted to account for innovation-induced changes in the quality of investment goods and no comparable analysis was conducted to derive equipment deflators in the tradition of Gordon (1990). A closer look at the real price of investment depicted in Figure 6 still reveals a decline of, on average, 34 percent over the entire sample period. However, at the same time, the equipment-to-GDP ratio, as a measure of the (changing) role of equipment investments in overall GDP, remains fairly stable over the 40 -year period. Hence, although equipment experienced technology-induced price reductions, equipment investments did not expand on average and a fairly negligible role of investment specific technology shocks for observed business cycle variations is expected. 
Figure 5: Variables in the Models
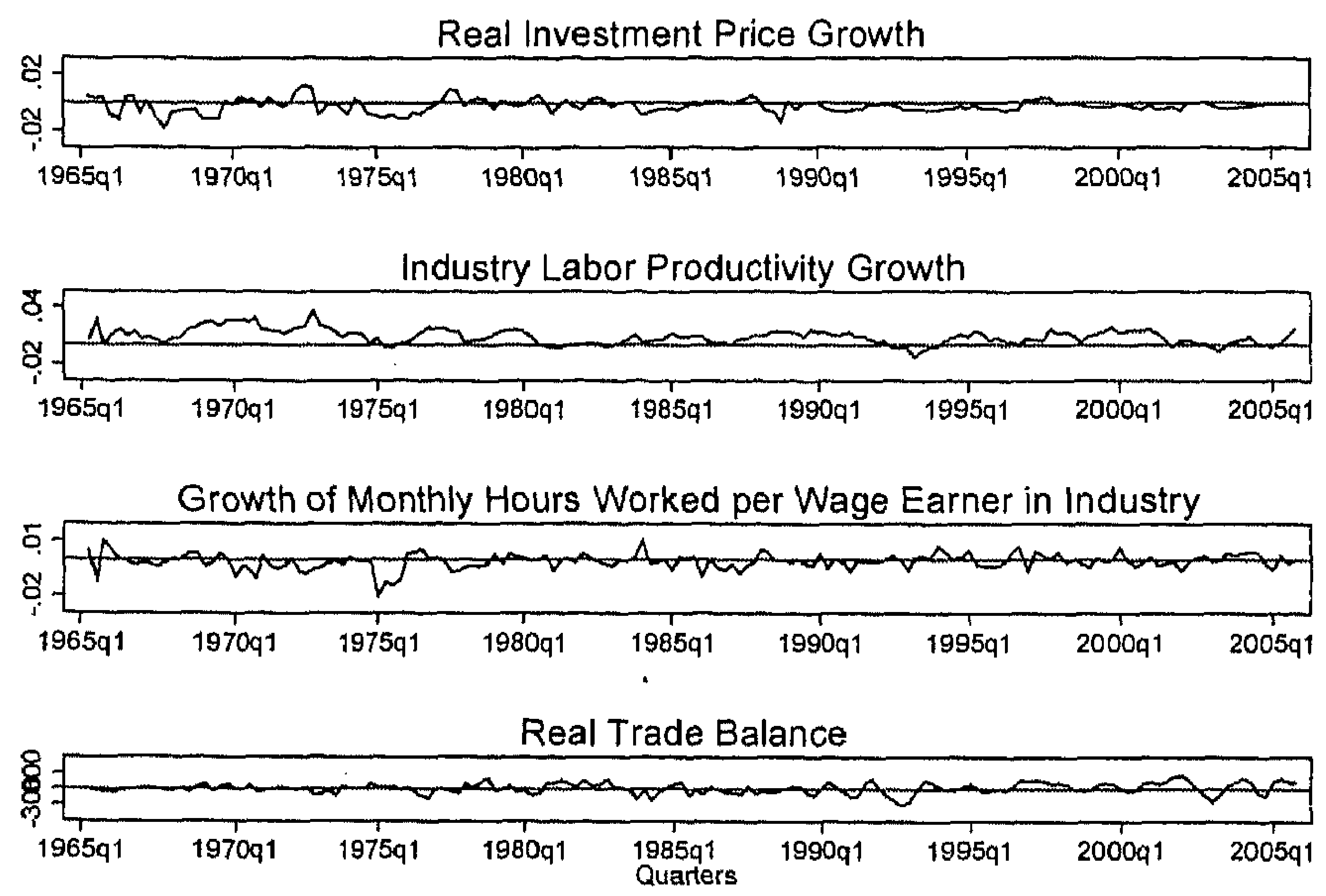

Source: Consumption Deflator: Quarterly National Accoumts, OECD; Investment Deflator: Quarterly National Accounts, OECD; Industry labor productivity: Economic Outlook, OECD; Hours worked: Main Economic Indicators, OECD; Trade Balance; Quarterly National Accounts, OECD.

Figure 6: The Real Price of Investment

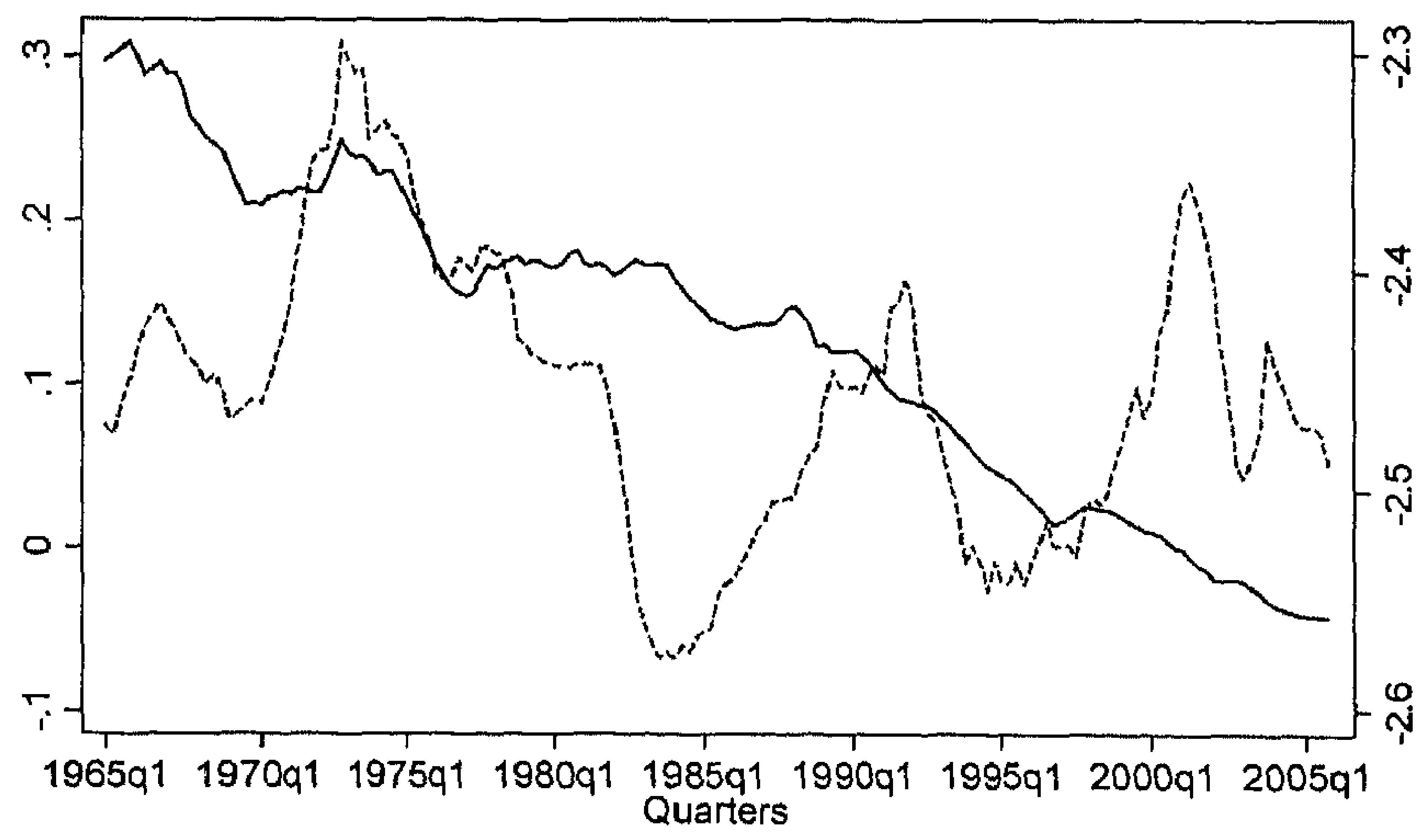

Real Price of Investment (LHS)

Real Share of Investment (RHS)

Source: Consumption Deflator: Quarterly National Accounts, OECD; Investment Deflator: Quarterly National Accounts, OECD; Real Share of Investment: Quarterly National Accounts, OECD. 
The business cycle components of the real price of investment and real GDP are depicted in Figure 7. Clearly, until the end of the 1970s a positive relationship is apparent. However, this relationship becomes negative thereafter which indicates that investment specific technological change had an important role in shaping output fluctuations at business cycle frequencies starting in the late 1970s only. Furthermore, to substantiate above observations, Table 7 in the appendix reports unconditional correlations between the business cycle components of the real price of investment and real GDP for both the overall sample period from 1965:1 to 2005:4 and a sub-sample between 1977:1 and 2005:4 for two lags and leads. The results highlight that the contemporaneous unconditional correlation between the real price of investment and real GDP is positive and significant with 0.31 for the overall sample but negative and significant with -0.20 for the sub-sample considered. Hence, in what follows, the analysis will focus on the 1977:1 to 2005:4 sub-sample.

Figure 7: The Real Price of Investment over the Business Cycle

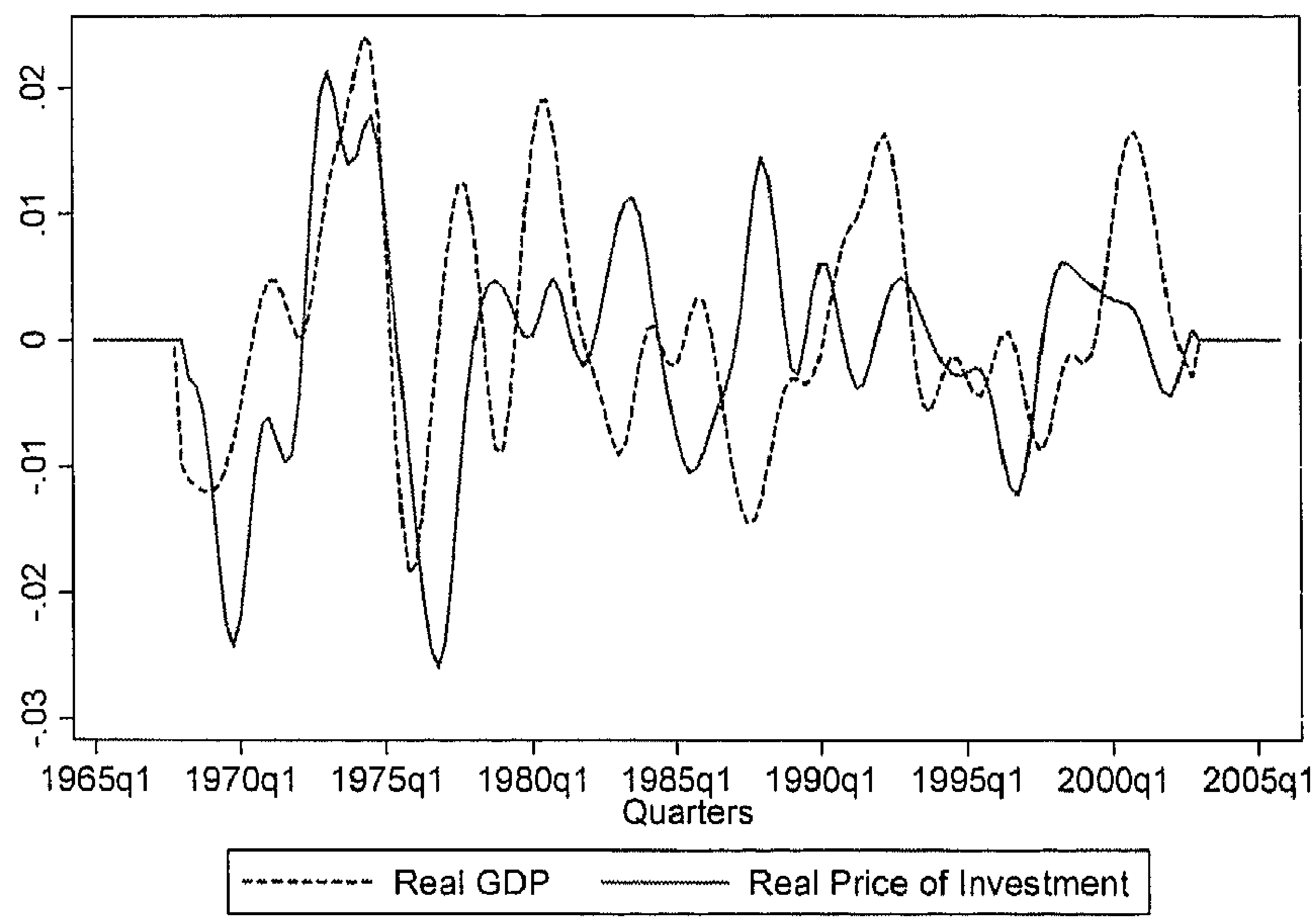

Source: Real GDP: Quarterly National Accoums, OECD; Consumption Deflator: Quarterly National Accounls. OECD: Investment Deflator: Quarterly National Accounts, OECD.

\section{The Role of Technology}

Based on the above structural assumptions, the following multivariate system with the real price of investment $p_{l}$, labor productivity $x_{1}$, hours worked $n_{l}$ and the real trade balance $k_{t}$ is formalized: 


$$
\left[\begin{array}{c}
\Delta p_{l} \\
\Delta x_{t} \\
\Delta n_{t} \\
\Delta k_{t}
\end{array}\right]=\left[\begin{array}{cccc}
C^{11}(L) & 0 & 0 & 0 \\
C^{21}(L) & C^{22}(L) & 0 & 0 \\
C^{31}(L) & C^{32}(L) & C^{33}(L) & C^{34}(L) \\
C^{41}(L) & C^{42}(L) & C^{43}(L) & C^{44}(L)
\end{array}\right]\left[\begin{array}{c}
v_{t} \\
a_{t} \\
\varepsilon_{n t} \\
\mu_{t}
\end{array}\right]
$$

with $v_{t}$ and $a_{t}$ as the orthogonal investment specific and neutral technology shocks, respectively, and $\varepsilon_{n t}$ and $\mu_{t}$ as the orthogonal non-technology shocks.

Augmented Dickey Fuller (ADF) tests of difference stationarity are applied to the data and reported in Table 5 in the appendix. The null hypothesis of difference stationarity of the series cannot be rejected at conventional significance levels. Since non-rejection of the null hypothesis does not automatically lead to the rejection of the alternative hypothesis, the Kwiatkowski, Phillips, Schmidt and Shin (1992) test of the null hypothesis of level stationarity against the alternative hypothesis of a unit root was applied. The null hypothesis is rejected at conventional significance levels and all variables are found to be $I(1)$.

Order selection was based on conventionally applied selection order criteria and the Final Prediction Error and the Akaike information criterion point at an optimal lag period of 3. Results of the SVAR are reported in Table 6 in the appendix.

\section{Vl.1. Findings}

The responses of hours worked and labor productivity to a one-time unit positive investment specific or neutral technology shock are estimated and described by means of impulse-response functions. Furthermore, the contributions of either technology shocks to the Austrian business cycle between 1977 and 2005 are estimated in terms of the dynamic correlation coefficient of cohesion as suggested by Croux et al. (2001).

\section{VI.1.1 Impulse-Response Functions}

The impulse-response functions (solid line) and their 95 percent Hall percentile confidence intervals for the three-lag scenario are depicted in Figure 8 below and show the short-term response of a positive one-time unit structural shock to one variable on other variables. Specifically, the two graphs on the left-hand side of Figure 8 show the effect of a positive one-time unit investment technology shock to labor productivity and hours worked per wage earner. The two graphs on the righthand side of Figure 8 depict the effect of a one-time unit neutral technology shock to 
labor productivity and hours worked. By construction, investment specific technology shocks are captured by structural shocks to the real price of investment while neutral technology shocks are captured by structural shocks to labor productivity.

\section{Figure 8: Structural Impulse-Response Functions to Structural Technology Shocks}

Investment Technology Shocks Labor Productivity

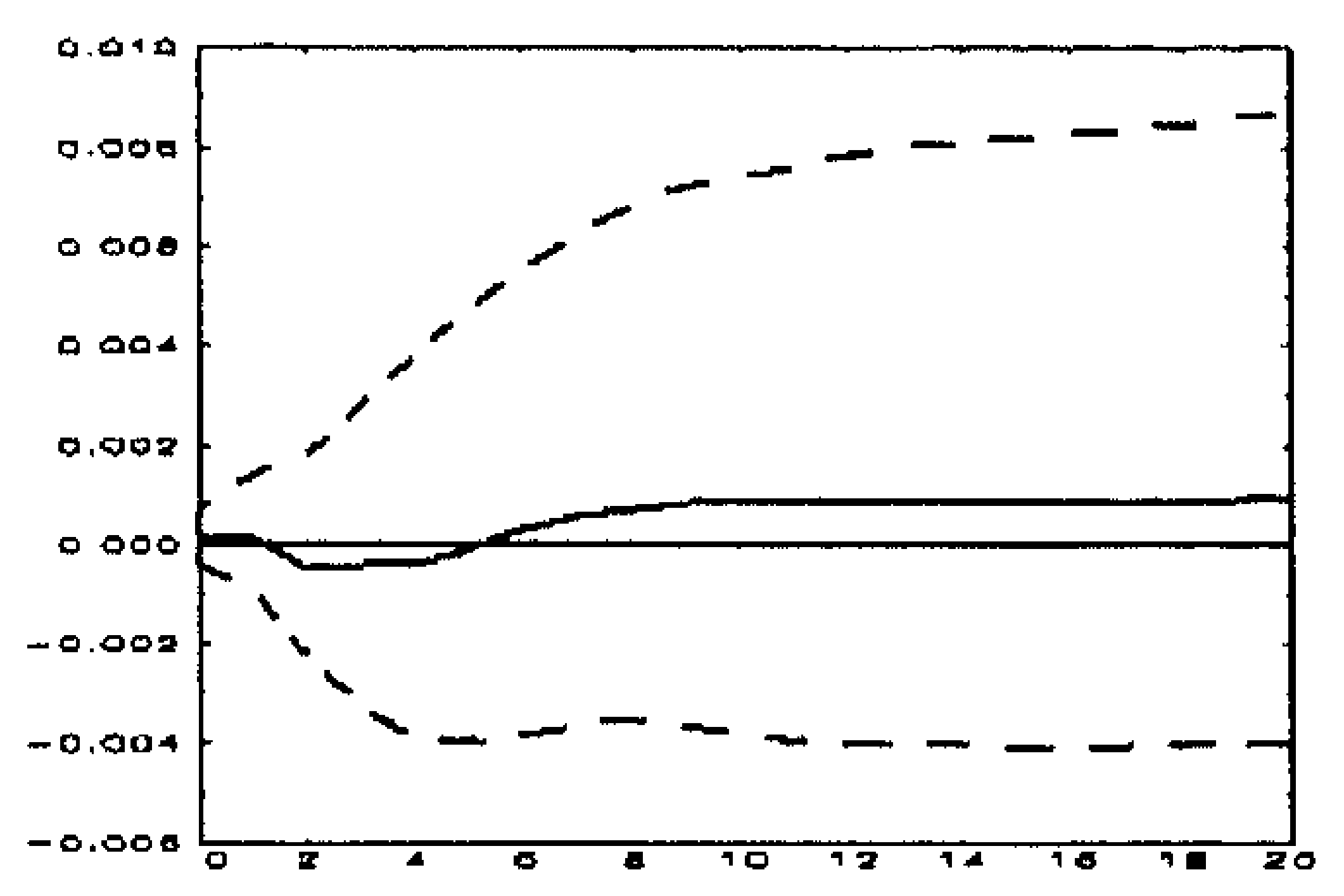

Monthly Hours Worked

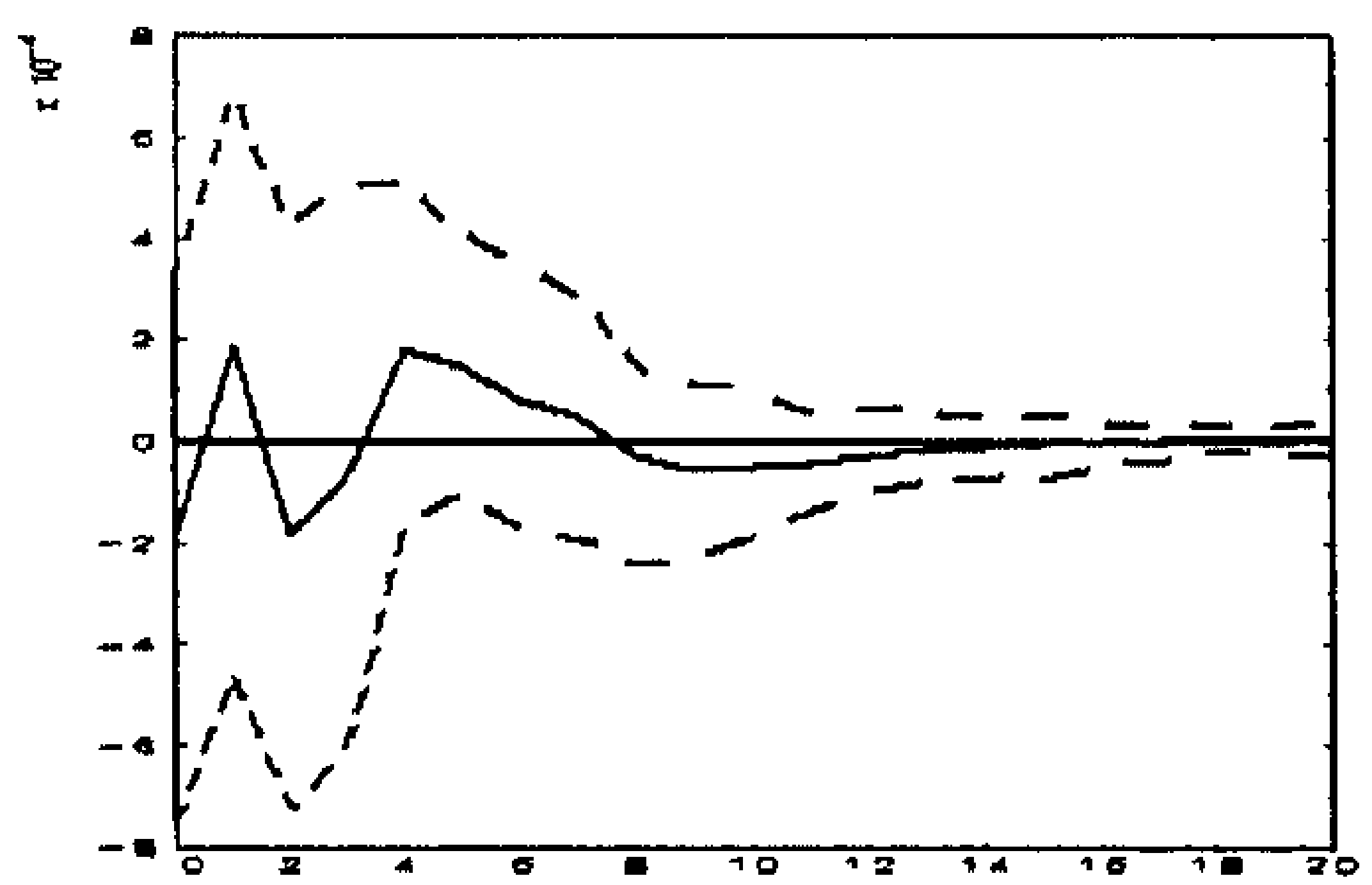

Neutral Technology Shocks Labor Productivity

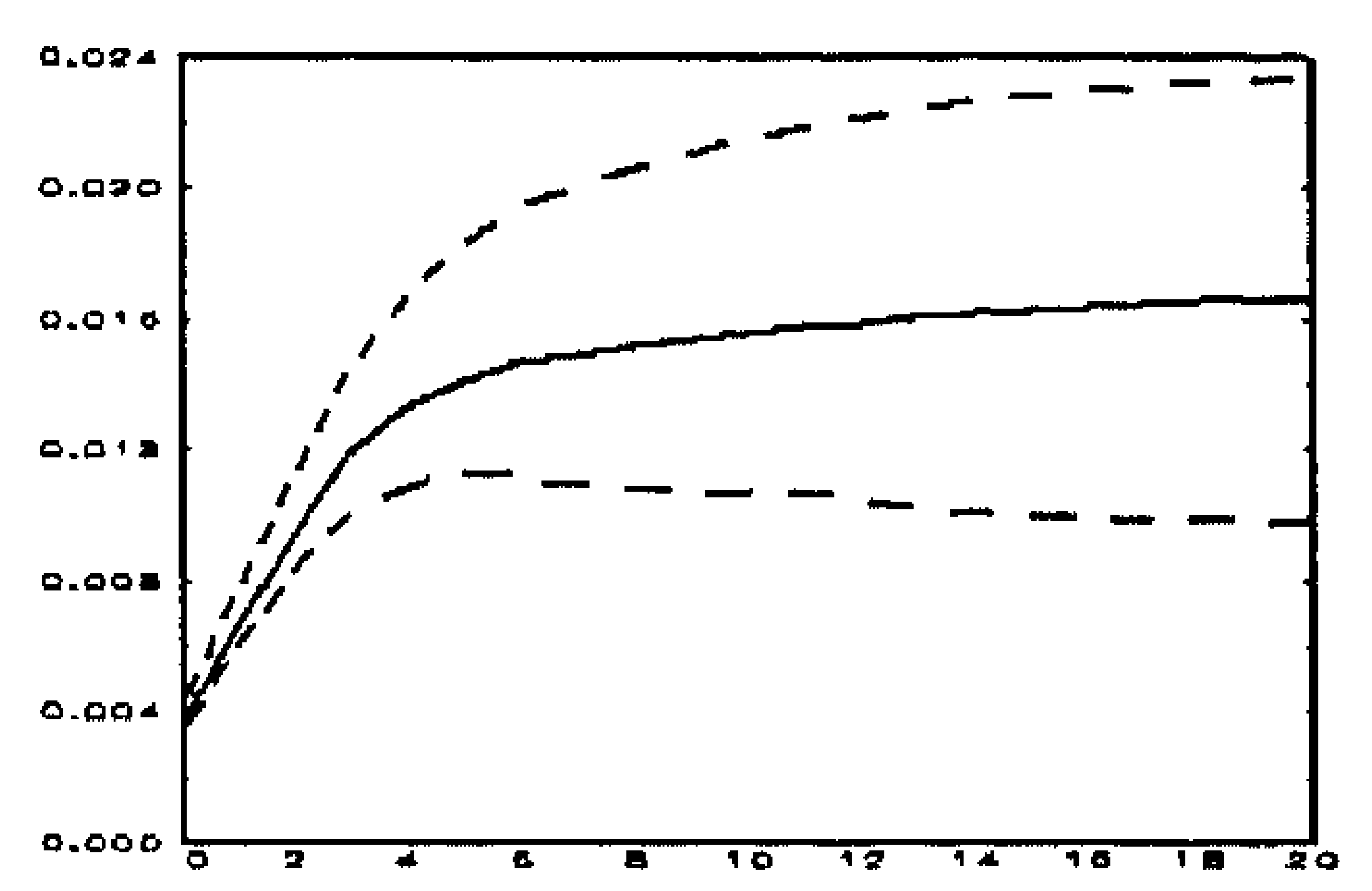

Monthly Hours Worked

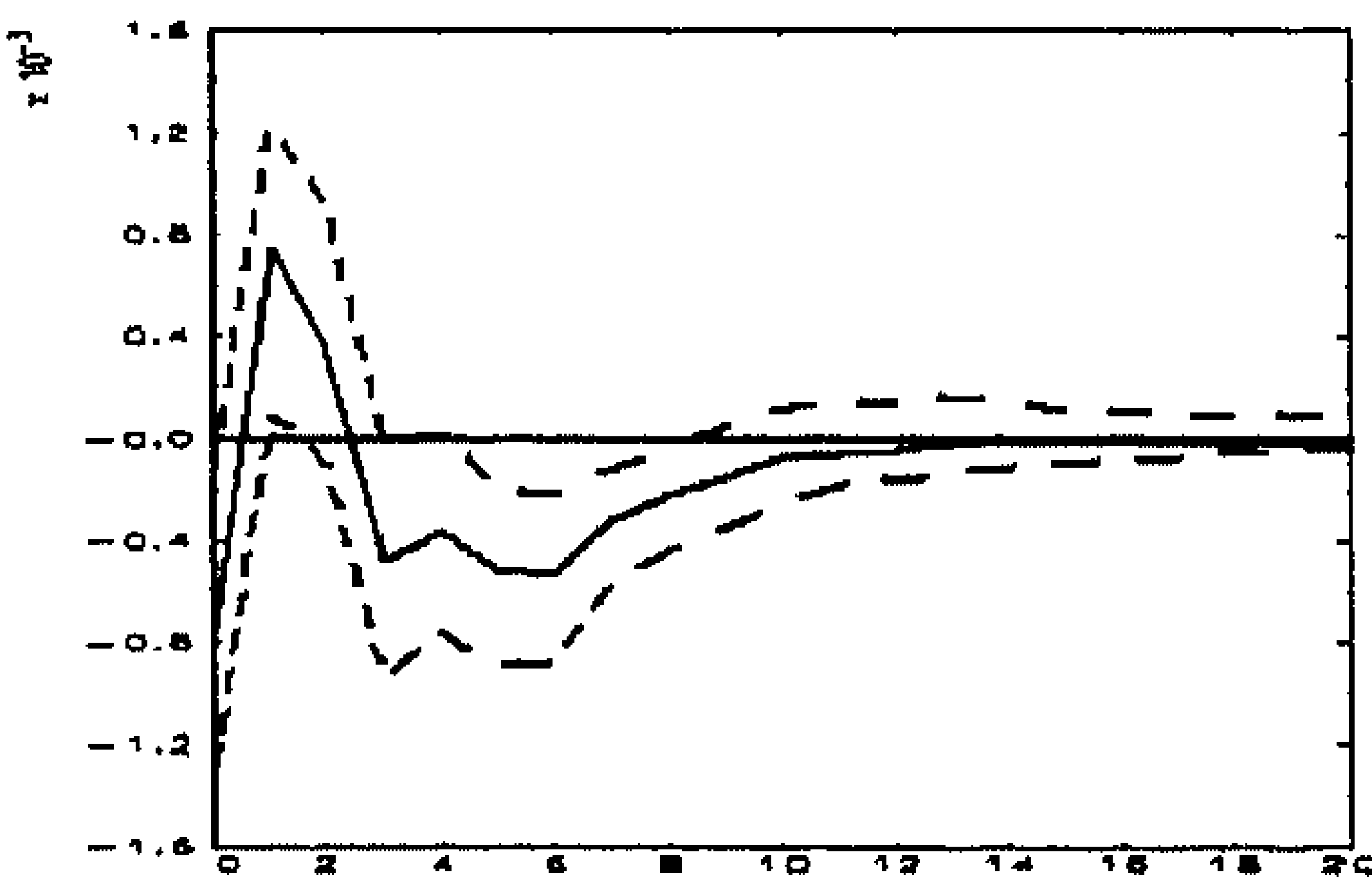

Source: Ow'n calculations

Investment specific technology shocks result in a significant initially low but persistent positive response of industry labor productivity.

At impact, the response of hours worked in industry to an investment specific technology shock is negative but quickly rises above zero in the first period already, before it again drops below zero. Overall, the initially negative response of hours worked dies off in an oscillating manner around zero and phases out in period 15.

The impact effect of a one-time unit neutral technology shock to industry labor productivity is positive and significant and rises up to period 4 before it levels off.

Finally, a neutral technology shock causes a negative impact effect on hours worked in industry, a positive effect in the two following periods and again negative responses thereafter. The effect vanishes after period 13.

Interestingly, hours worked in Industry respond negatively to both technology shocks considered. The underlying theoretical model presented in section II high- 
lights that just like traditional business cycle models with only neutral technology shocks, business cycle models that also account for investment specific technology shocks should generate positive responses of hours worked to either technology shocks. Hence, the negative technology-related response of hours worked is at odds with predictions of the standard and extended Real Business Cycle (RBC) theory but in line with recent empirical studies on the cyclical reaction of the hours/input measure to positive technology shocks found by Shea (1998), Gall (1999), Fisher (2002) or Basu et al. (2006).

According to the Real Business Cycle Theory, exogenous sector neutral technology shocks enhance labor productivity and - given that labor is paid its marginal product - real wages increase. Consumers maximize expected lifetime utility from consumption of goods and services $c_{1}$ as well as leisure $1-l_{1}$. With respect to labor supply, an intertemporal decision rule is applied based on the comparison of the relative real wage rates in periods 2 and 1: with an increase in the real wage rate in period 1, supply of labor also increases since period-1 employment becomes more profitable.

\section{VI.1.2 Discussiont of the Hours Response}

Sticky-Price Models: Gali (1999) and Basu et al. (2006) suggest that sticky-price models are able to explain the negative response of hours to positive technology shocks while Francis and Ramey (2005) emphasize that a flexible-price model with habit formation and sizeable capital adjustment costs generates the same negative hours response.

Gali (1999) specifies a sticky-price model with monopolistic competition and two shocks in terms of technology and monetary shocks to affect economic behavior. He demonstrates that when prices are sticky and monetary accommodation is not too strong, a positive technology shock can result in a decline in labor input in the short run. In the extreme case of zero monetary expansion, real money balances and aggregate demand remain unchanged if prices are sticky. With an observed permanent increase in labor productivity in response to a positive technology shock, the same level of output can be produced with less labor input and hours decline. And as long as monetary expansion (and therefore aggregate demand growth) is not too strong and proportionally less than the increase in labor productivity, a decline in hours emerges. In the long run, when prices change too, hours worked rise again.

Basu et al. (2006) shows that hours worked and investments drop in response to positive technology shocks captured by the Solow residual calculated on the basis of industry data for 29 U.S. industries between 1949 and 1996. He emphasizes that the observed short-term reactions are consistent with predictions of sticky-price models. With sticky prices and aggregate demand depending on real money balances, output does not change in response to a positive technology shock so that entrepreneurs 
produce an unchanged level of output with less labor input and hours decline. At the same time, investments are reduced since the need for expansionary investment activities vanishes. Over time, however, prices fall and output and investments rise.

Francis and Ramey (2004) also discover a drop in U.S. hours worked after a positive technology shock and offer a flexible-price model to reconcile empirical evidence with theoretical considerations. Specifically, with habit persistence in consumption and positive adjustment costs associated with rapid modifications of the capital stock, both consumption and investment activities are slow to adjust and a positive productivity-enhancing technology shock results in a decline in hours since the same output is produced with less labor input and a slow increase in output. consumption and investments over time.

Open Economy Real Business Cycle Models: Furthermore, Collard and Dellas (2002) demonstrate that an observed decline in hours worked in response to a positive technology shock also emerges in open economy Real Business Cycle models with fixed or flexible prices.

They show that the decline in hours in the flexible-price open economy strongly depends on the degree of trade openness, the trade elasticity between domestic and foreign (intermediate) products and the presence of capital adjustment costs to investments. Specifically, a negative response to domestic positive technology shocks is guaranteed if the degree of openness is sufficiently high, domestic and foreign goods are not good substitutes and there are capital adjustment costs. Furthermore, they stress that high capital adjustment costs per se are sufficient for a negative hours response irrespective of open economy considerations.

Fixed-price open economy models however are found to not critically depend on the presence of open economy elements to generate negative responses of hours to positive technology shocks.

With respect to empirical evidence on price-stickiness in Austria, Baumgartner et al. (2005) use a unique set of monthly price quotes collected by Statistics Austria between January 1996 and December 2003 in order to compute the Austrian consumer price index to show that national consumer prices are quite sticky with a weighted average duration of price spells for all products of 10 months. They find strong inter-industry heterogeneity with prices for service, health care or education changing the least frequent (only once a year) while prices of product types of food, energy and communication are adjusted on average every 6 to 8 months.

However, no empirical evidence is available on the elasticity of substitution between domestic and foreign goods or the degree of capital adjustment costs prevailing in Austrian manufacturing so one cannot discriminate between sticky-price models and open economy RBC models since both predict an initial fall in hours worked after a positive technology shock. 


\section{VI.1.3 The Role of Technology for the Variation in Monthly Hours Worked and Output}

For two major reasons, the concept of cohesion as suggested by Croux et al. (2001) is applied to capture the role of technology shocks for the Austrian business cycle.

One, trend-cycle decomposition techniques in terms of Hodrick-Prescott filters to extract information relevant for business cycle related questions were shown to alter variability and persistence of underlying data and to impose spurious cycles and correlations (Harvey and Jaeger, 1993 or Cogley and Nason, 1995). In that respect, the measures of business cycle variability and contributions of investment specific and neutral technology shocks to observed business cycles on the basis of standard filtered data may be misspecified and uninformative. So, shifting the analysis from the time to the frequency domain circumvents any adverse effects imposed by applying technical filtering procedures.

And two, as a dynamic correlation coefficient, cohesion is decomposable by frequency and frequency bands and serves to tackle questions related to business cycle as well as short and long-run phenomena and therefore allows to also shed light on the significance of different economic variables of interest for other than business cycle variations.

Cohesion between the two variables $x$ and $y$ is defined as follows:

$\operatorname{cohesion}_{x y}\left(\Lambda_{+}\right)=\frac{\sum_{i} w_{x i} w_{y i} \rho_{x y}\left(\Lambda_{+}\right)}{\sum_{1} w_{x i} w_{y i}}$

where $\Lambda_{+}$represents the frequency band and is typically set to $\Lambda_{+}=[0, \pi]$ and for sake of simplicity the weights $w=1$ for all variables so that cohesion becomes a function of $\rho_{x y}\left(\Lambda_{+}\right)$, the frequency-dependent dynamic correlation between $x$ and $y$, only:

cohesion $_{x y}\left(\Lambda_{+}\right)=\rho_{x y}\left(\Lambda_{+}\right)=\frac{C_{x y}\left(\Lambda_{+}\right)}{\sqrt{S_{x}\left(\Lambda_{+}\right) S_{y}\left(\Lambda_{+}\right)}}$

$S_{x}\left(\Lambda_{+}\right)$and $S_{y}\left(\Lambda_{+}\right)$are the spectral density functions of $x$ and $y$ and $C_{x y}\left(\Lambda_{+}\right)$is the co-spectrum of these variables in the range $\Lambda_{+}=[0, \pi]$. The spectrum represents a decomposition of variance by frequency and therefore allows for the identification of periodicities inherent in the data. The co-spectrum represents the real part of the cross spectrum which itself describes the frequency dependent covariance and can be utilized to study the correlation between two variables. Since dynamic correlation can vary between -1 and +1 , cohesion also lies between -1 and +1 . 
The literature has attributed time-related economic interpretation to three different frequency intervals: the long-run interval is associated with cycles longer than 8 years of duration and corresponds to frequencies between 0 and 0.2 for quarterly data; the business cycle interval is related to cycles between 3 to 8 years and covers frequencies between 0.2 and 0.5 for quarterly data; finally, the short term interval refers to cycles shorter than 3 years and corresponds to frequencies between 0.5 and $\pi$. Furthermore, a spectral density of rank one at frequency zero refers to a cointegrated process.

Figure 9: Cohesion of Technology Related Variations to Overall Variations in Monthly Hours Worked and Output with the Real Trade Balance as Openness Indicator (3 lags)
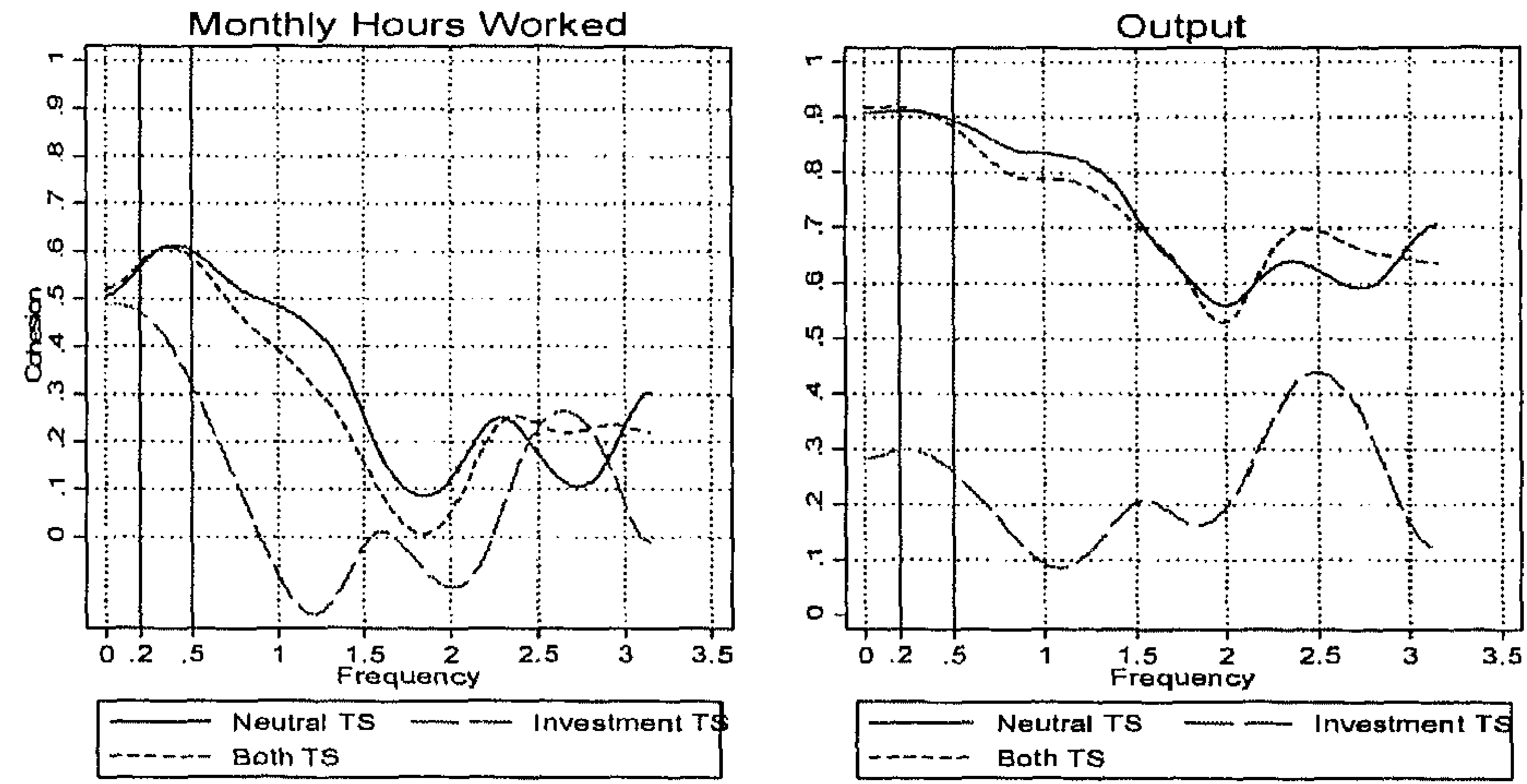

Source: Own calculations

Results of the frequency dependent role of either technology shocks in "explaining" cyclical variations in hours worked and output in Industry are presented in Figure 9. Clearly, at business cycle frequencies dynamic correlation of hours worked driven by both technology shocks with actual hours worked is relatively moderate and varies between 0.58 and 0.61 . A decomposition of the overall effect furthermore highlights the dominant role neutral technology shocks play with a cohesion of the same range and magnitude.

Similar results can be inferred for output variations and the significance of either technology shocks. Neutral technology shocks again show stronger dynamic correlations in the range of 0.90 to 0.91 while investment specific technology shocks are only weakly correlated with overall output variations.

The results also emphasize that investment specific technology shocks more strongly contribute to cyclical variations in hours worked compared to variations in output. Furthermore, said shocks have the strongest effect on output variations in the very short run only. 
The overall observed stronger effect of technology on variations in output stems from the productivity-enhancing effect of technological change and the resulting expansion of output. In contrast to that, variations in hours worked in response to technology shocks appear relatively moderate. Hence technology shocks do not seem to require strong changes or adjustments in hours to accompany changes in output. Or, alternatively, it is also conceivable that the emerging lacking effect of technology on hours results from entrepreneurs' decision to also adjust employment in such a way that average hours per employee remain unaltered. However, sizeable costs of adjustment associated with hiring (or firing) employees renders employment adjustments more expensive and less likely.

Furthermore, the effects of neutral technology shocks on variations in hours or output are considerably lower in the very short run as compared to the medium or the long run. This observation is generally consistent with the existence of learning effects and the need to learn how to exploit productivity-enhancing changes most efficiently. And since it takes time to learn, effects on output and hours increasingly unfold over time.

Finally, investment specific technology shocks lead to an initial hump-shaped reaction of variations in both hours and output, before it starts to rise again over the medium and long run. Hence, initially, at the very short run, the contribution of investment shocks to the variation in hours and output is high before it quickly drops and starts to rise again. This loss of importance of investment specific technology shocks may be explained by the swarming effect of investment activities together with the prevalence of disruptive effects present in the course of the implementation of technological novelties and the temporary associated drop in labor productivity. Initially, a small group of first-movers implements the latest technology and faces temporary productivity losses. Over time, learning effects set in and output changes. As late-comers, a large group of entrepreneurs also invests and faces similar disruption costs. Given the size of this group, productivity experiences a significant drop before learning effects again set in and the contribution of investment specific technology shocks to variations in output rises again. And for hours, output changes are accompanied by changes in hours.

Table 3: Cohesion Results for Different Openness Indicators

\begin{tabular}{|c|c|c|c|c|c|c|}
\hline & \multicolumn{3}{|c|}{ Hours Worked } & \multicolumn{3}{|c|}{ Output } \\
\hline & $\begin{array}{l}\text { Neutral } \\
\text { Shocks }\end{array}$ & I-Shocks & $\begin{array}{l}\text { Both } \\
\text { Shocks }\end{array}$ & $\begin{array}{l}\text { Neutral } \\
\text { Shocks }\end{array}$ & I-Shocks & $\begin{array}{l}\text { Both } \\
\text { Shocks }\end{array}$ \\
\hline Trade Balance' & $0.57-0.61$ & $0.33-0.47$ & $0.58-0.61$ & $0.90-0.91$ & $0.26-0.30$ & $0.88-0.92$ \\
\hline Terms of Trade ${ }^{2}$ & $0.59-0.62$ & $0.27-0.47$ & 0.60 & $0.78-0.85$ & $0.08-0.30$ & $0.77-0.87$ \\
\hline Openness $^{3}$ & $0.49-0.57$ & $0.44-0.57$ & $0.56-0.61$ & 0.83 & $0.31-0.42$ & $0.87-0.88$ \\
\hline
\end{tabular}

'Defined as the difference between real exports and real imports, estimated with 3 lags.

2 Defined as the ratio of export to import price indices, estimated with 5 lags.

' Defined as the ratio of the sum of real exports and imports to real GDP, estimated with 5 lags.

To identify the sensitivity of results with respect to the openness indicator used above, the terms of trade defined as the ratio of export and import indices and openness 
defined as the ratio of the sum of real exports and real imports to real GDP are utilized in separate analyses. The impulse-response functions and cohesion results are depicted in Figure 12 and Figure 13 as well as Figure 16 and Figure 17 in the appendix, respectively. The cohesion analyses consistently demonstrate that irrespective of the openness indicator considered, technology shocks have a stronger impact on variations in output as compared to hours worked. Furthermore, neutral technology shocks are relatively more important for cyclical variations in both hours worked and output than investment specific technology shocks. An overview of the results is provided in Table 3.

\section{VI.1.4 Larger VAR Systems}

A priori, however, there is no reason to believe that results derived from a small fourvariable specification will also emerge in larger specifications. Hence, to eliminate any potential small-sample bias and to check for the consistency and sensibility of results, larger VARs are analyzed. To also identify the role of monetary policy an extended six-variable VAR is estimated, additionally accounting for the inflation rate and the interest rate. Furthermore, as suggested by Christiano et al. (2005) the ratio of nominal total consumption to nominal GDP is included and an extended sevenvariable specification is analyzed (Figure 14 in the appendix depicts all additional variables included in the two extensions).

With the establishment of the European Monetary Union, marked by the introduction of the EURO as a real currency, EU-member countries (like Austria) no longer reported country-specific interest rates. Instead, the European Central Bank, as the Union's monetary authority, commenced to identify Euro-area specific interest rates. Hence, Austrian short-term interest rates, available for 1967:1 up to 1998:4, were completed by short-term EURIBOR rates for the period 1999:1 to 2005:4. Furthermore, the inflation rate as captured by the GDP deflator is included.

The theoretical framework discussed in section II suggests nominal total consumption and investment ratios defined as nominal total consumption (public and private) over nominal GDP and nominal investment over nominal GDP as potential extensions. Starting from 1987:4, the observed time series of total consumption extracted from the ESA 1995 was interpolated to $1965: 1$ by means of annual growth rates calculated for total consumption under the SNA 1968 accounting approach. However, SNA 1968 does not provide gross investments but the subgroup of gross fixed capital formation only. Since the growth rate of total gross fixed capital formation was already applied to derive the extended time series for gross equipment investments, inclusion of the nominal investment share was refrained from to avoid statistical problems. Instead, the VAR is extended by the total nominal consumption share only - as the sum of public and private consumption. 
Augmented Dickey Fuller (ADF) tests of difference stationarity were applied to all additional data. The null hypothesis of difference stationarity cannot be rejected at conventional significance levels. Additionally, the Kwiatkowski, Phillips, Schmidt and Shin (1992) test of the null hypothesis of level stationarity against the alternative hypothesis of a unit root was applied to the data and rejected. Hence, the variables are all $\mathrm{l}(1)$.

Figure 10: Cohesion of Technology Related Variations to Overall Variations in Monthly Hours Worked and Output with the Real Trade Balance as Openness Indicator; 6-variable Specification with 4 lags
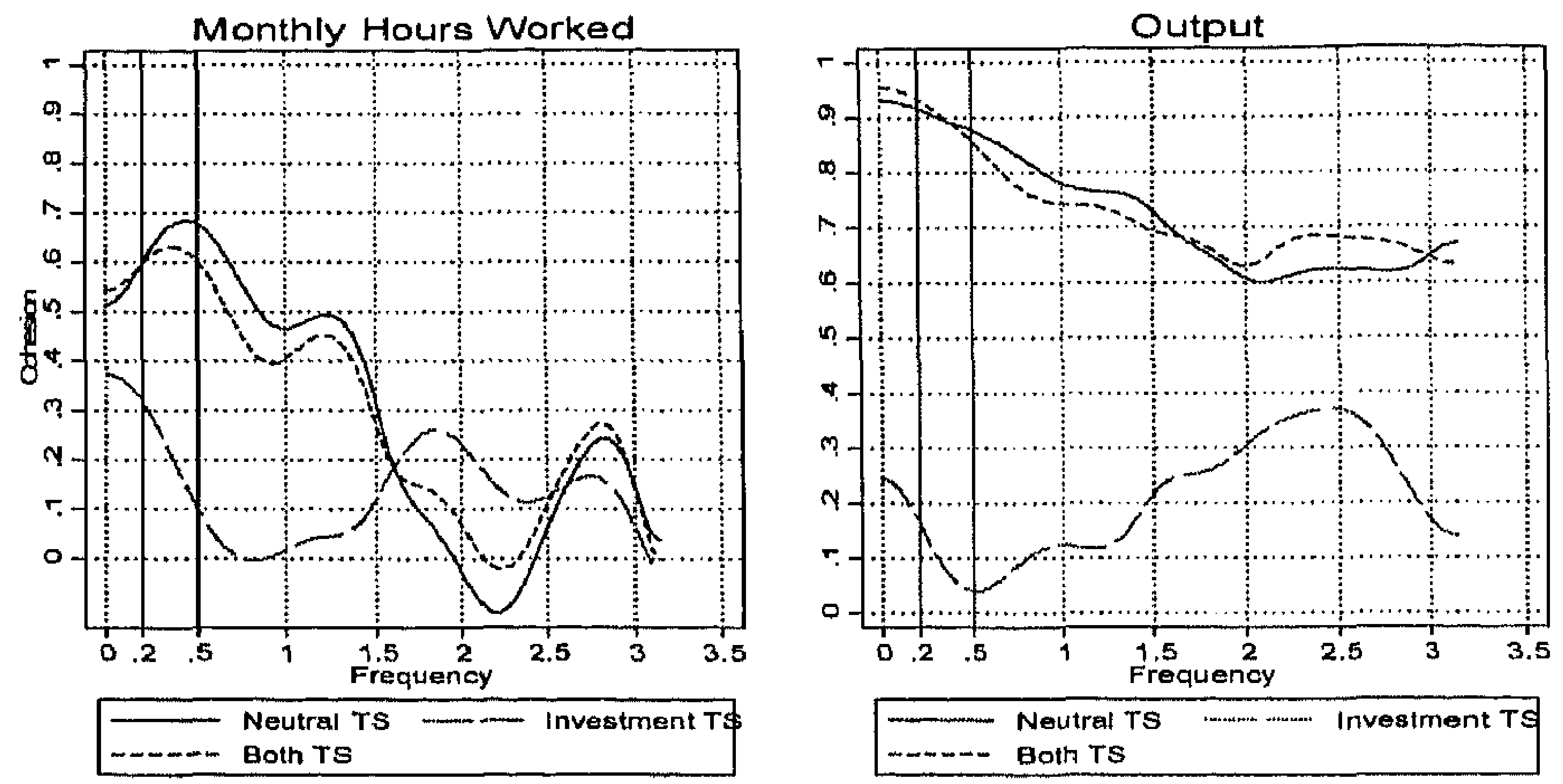

Source: Own calculations

Lag-order selection was again based on conventionally applied selection order criteria and as suggested by the Final Prediction Error and the Akaike information criterion a four-lag specification was chosen for the six-variable VAR including the real price of investment, labor productivity, hours worked, the real trade balance, the inflation rate and the interest rate. The seven-variable system that also accounts for the nominal consumption share was specified with a five-lag structure instead.

Figure 10 depicts the results for the extended six-variable system and highlights that the dynamic correlation of variations in hours worked driven by overall technology shocks with observed variations in hours worked ranges between 0.63 and 0.60 only. Neutral technology shocks again dominate with a cohesion ranging between 0.69 and 0.60 , while investment specific technology shocks result in a relatively low cohesion coefficient of simulated hours worked with actual hours worked.

Similar inferences can be drawn for cyclical variations in output with a dynamic correlation of output variations driven by overall technology shocks with actual output variations between 0.94 and 0.86 . Neutral technology shocks again dictate observed correlations. However, while the general patterns reemerge, in contrast to 
above four-variable results, cyclical variations of output in response to investment specific technology shocks with actual variations in output are considerably lower.

Results for the modified seven-variable scenario are shown in Figure 11 while the associated impulse-response functions are depicted in Figure 15 in the appendix.

In the extended seven variable setting, dynamic correlation of overall technology shocks with hours worked is again rather moderate and varies between 0.66 and 0.62 . Neutral technology shocks dominate with cohesion ranging between 0.66 and 0.61 .

Figure 11: Cohesion of Technology Related Variations to Overall Variations in Monthly Hours Worked and Output with the Real Trade Balance as Openness Indicator; 7-variable Specification with 5 lags
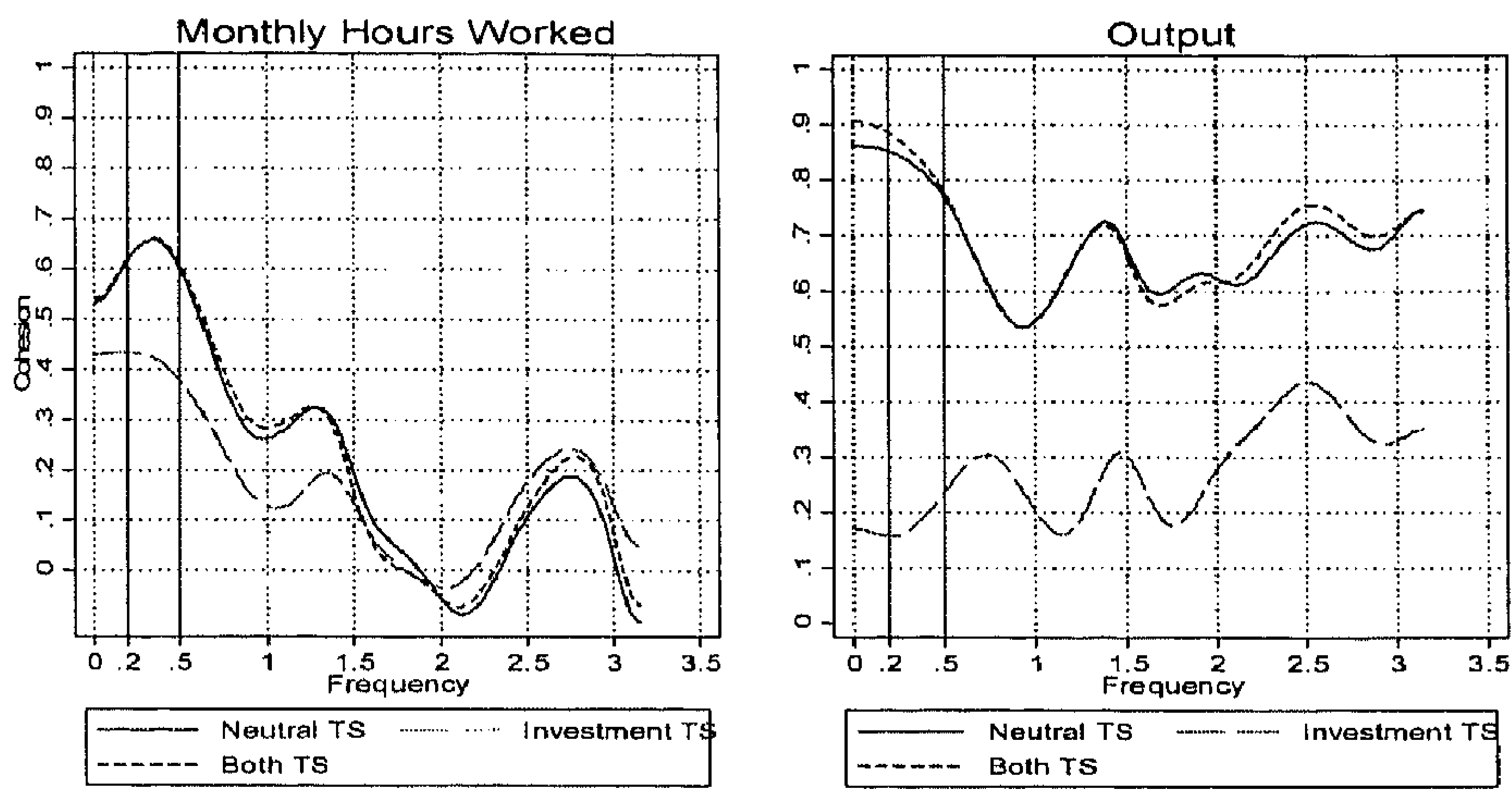

Source: Ow'n calculations

Results for the cohesion of technology driven output with overall actual output well compare to those derived in the basic scenario. They again highlight the relative importance of neutral technology shocks for cyclical variations at business frequencies. For output, investment specific technology shocks are more relevant for shorter than business cycle frequencies.

Clearly, the results derived from larger VAR specifications indicate that the inclusion of additional monetary policy and nominal consumption variables leaves the basic results unaltered. This underscores the initial finding that neutral technology shocks consistently play a decisive role in explaining business cycle variations of output and hours worked and that technology shocks in general are considerably more important for variations in output as compared to variations in hours worked. Furthermore, investment specific technology shocks are found to have the strongest impact on variations in output in the very short run. 


\section{Exogeneity of Identified Technology Shocks}

However, above results on the role of technology-related shocks for observed cyclical variations critically depend on the standard Real Business Cycle assumption of exogenous technology shocks that are uninfluenced by other economic factors. Hall (1988) and Evans (1992) argue that therefore technology shocks should not be correlated with any other exogenous shocks that are not related to technology. By stressing the importance of money, interest rates and government spending for explaining the Solow residual, Evans (1992) casts serious doubts on the underlying exogeneity assumption for the U.S economy covering the period 1954:4 to 1978:4. Instead he emphasizes that the standard Solow residual overstates the true role of neutral technology shocks for economic fluctuations. To account for this potential upward bias, an Evans-Hall exogeneity test is conducted on estimated investmentspecific and neutral technology shocks.

Specifically, in accordance with Francis and Ramey (2005) and as suggested by Hoover and Perez (1994), oil shock dummies, and as suggested by Evans (1992), the MI measure of money are included. Traditional RBC models generally viewed such monetary measures as unrelated to technology shocks. In accordance with Hoover and Perez (1994) and based on quarterly growth rates of crude oil prices, 11 oil price shocks are identified between 1965:1 and 2005:4: 1969:1, 1970:1, 1974:1, 1978:1, $1979: 3,1981: 1,1987: 1,1990: 4,1996: 4,1999: 1$ and 2003:1. Money enters in growth rates.

Estimated investment-specific and neutral technology shocks are regressed on a constant and current and four lagged values of the oil shock dummies and on a constant and four lagged values of the money growth rates:

$\varepsilon_{\|}=\alpha_{i}+\beta(L) z_{t-1}+\omega_{t}$

where $\beta(L)$ are polynomials in the lag operator $L$. Lags of the technology shocks $\varepsilon$, are not included since, by construction, they are not serially correlated. By assumption, $z$ should be unrelated to either technology shock.

Table 4: Exogeneity Test - p-values

\begin{tabular}{|l|c|c|}
\hline Shocks & Oil price shocks & $\mathrm{Ml}^{1}$ \\
\hline Investment Technology Shocks & 0.1555 & 0.3115 \\
Neutral Technology Shocks & 0.9578 & 0.1875 \\
\hline
\end{tabular}

$' M l$ is measured as a growth rate.

Invesiment-specific and neutral technology shocks are regressed on a constant and current and four lagged values of the oil price shock dummies and on a constant and four lagged values of the money growth rate. The table reports p-values of the F-test that the coefficients of all variables are jointly equal to zero.

Table 4 shows that the results of the F-test that the coefficients of all variables are jointly equal to zero cannot be rejected for all variables considered. Hence, all identi- 
fied technology shocks that are found to affect the business cycle measure of hours worked and labor productivity are exogenous and indeed capture variations in technology.

\section{Summary and Conclusion}

As opposed to previous research on the U.S. or the UK, the small and open economy of Austria was selected as an empirical platform to contribute to the discussion as to the role technology plays for observed business cycle variations. Based on the assumption that only technology shocks have permanent effects, a structural vector autoregression approach was chosen to account for technology-induced variations in output and hours worked, and to decompose the overall effect into a component attributable to neutral technology shocks and a component ascribable to investment specific technology shocks.

Counter predictions of traditional Real Business Cycle models, hours worked are found to fall in response to either technology shocks, which is consistent with either sticky-price models or open Real Business Cycle models with fixed or flexible prices. Lacking additional empirical evidence however renders any unambiguous identification impossible.

To circumvent adverse and spurious effects of filtering, the analysis takes a new approach and applies the frequency-dependent dynamic correlation coefficient of cohesion to capture the effects of either technology shocks on observed business cycle variations in output and hours worked. Moreover, the analysis also sheds light on the relative importance of either technology shocks for other than business cycle frequencies. It demonstrates that investment specific technology shocks are more important for variations in output in the very short run and more relevant for variations in hours worked in the medium to long run.

The results emphasize the dominant role neutral technology shocks play in explaining cyclical variations in hours worked and output and the moderate role investment specific technology shocks seem to have. These quantitatively different roles of technology shocks can be partly traced back to the qualitatively inferior investment specific technology measure of the real price of investment paired with the relatively low diffusion rate of leading-edge technologies embodied in machinery and equipment as represented by the volatile but low ratio of investment to GDP.

Furthermore, technology in general is found to be important but more strongly affects variations in output as compared to variations in hours worked. Hence, observed variations in output in response to productivity enhancing technology shocks are not accompanied by comparable variations in hours. Furthermore, outlined results are robust and prove to be consistent across openness indicators applied or specifications used. 


\section{Data Appendix}

Table 5: Stationarity Tests for the Subperiod: 1977:1 to 2005:4

\begin{tabular}{|l|c|c|c|}
\hline & $\begin{array}{c}\text { ADF } \\
\text { Constant }\end{array}$ & $\begin{array}{c}\text { ADF } \\
\text { Constant \& Trend }\end{array}$ & $\begin{array}{c}\text { KPSS } \\
\text { Constant \& Trend }\end{array}$ \\
\hline Real price of investment & 1.583 & -4.008 & $0.277^{*}$ \\
Hours worked & $(0.9978)$ & $(0.0086)$ & \\
& -2.492 & -1.915 & $0.372^{*}$ \\
Labor productivity & $(0.1175)$ & $(0.6471)$ & \\
& 1.850 & -0.834 & $0.330^{*}$ \\
Trade balance & $(0.9984)$ & $(0.9627)$ & \\
& 1.219 & 0.278 & $0.374^{*}$ \\
Openness & $(0.9961)$ & $(0.9962)$ & \\
& 4.432 & 1.230 & $0.400^{*}$ \\
Interest rate & $(1.0000)$ & $(1.0000)$ & $0.124^{*}$ \\
& -1.095 & -2.161 & \\
Nominal consumption ratio & $(0.7170)$ & $(0.5118)$ & $0.299 *$ \\
& -1.117 & -0.943 & $(0.9514)$ \\
\hline
\end{tabular}

palues of $A D F$ tests are in parentheses.

* indicate that the KPSS test rejects the null of stationarity at the 10 percent level. 
Table 6: Structural Vector Autoregression Results with the Real Trade Balance as Openness Indicator: 1977:1 to 2005:4

\begin{tabular}{|c|c|c|c|c|c|c|c|}
\hline \multicolumn{2}{|c|}{ RPI } & \multicolumn{2}{|c|}{ Labor produclivity } & \multicolumn{2}{|c|}{ Hours worked } & \multicolumn{2}{|c|}{ Trade balance } \\
\hline Constant & $\begin{array}{l}-0.001 \\
(2.54)^{*}\end{array}$ & Constant & $\begin{array}{l}0.002 \\
(2.52)^{* *}\end{array}$ & Constant & $\begin{array}{l}0.000 \\
(0.61)\end{array}$ & Constant & $\begin{array}{l}19.52 \\
(1.26)\end{array}$ \\
\hline$\Delta R P l_{1-1}$ & $\begin{array}{l}0.516 \\
(4.75)^{* * *}\end{array}$ & $\triangle R P I_{1-1}$ & $\begin{array}{l}0.012 \\
(0.10)\end{array}$ & $\Delta R P I_{1-1}$ & $\begin{array}{l}0.005 \\
(0.05)\end{array}$ & $\triangle R P I_{1-1}$ & $\begin{array}{l}366.72 \\
(0.12)\end{array}$ \\
\hline$\Delta R P I_{1-2}$ & $\begin{array}{l}-0.067 \\
(0.51)\end{array}$ & $\triangle R P I_{1-2}$ & $\begin{array}{l}-0.214 \\
(1.58)\end{array}$ & $\Delta R P I_{1-2}$ & $\begin{array}{l}-0.092 \\
(0.82)\end{array}$ & $\triangle R P I_{1-2}$ & $\begin{array}{l}-1391.87 \\
(0.41)\end{array}$ \\
\hline$\Delta R P I_{1-3}$ & $\begin{array}{l}-0.013 \\
(0.11) \\
\end{array}$ & $\Delta R P I_{r-3}$ & $\begin{array}{r}0.224 \\
(1.85)^{*} \\
\end{array}$ & $\Delta R P I_{1-3}$ & $\begin{array}{l}0.08 \\
(0.81) \\
\end{array}$ & $\triangle R P I_{1-3}$ & $\begin{array}{l}490.11 \\
(0.17) \\
\end{array}$ \\
\hline$\Delta^{2} L P$, & $\begin{array}{l}-0.139 \\
(0.53)\end{array}$ & $\Delta L P_{r-1}$ & $\begin{array}{l}0.795 \\
(8.11)^{* * *}\end{array}$ & $\Delta L P_{1-1}$ & $\begin{array}{l}0.209 \\
(2.73)^{* * *}\end{array}$ & $\Delta L P_{1-1}$ & $\begin{array}{l}556.99 \\
(0.24)\end{array}$ \\
\hline$\Delta^{2} L P_{1-1}$ & $\begin{array}{l}-0.123 \\
(1.32)\end{array}$ & $\Delta L P_{i-2}$ & $\begin{array}{l}0.167 \\
(1.33)\end{array}$ & $\Delta L P_{1-2}$ & $\begin{array}{l}-0.078 \\
(0.77)\end{array}$ & $\Delta L P_{1-2}$ & $\begin{array}{l}-1735.19 \\
(0.57)\end{array}$ \\
\hline$\Delta^{2} L P_{1-2}$ & $\begin{array}{l}0.027 \\
(0.33) \\
\end{array}$ & $\Delta L P_{1-3}$ & $\begin{array}{l}-0.178 \\
(1.84)^{*} \\
\end{array}$ & $\Delta L P_{1-3}$ & $\begin{array}{l}-0.245 \\
(3.12)^{* * *} \\
\end{array}$ & $\Delta L P_{1-3}$ & $\begin{array}{l}-223.80 \\
(0.10)\end{array}$ \\
\hline$\Delta^{2} H W$ & $\begin{array}{l}0.193 \\
(1.06)\end{array}$ & $\Delta^{2} H H^{\prime}$ & $\begin{array}{l}0.062 \\
(0.32)\end{array}$ & $\Delta H W_{1-1}$ & $\begin{array}{l}0.097 \\
(1.07)\end{array}$ & $\Delta H H_{t-1}$ & $\begin{array}{l}-7040.70 \\
(2.57)^{* *}\end{array}$ \\
\hline$\Delta^{2} H H_{t-1}$ & $\begin{array}{c}0.011 \\
(0.07)\end{array}$ & $\Delta^{2} H W_{1-1}^{\prime}$ & $\begin{array}{l}0.146 \\
(0.96)\end{array}$ & $\Delta H W_{1-2}^{\prime}$ & $\begin{array}{l}-0.05 \\
(0.54)\end{array}$ & $\Delta H W_{1-2}$ & $\begin{array}{l}1689.59 \\
(0.61)\end{array}$ \\
\hline$\Delta^{2} H W_{1-2}$ & $\begin{array}{r}0.03 \\
(0.18) \\
\end{array}$ & $\Delta^{2} H W_{1-2}$ & $\begin{array}{c}0.353 \\
(2.88)^{* * *} \\
\end{array}$ & $\Delta H W_{1-3}$ & $\begin{array}{c}0.1 \\
(1.10) \\
\end{array}$ & $\Delta H W_{1-3}$ & $\begin{array}{l}2857.24 \\
(1.06) \\
\end{array}$ \\
\hline$\Delta^{2} R T B$ & $\begin{array}{l}0.000 \\
(1.39)\end{array}$ & $\Delta^{2} R T B$ & $\begin{array}{l}0.000 \\
(1.32)\end{array}$ & $\Delta R T B_{1-1}$ & $\begin{array}{l}0.000 \\
(0.71)\end{array}$ & $\Delta R T B_{t-1}$ & $\begin{array}{l}0.72 \\
(7.33)^{* * *}\end{array}$ \\
\hline$\Delta^{2} R T B_{1-1}$ & $\begin{array}{l}0.000 \\
(0.18)\end{array}$ & $\Delta^{2} R T B B_{-1}$ & $\begin{array}{l}0.000 \\
(3.13)^{* * * *}\end{array}$ & $\Delta R T B_{1-2}$ & $\begin{array}{l}0.000 \\
(1.18)\end{array}$ & $\triangle R T B_{1-2}$ & $\begin{array}{l}-0.19 \\
(1.51)\end{array}$ \\
\hline \multirow[t]{2}{*}{$\Delta^{2} R T B_{1-2}$} & $\begin{array}{l}0.000 \\
(0.51) \\
\end{array}$ & $\Delta^{2} R T B_{1-2}$ & $\begin{array}{l}0.000 \\
(0.31) \\
\end{array}$ & $\Delta R T B_{1-3}$ & $\begin{array}{l}0.000 \\
(0.81) \\
\end{array}$ & $\Delta R T B_{t-3}$ & $\begin{array}{r}-0.09 \\
(0.90) \\
\end{array}$ \\
\hline & & Residl & $\begin{array}{l}0.365 \\
(2.70)^{* * *}\end{array}$ & $\begin{array}{l}\text { Resid1 } \\
\text { Resid2 }\end{array}$ & $\begin{array}{l}-0.329 \\
(3.59)^{* * *} \\
-0.127 \\
(1.54) \\
\end{array}$ & $\begin{array}{l}\text { Resid1 } \\
\text { Resid2 }\end{array}$ & $\begin{array}{l}4676.76 \\
(1.70)^{*} \\
3374.39 \\
(1.37) \\
\end{array}$ \\
\hline
\end{tabular}

RP/ refers to the real price of investment, LP no labor productivity, HW to hours worked and RTB to the real rade balance.

Residl captures investment specific technology shocks while Resid2 refers to newral technology shocks. t-valles are in parentheses. 
Table 7: Unconditional Correlation

(BC-component of the Real Price of Investment and real GDP)

\begin{tabular}{|l|c|c|}
\hline \multirow{2}{*}{} & Overall Sample & $\begin{array}{c}\text { Sub-sample } \\
(1977: 1-2005: 4)\end{array}$ \\
\cline { 2 - 3 } & Output & Output \\
\hline RPI & 0.3066 & -0.1973 \\
RPI (1 lag) & $(0.0001)^{* * *}$ & $(0.0338)^{* *}$ \\
& 0.1481 & -0.0601 \\
RPI (2 lags) & $(0.0599)^{*}$ & $(0.5214)$ \\
RPI (1 lead) & -0.0411 & 0.0819 \\
& $(0.6049)$ & $(0.3820)$ \\
RPI (2 leads) & 0.2568 & -0.1607 \\
& $(0.0010)^{* * *}$ & $(0.0849)^{*}$ \\
& 0.1992 & -0.1147 \\
& $(0.0113)^{* *}$ & $(0.2203)$ \\
\hline
\end{tabular}

RPI refers to the real price of investment. Band-Pass filtering was applied to derive the business-cycle components of the data.

p-values in parentheses. 
„re 12: Structural Impulse-Response Functions to Structural Technology Shocks with the Terms of Trade as Openness Indicator (4-variable Specification)

Investment Technology Shocks Labor Productivity

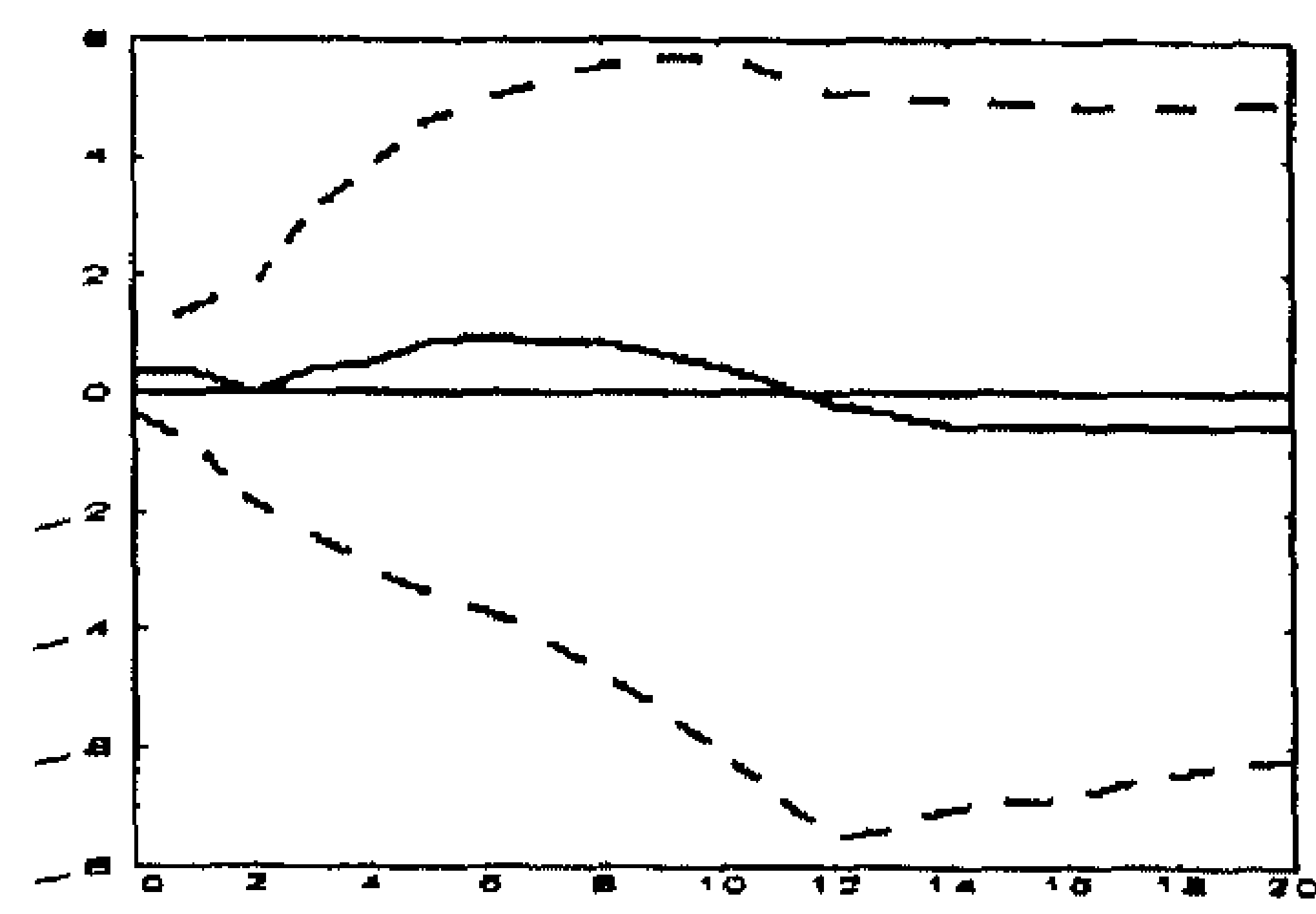

Monthly Hours Worked

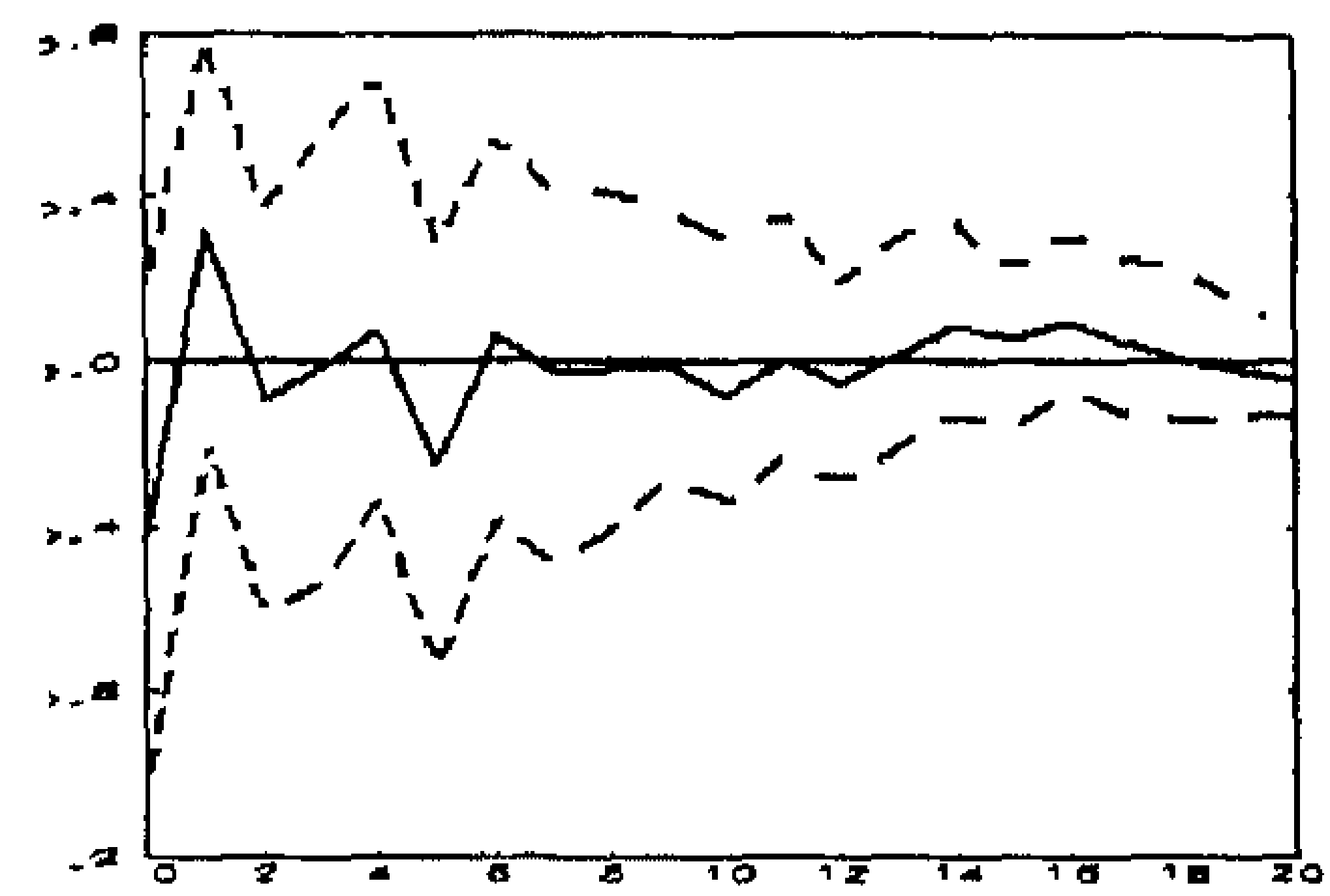

ze: On'n calculations
Neutral Technology Shocks Labor Productivity

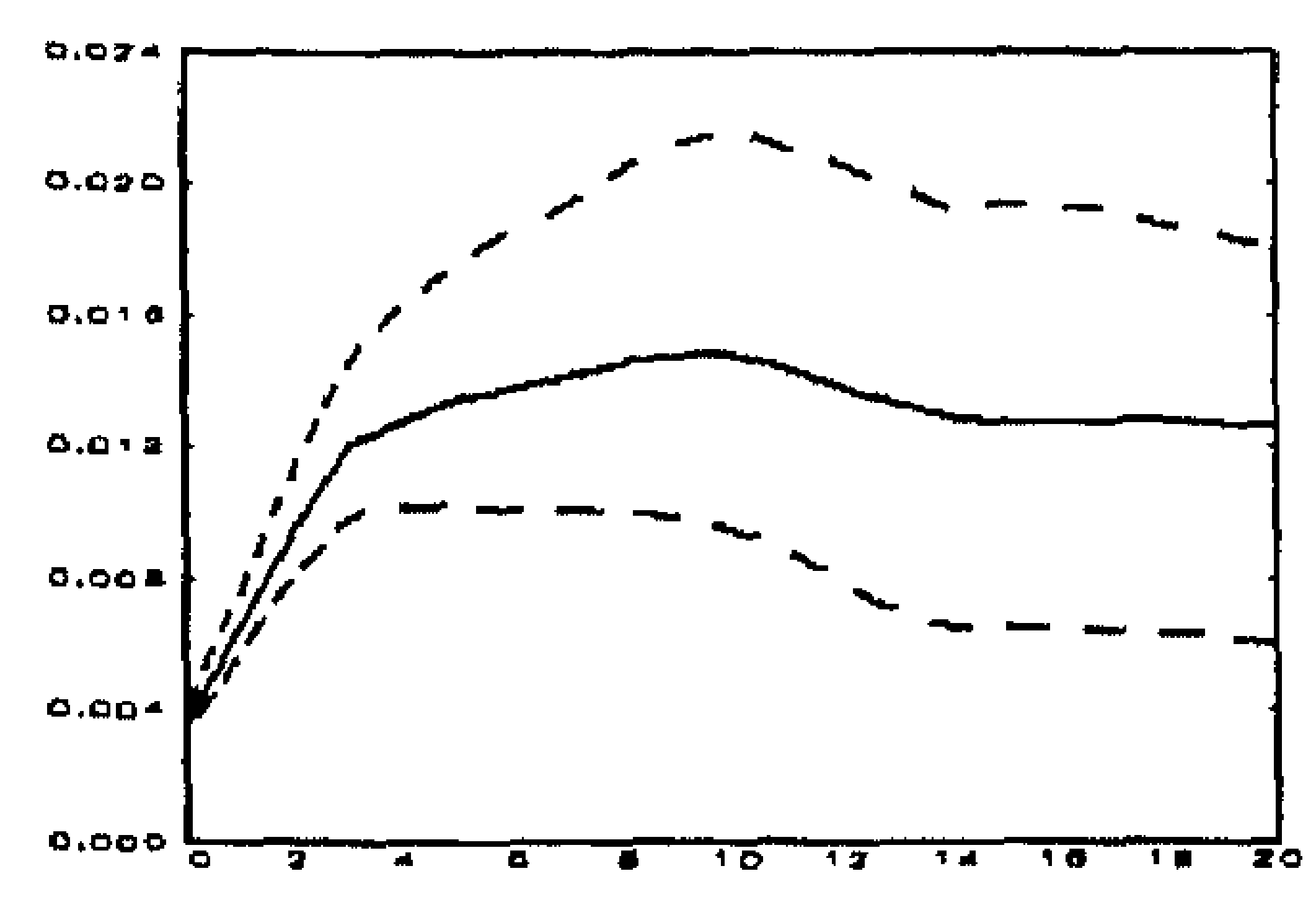

Monthly Hours Worked

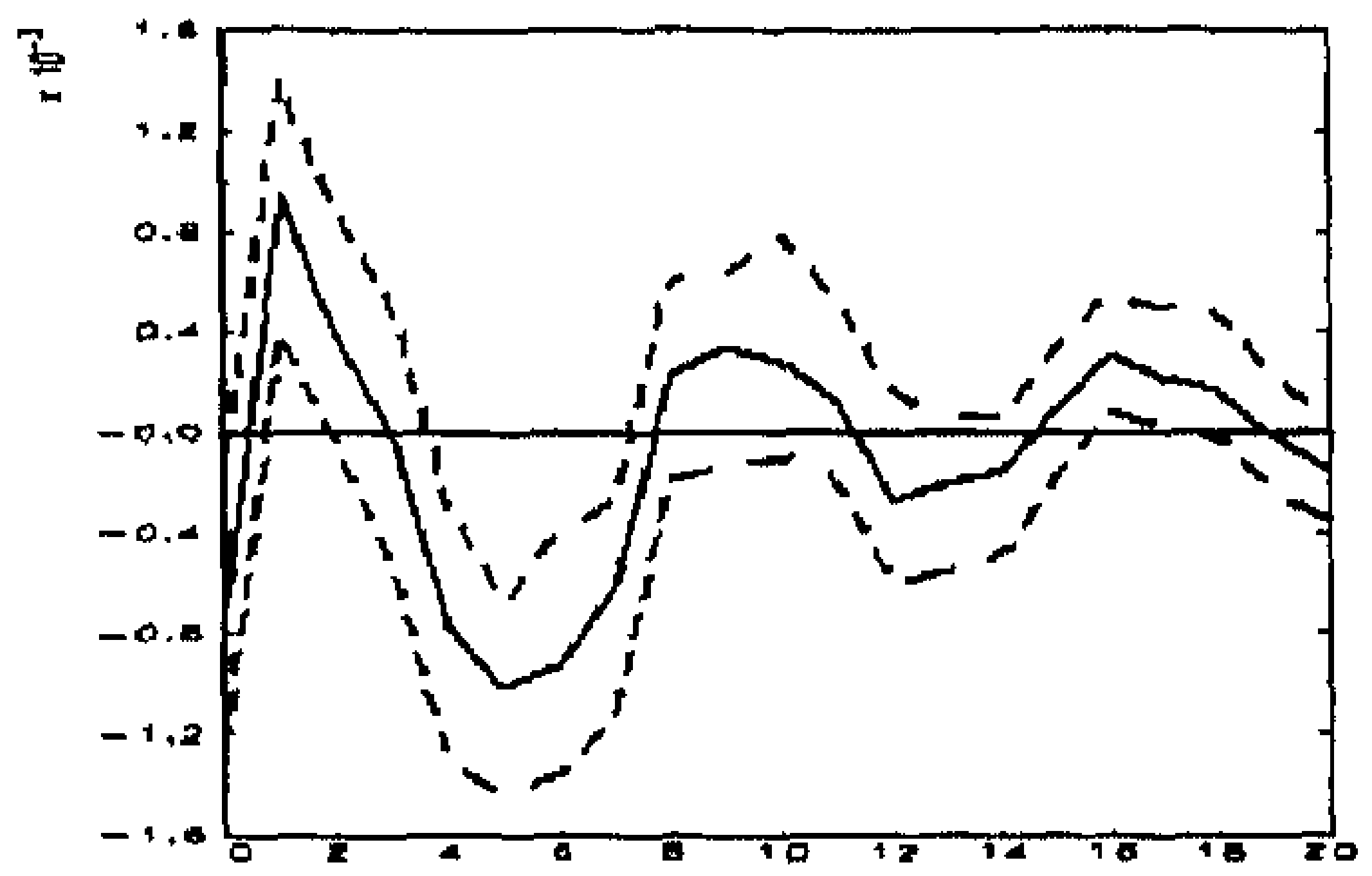


Figure 13: Structural Impulse-Response Functions to Structural Technology Shocks with Real Openness as Openness Indicator (4-variable Specification)

Investment Technology Shocks Labor Productivity

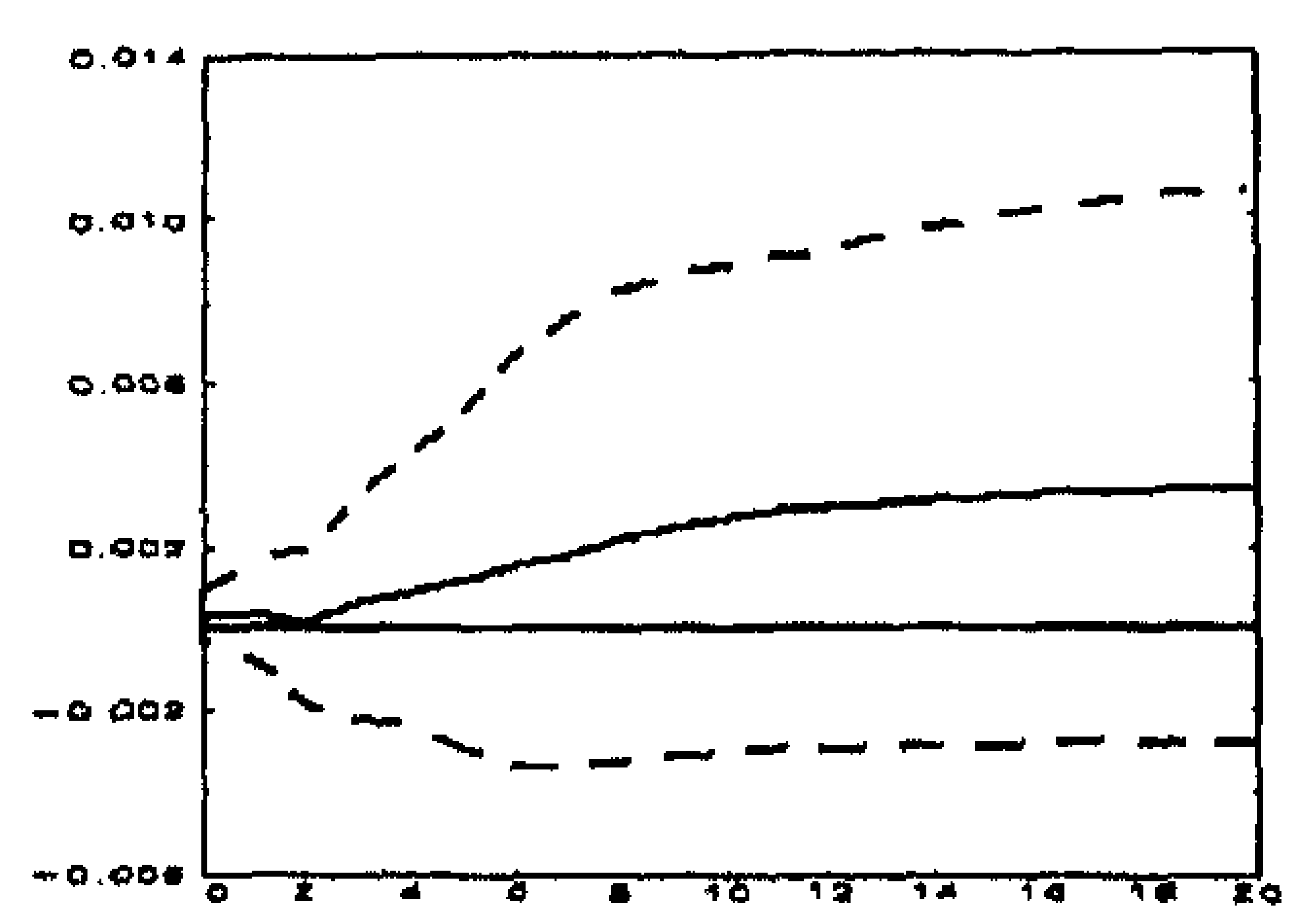

Monthly Hours Worked

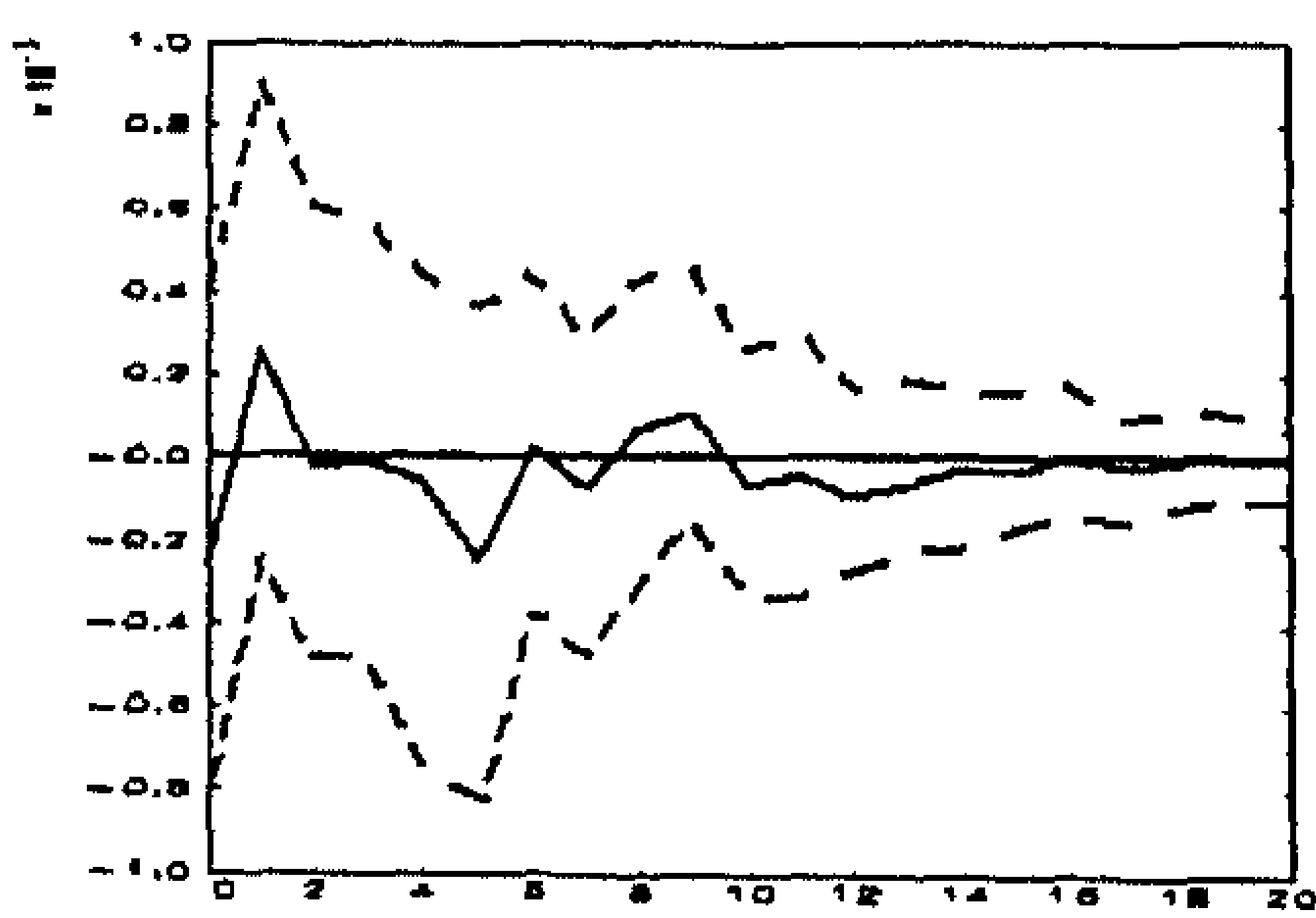

Neutral Technology Shocks Labor Productivity

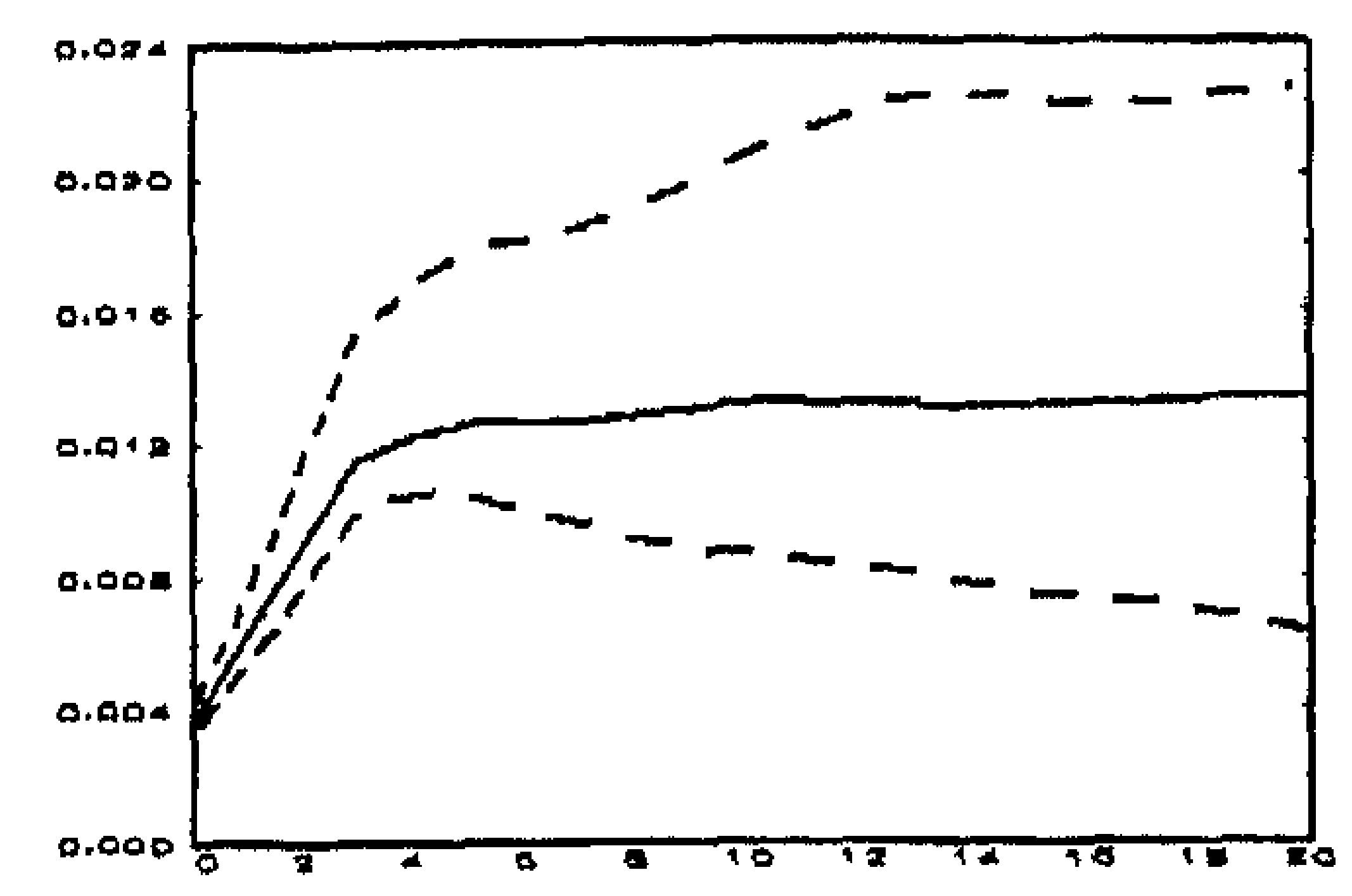

Monthly Hours Worked

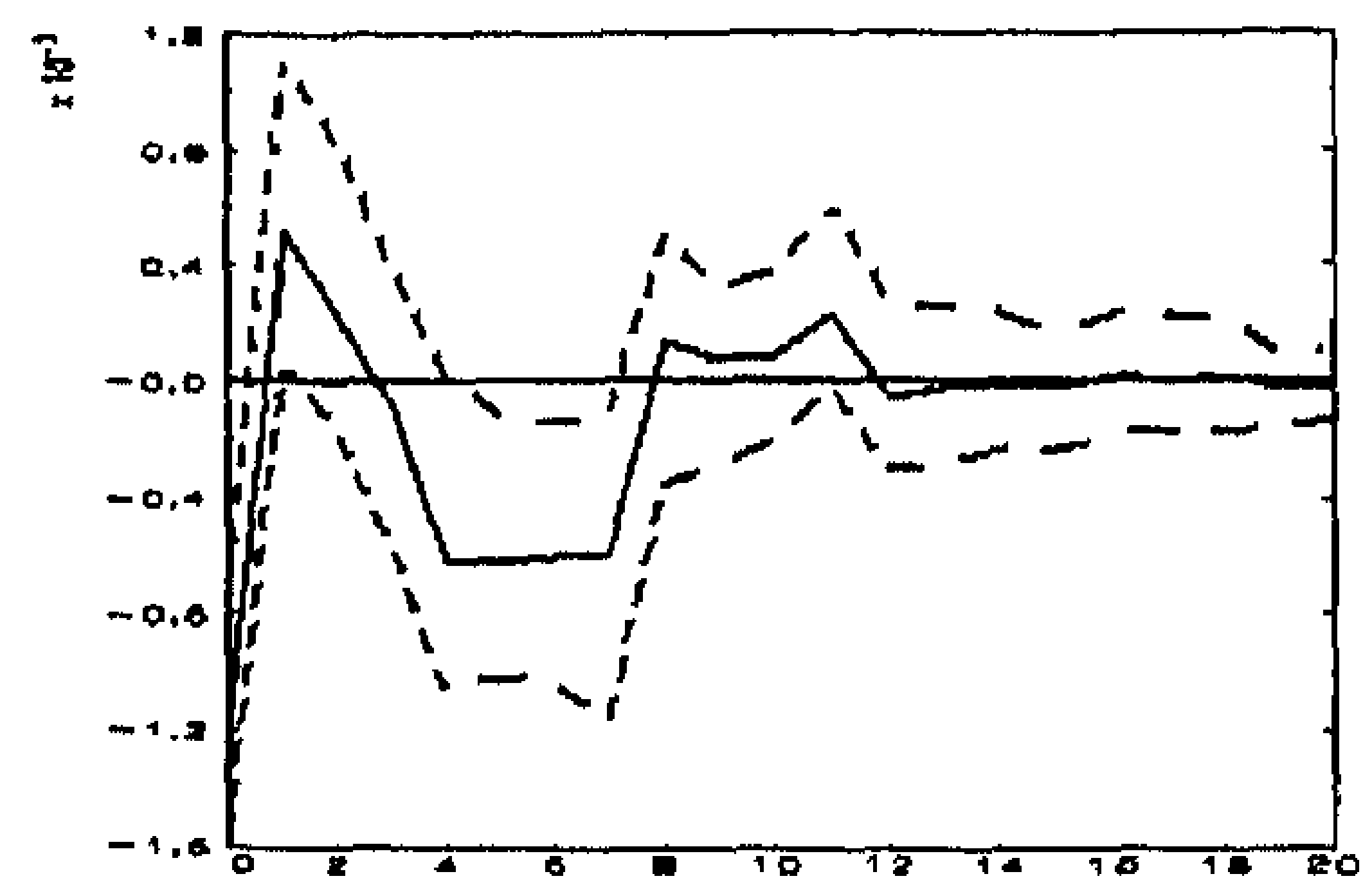

Source: Own calculations 
Figure 14: Additional Variables

Growth of the Total Nominal Consumption Share

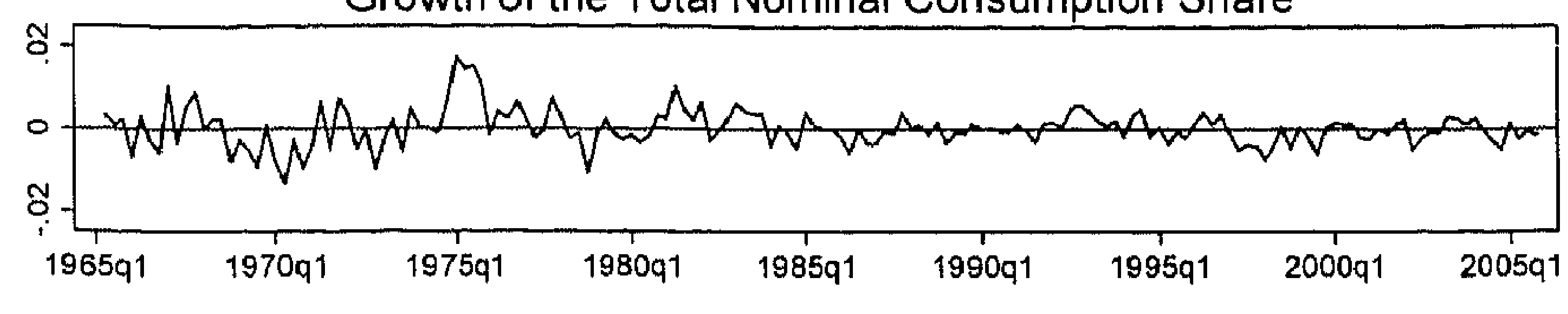

Inflation Rate

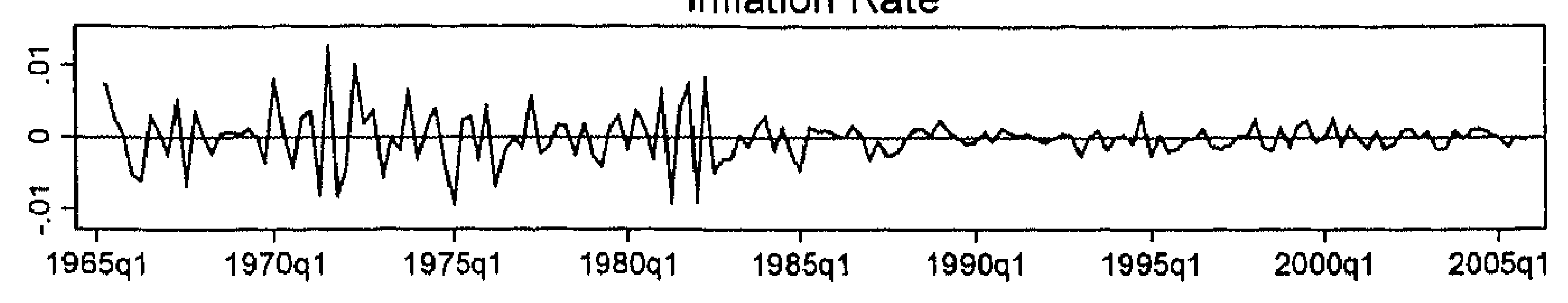

Interest Rate

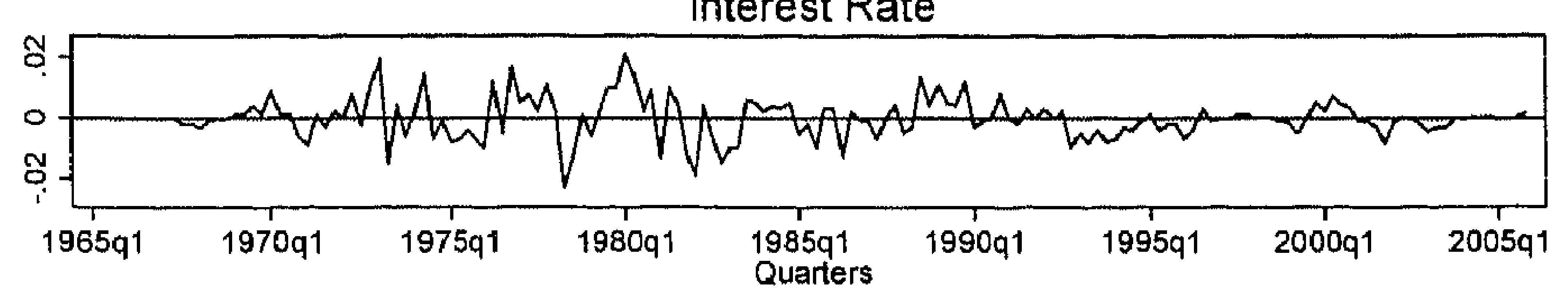

Source: Nominal Consumption Share: Quarterly National Accounts, OECD; Inflation Rate: Economic Outlook. OECD; Interest Rate: International Financial Statistics, IMF. 
Figure 15: Structural Impulse-Response Functions to Structural Technology Shocks with the Real Trade Balance as Openness Indicator (7-variable Specification)

Investment Technology Shocks Labor Productivity

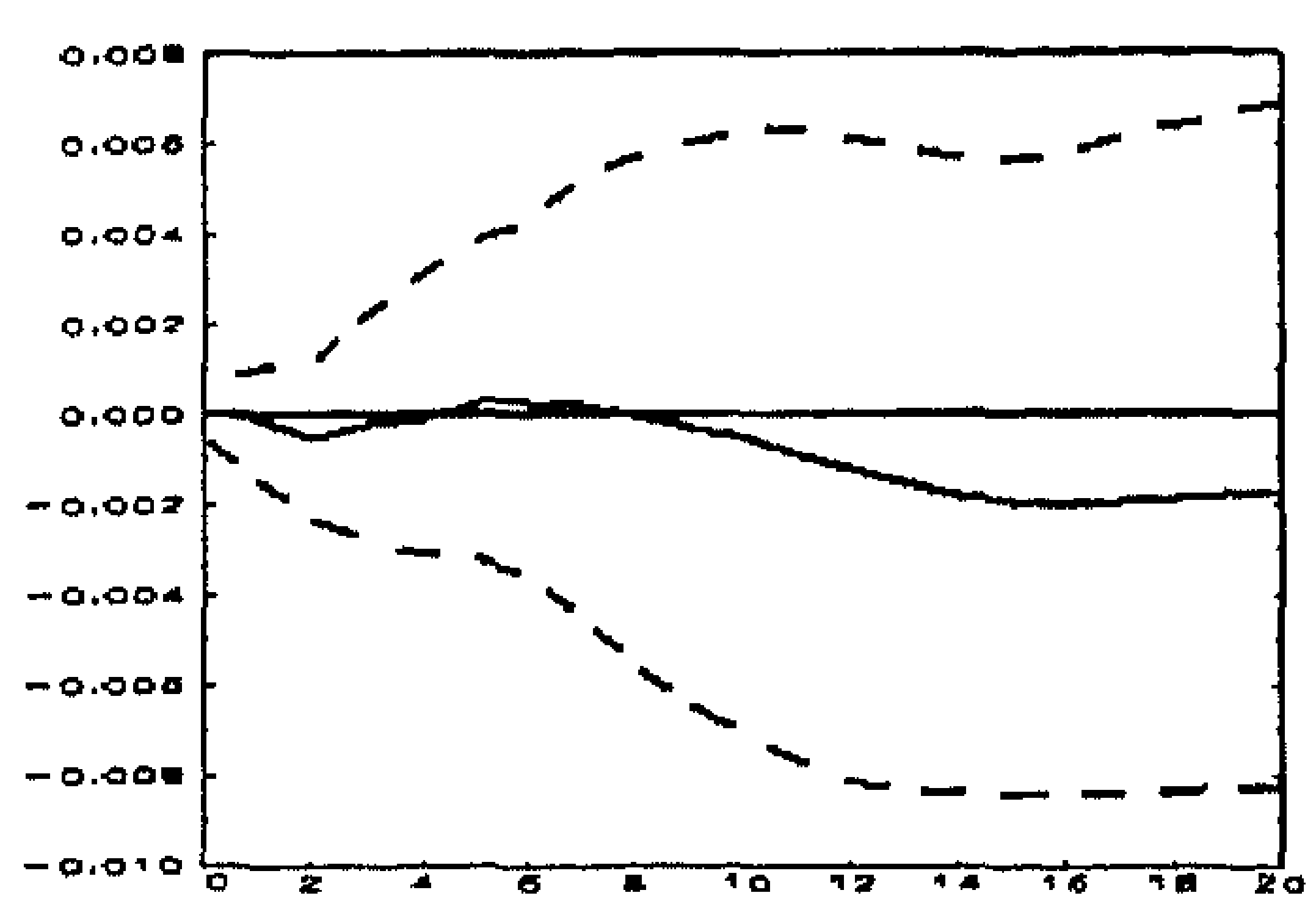

Monthly Hours Worked

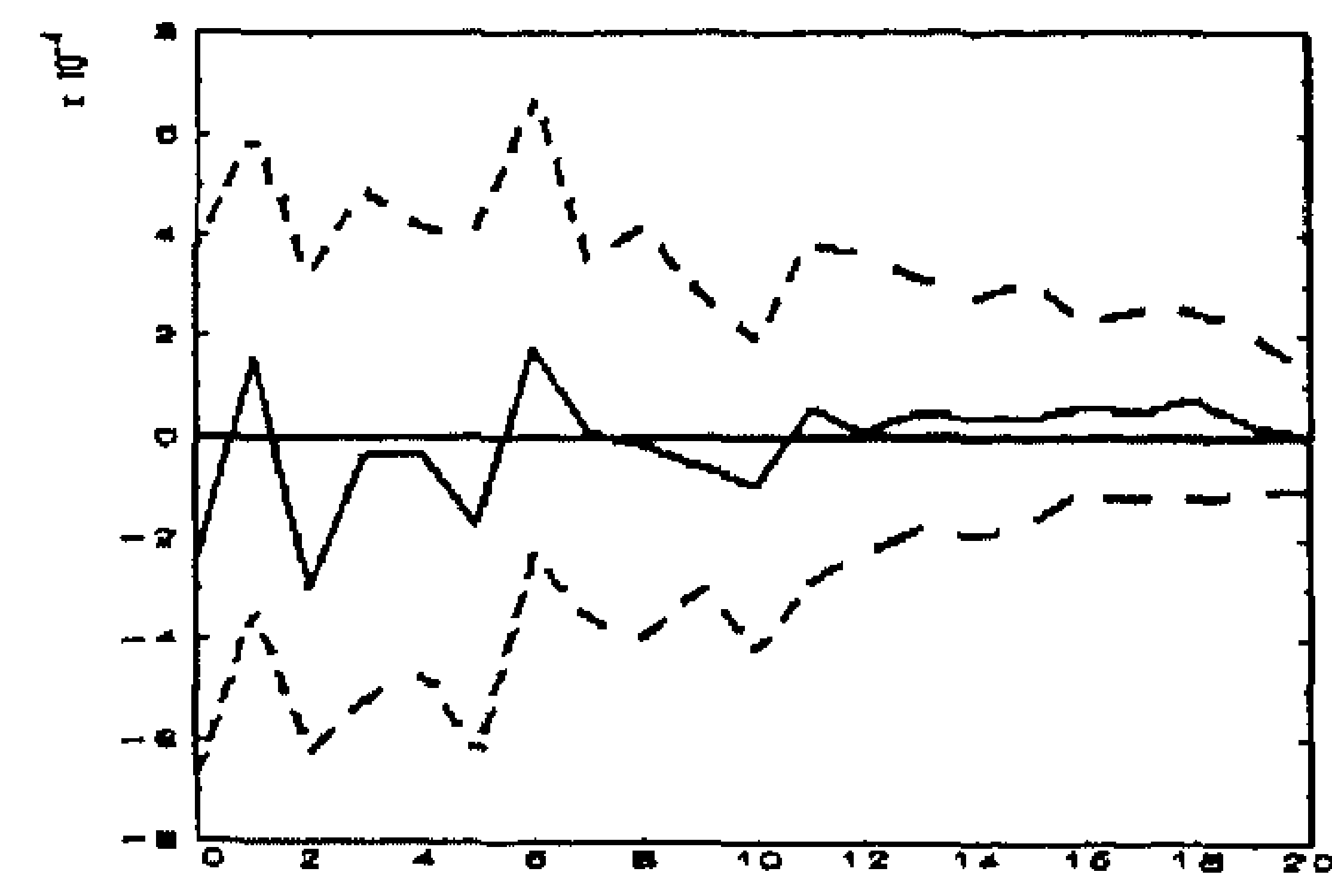

Neutral Technology Shocks Labor Productivity

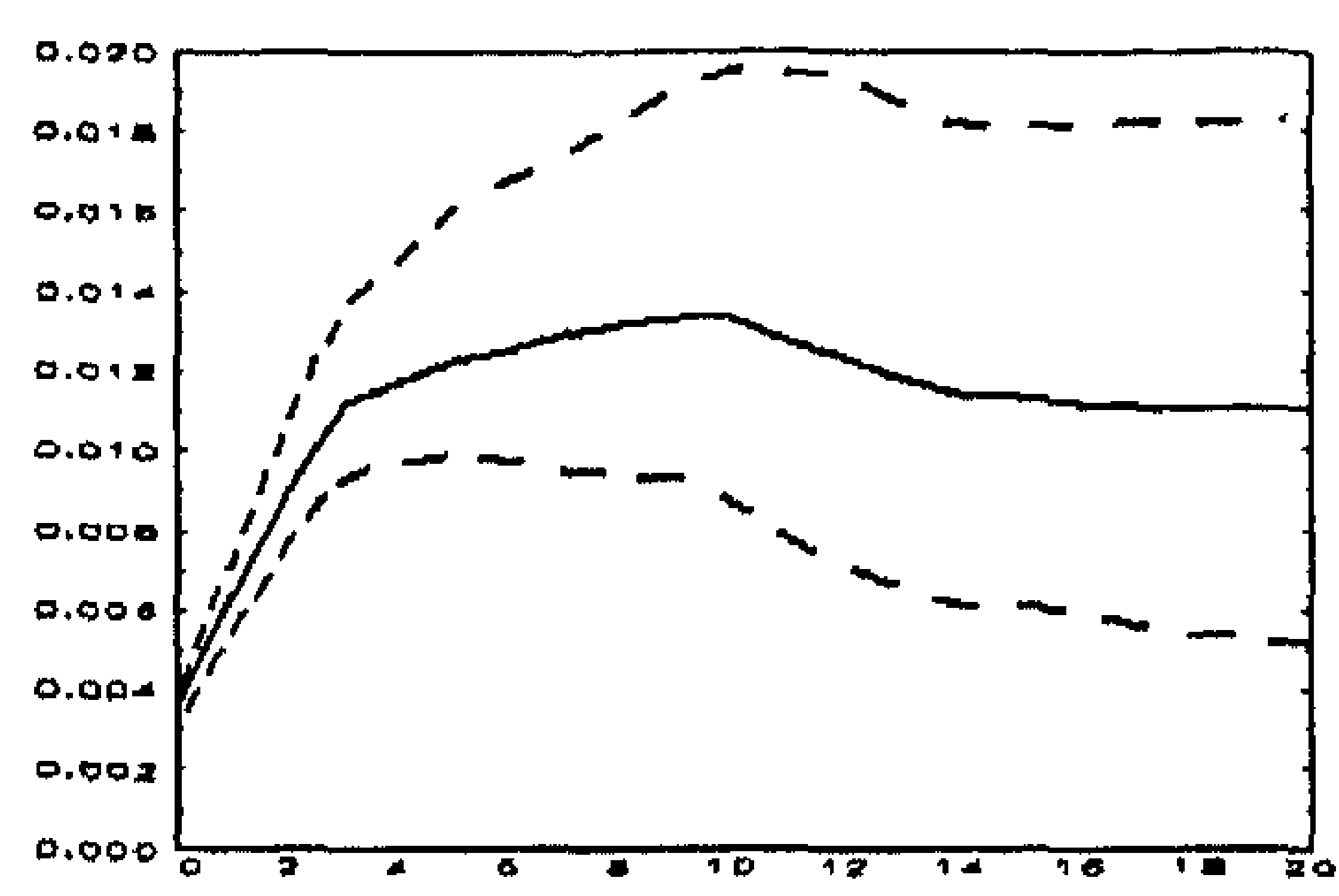

Monthly Hours Worked

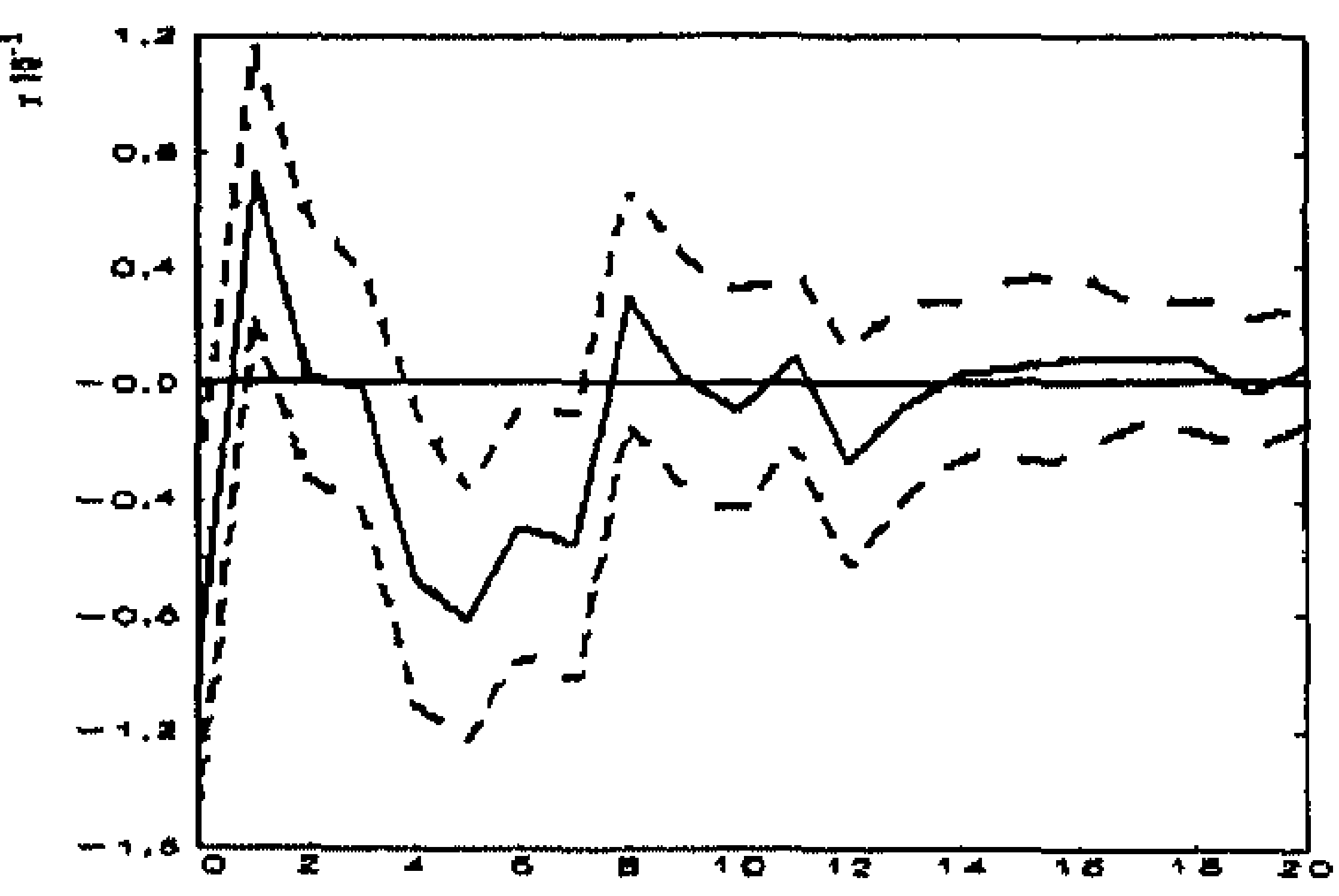

Source: Own calculations 
Figure 16: Cohesion of Technology Related Variations to Overall Variations in Monthly Hours Worked and Output with the Terms of Trade as Openness Indicator
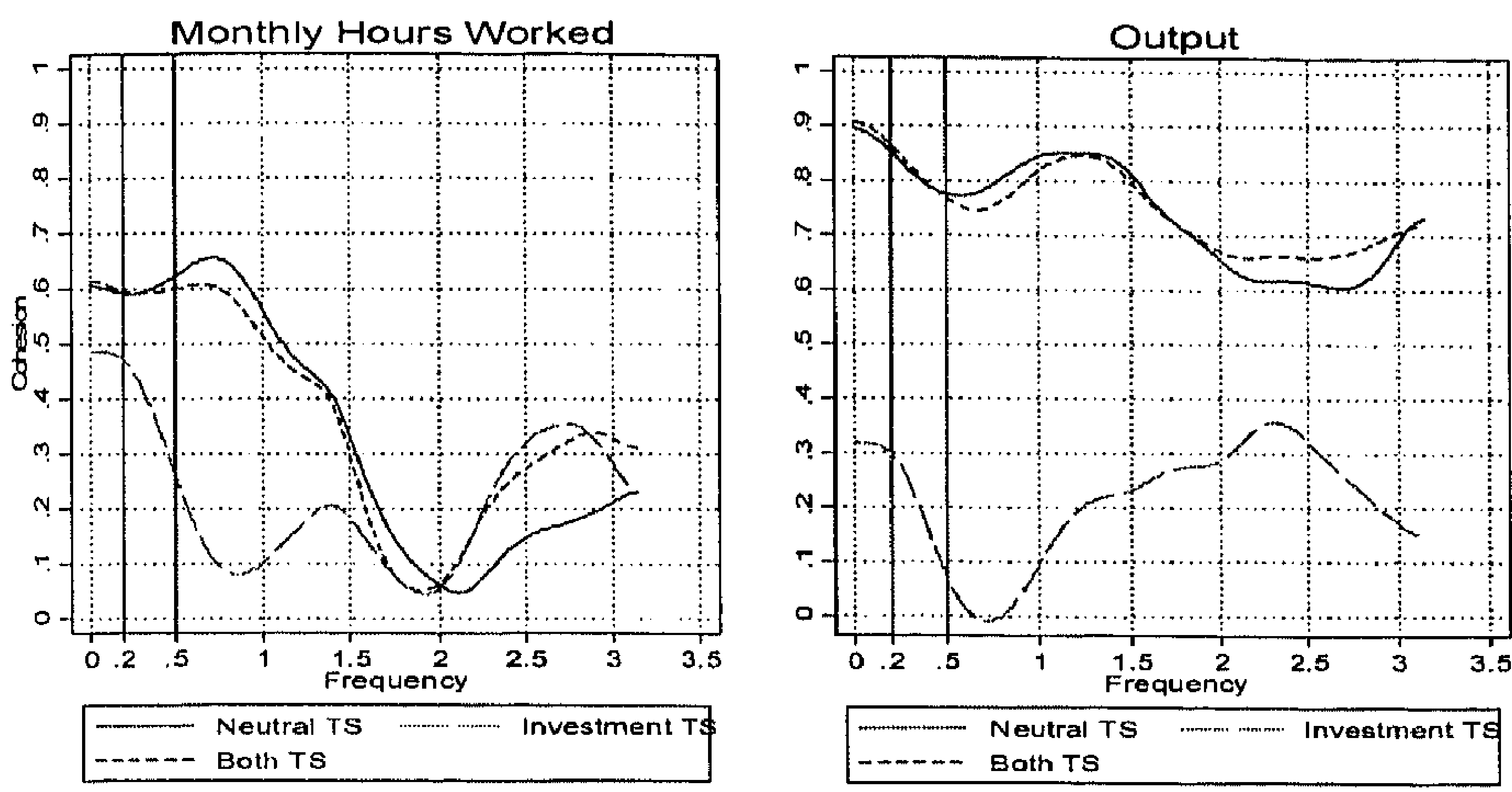

Source: On'n calculations

Figure 17: Cohesion of Technology Related Variations to Overall Variations in Monthly Hours Worked and Output with Real Openness as Openness Indicator
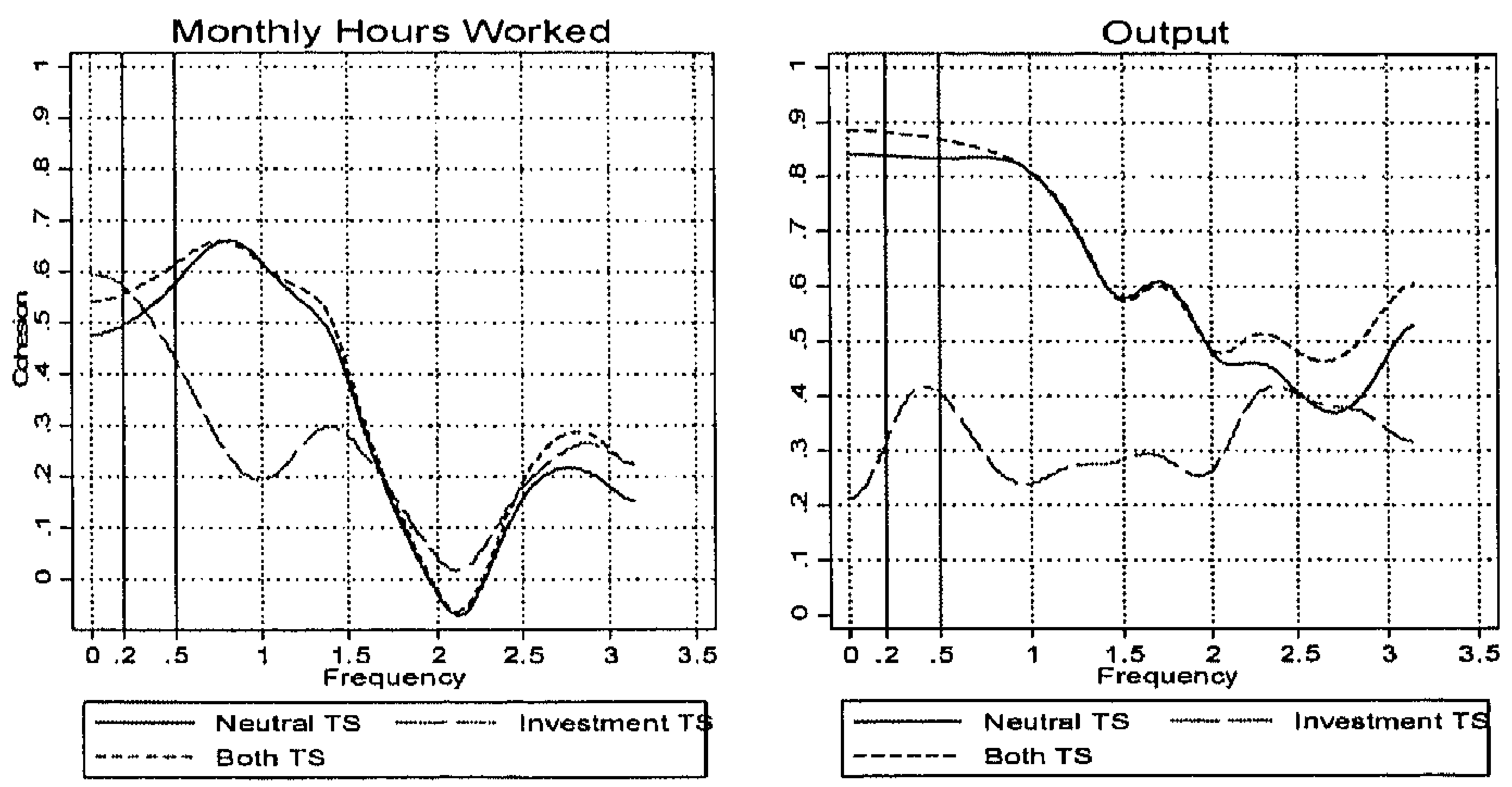

Source: Own calculations 


\section{Methodological Appendix}

To derive

$\Delta p_{t}=\sum_{j=1}^{m} \alpha_{p p, j} \Delta p_{t-j}+\sum_{j=0}^{m-1} \alpha_{p x, j} \Delta^{2} x_{t-j}+\sum_{j=0}^{m-1} \alpha_{m m, j} \Delta^{2} n_{t-j}+v_{t}$

from

$\Delta p_{l}=\sum_{j=1}^{m} \alpha_{p n_{, j}} \Delta p_{t-j}+\sum_{j=0}^{m} \alpha_{p x, j} \Delta x_{t-j}+\sum_{j=0}^{m} \alpha_{m m, j} \Delta n_{t-j}+v_{t}$

assume a lag-length of $m=3$ and rewrite (A2) as

$\Delta p_{l}=\alpha_{p p, t} \Delta p_{t-1}+\alpha_{p p, 2} \Delta p_{t-2}+\alpha_{p p, 3} \Delta p_{t-3}+\alpha_{p x, 0} \Delta x_{t}+\alpha_{p x, 1} \Delta x_{t-1}+\alpha_{p x, 2} \Delta x_{t-2}+\alpha_{p x, 3} \Delta x_{t-3}$

$+\alpha_{m n, 0} \Delta n_{t}+\alpha_{m n, 1} \Delta n_{t-1}+\alpha_{m n, 2} \Delta n_{t-2}+\alpha_{m m, 3} \Delta n_{t-3}+v_{t}$

Which is equivalent to

$$
\begin{aligned}
& \Delta p_{t}=\sum_{j=1}^{m} \alpha_{p p, j} \Delta p_{t-j}+\alpha_{p x, 0}\left(\Delta x_{t}-\Delta x_{t-1}\right)+\left[\alpha_{p x, 0}+\alpha_{p x, 1}\right]\left(\Delta x_{t-1}-\Delta x_{t-2}\right) \\
& +\left(\alpha_{p x, 0}+\alpha_{p x, 1}+\alpha_{p x, 2}\right)\left[\Delta x_{t-2}-\Delta x_{t-3}\right]+\left(\alpha_{p x, 0}+\alpha_{p x, 1}+\alpha_{p x, 2}+\alpha_{p x, 3}\right) \Delta x_{t-3} \\
& +\alpha_{m n, 0}\left(\Delta n_{t}-\Delta n_{t-1}\right)+\left[\alpha_{m n, 0}+\alpha_{p n, 1}\right]\left(\Delta n_{t-1}-\Delta n_{t-2}\right)+\left(\alpha_{p n, 0}+\alpha_{p m, 1}+\alpha_{m n, 2}\right)\left[\Delta n_{t-2}-\Delta n_{t-3}\right] \\
& +\left(\alpha_{m n, 0}+\alpha_{p n, 1}+\alpha_{p n, 2}+\alpha_{p n, 3}\right) \Delta n_{t-3}+v_{t}
\end{aligned}
$$

The long-run restrictions imply: $\quad \alpha_{p x, 0}+\alpha_{p x, 1}+\alpha_{p x, 2}+\alpha_{p x, 3}=0 \quad$ and $\alpha_{m n, 0}+\alpha_{p n, 1}+\alpha_{m n, 2}+\alpha_{m m, 3}=0$ so that the coefficients of $\Delta x_{t-3}$ and $\Delta n_{t-3}$ become zero. Thus, the above expression becomes

$$
\begin{aligned}
& \Delta p_{t}=\sum_{j=1}^{3} \alpha_{p p, j} \Delta p_{t-j}+\alpha_{p x, 0} \Delta^{2} x_{t}+\left[\alpha_{p x, 0}+\alpha_{p x, 1}\right] \Delta^{2} x_{t-1}+\left(\alpha_{p x, 0}+\alpha_{p x, 1}+\alpha_{p x, 2,2}\right) \Delta^{2} x_{t-2} \\
& +\alpha_{m n, 0} \Delta^{2} n_{t}+\left[\alpha_{m m, 0}+\alpha_{p n, 1}\right] \Delta^{2} n_{t-1}+\left(\alpha_{m m, 0}+\alpha_{m m, 1}+\alpha_{m n, 2}\right) \Delta^{2} n_{t-2}+v_{l}
\end{aligned}
$$

With the $\beta^{\prime} s$ as functions of the $\alpha^{\prime} s$, this expression can be rewritten as

$$
\Delta p_{t}=\sum_{j=1}^{3} \alpha_{p p, j} \Delta p_{t-j}+\sum_{j=0}^{2} \beta_{p x, j} \Delta^{2} x_{t-j}+\sum_{j=0}^{2} \beta_{p n, j} \Delta^{2} n_{t-j}+v_{t}
$$

which is equivalent to (A2). 


\section{Interrelatedness, Dynamic Factor Adjustment Patterns and Firm Heterogeneity in Austrian Manufacturing}

\section{Introduction}

Recent and extensive empirical evidence on micro-level data emphasizes the presence of non-negligible jumps in input adjustment patterns, irrespective of input or state of economic development considered or industry chosen. Such rapid input adjustments, however, do not occur in isolation but, by nature, necessitate additional adjustments in strategic complements or substitutes and bring about changes in economic performance.

To identify and describe interrelatedness and dynamic adjustment processes associated with observed input spikes, the analysis focuses on key inputs like employment and skill-related subcomponents like non-production and production labor as well as investments in equipment and machinery and on performance indicators like output, labor productivity or profits.

With respect to labor, Austria is of particular interest since its labor market is strongly regulated with institutions, rules and regulations aimed at helping achieve a higher level of employment under socially acceptable and fair conditions. Particularly, relatively restrictive firing rules regulating individual and collective dismissals encompassing long pre-notification periods, high financial compensations governed by the length of service and lengthy discussions with trade unions and approval of the works council prior to planned layoffs were enacted. In addition, shop stewards, handicapped and women on maternity leave represent specifically protected individuals. Given all said labor market regulations, downward adjustment of labor becomes more expensive and any planned reductions in employment levels are not immediately translated into actual changes. Hence, employment reductions are expected to show a relatively strong lumpy pattern.

Additionally, from a vintage-model point of view, investments in equipment and machinery are of interest. Accordingly, newly implemented machinery and equipment embodies recent and productivity enhancing technological developments and knowledge and acts as carrier of technology across industries and countries. The presence of technology-skill complementarities as documented by Bartel and Lichtenberg (1987) as well as the temporary loss of labor productivity during periods of retooling and reorganization that disrupt smooth production processes become interesting issues to analyze.

Furthermore, empirical micro-level evidence shows that only a relatively small fraction of employment restructuring and investment projects is realized in a spikelike manner, revealing non-negligible micro-heterogeneity in adjustment behavior. 
Identification of firm characteristics associated with observed adjustment spikes becomes a vital research thrust. And since the state of the economy is also expected to impact on rapid input adjustments, macroeconomic indicators are included in the analysis to tackle issues of cyclicality of input spikes or asymmetric hiring and firing activities.

Methodologically, an indicator approach is applied for the first research question that sheds light on factor interrelatedness, i.e. input factor adjustment dynamics in response to lumpy adjustment episodes. Specifically, the response of any particular input to any input spike in the year of, the year after or the year preceding said spike is identified, where dummy variables capture the prevalence of any spike in the current, previous or next period.

The second research question as to the role of firm-heterogeneity in determining the probability of any positive or negative input spike is tackled by using a binary response logit-model, where control variables' quartiles are included to capture dynamic effects. Quartile calculations were based on industry distributions of variables to account for industry effects and heterogeneity.

To account for a potential missing variables bias, both analyses include the same set of explanatory variables, controlling for macroeconomic and firm-level properties. A unique sample of Austrian Manufacturing firm-groups for the period 1982 to 1991 is subject to the analysis.

The results demonstrate that there is considerable interrelatedness observable, all pointing towards strong complementarities between equipment investments, employment, production and non-production labor, supporting the hypothesis of technology-skill complementarities as advocated by Bartel and Lichtenberg (1987). Hence, no evidence of any skill bias in the implementation of leading-edge technologies was detected.

Additionally, results for performance indicators like output, labor productivity or profitability point towards asymmetric adjustment processes in response to either investment or labor-related spikes. In particular, the hypothesis of a temporary disruptive effect of newly implemented machinery and equipment on smooth and routinized production processes is consistently invalidated for all investment spike definitions. However, proof of learning-by-doing effects is found. Furthermore, while major reductions in non-production labor significantly and more permanently reduce profitability, drastic personnel cuts of production labor, however, exhibit no significant long-term effect on firm-group profitability.

The spike-occurrence probability analysis reveals strong firm heterogeneity and identifies production labor as the more flexible and consequently less expensive factor to adjust. Firm-group size also matters for spike occurrence with small firms being relatively less likely to experience any positive spike. The results also highlight the absence of any significant cost-related effects in the course of drastic reductions of non-production labor which points at the importance of asymmetric fixed labor adjustment costs associated with the reduction of non-production labor. Both, relatively restrictive firing rules characteristic of the Austrian labor market and identified significant profitability losses after drastic non-production labor cuts are compatible 
with this pattern. Furthermore, labor cost considerations appear irrelevant and large investment projects are carried out irrespective of adverse labor cost developments. Finally, neither the gender composition of the workforce nor labor productivity exerts much effect on any spike occurring.

The paper is organized as follows: while section II reviews related empirical evidence, section III describes the data and provides results for the degree of interrelatedness prevailing between different input factors. Section IV emphasizes the role of firm heterogeneity for lumpy input adjustment dynamics and discusses firm-group characteristics that are associated with any drastic input modifications. Finally, section $\mathrm{V}$ concludes.

\section{II. $\quad$ Related Recent Literature}

Numerous studies have emphasized the lumpy nature of firms' input adjustment behavior with periods of more or less zero changes being superseded by periods of feverish non-negligible changes ${ }^{5}$. Irrespective of country, industry or capital good considered, a series of "stylized facts" emerges from this literature for investment as well as employment adjustment patterns:

One, as suggested by Gelos and lsgut (2001) and Fuentes et al. (2005) in their studies on Columbia and Mexico on the one hand and Chile on the other, investment activities appear lumpier in developing countries as compared to developed countries which is predominantly attributed to shallow capital goods markets or underdeveloped capital markets for external funding ; two, in their analyses on capital good specific investment dynamics, Nilsen and Schiantarelli (2003), Attenasio et al. (2003) and Fuentes et al. (2005) stress that investment adjustments are more sporadic for buildings and vehicles as compared to machinery; three, the majority of investment activities occurs in just three years; four, aggregation appears to cushion prevailing lumpiness so that input adjustment patterns are found to be jumpier for plants compared to firms and are smoothed away at the macro-level, and five, Doms and Dunne (1998), Nilsen et al. (2007), Attenasio et al. (2003) as well as Fuentes et al. (2005) emphasize that smaller or younger plants and plants that undergo changes in organizational structure as well as plants that switch industries show lumpier investment patterns.

\footnotetext{
5 For capital adjustments see: Doms and Dumne (1998), Caballero, Engcl and Haltiwanger (1995a), Cooper, Haltiwanger and Power (1999), Barnett and Sakellaris (1998) for the US, Carlsson and Laséen (2005) for Sweden, Nilsen and Schiantarelli (2003) for Norway, Attenasio, Pacelli and do Reis (2003) for the UK, Verick, Letterie and Pfann (2004) for West-Germany, Letterie and Pfann (2007) for the Netherlands, Licandro, Maroto and Puch (2005) for Spain, Gelos and Isgut (2001) for Columbia and Mexico and Fuentes, Gilchrist and Rysman (2005) for Clile.

For labor adjustments see: Hamermesh (1989), Caballero, Engel and Haltiwanger (1995b) for the US, Rota (2001) for Italy, Varejão and Portugal (2007) for Portugal and Nilsen, Salvanes and Schiantarelli (2003) for Norway.
} 
Additionally, in line with results found by Nielsen et al. (2007) on Norway, in their study on Portuguese establishment data Varejão and Portugal (2007) show that the probability of employment changes is lower for smaller plants which is suggestive of more intermittent employment adjustment patterns in smaller firms. And Nilsen et al. (2007) and Varejão and Portugal (2007) found that employment adjustment patterns are lumpier for separations than for hirings.

However, all above-mentioned studies examine the adjustment of only one input factor of production in isolation and ignore any potential interrelatedness between labor and capital, particularly during periods of rapid input changes. In that respect, Letterie et al. (2004), Sakellaris (2004) and Nilsen et al. (2006) highlight that capital and labor are strategic complements. More specifically, in their study on plants in the Dutch manufacturing sector for 1978 to 1992 Letterie et al. (2004) find that employment and investment decisions are considerably interrelated in that employment changes are significantly higher in the year of as well as in the years preceding and succeeding any investment spike and investment rates are significantly higher (lower) in the year of a positive (negative) employment spike. The early employment adjustments ahead of any investment spikes are suggestive of preparatory training activities to better absorb major changes in capital stocks and production processes.

Furthermore, Sakellaris (2004) looks at a set of plants operating in the U.S. manufacturing sector between 1972 and 1993, and highlights that capital and labor, in terms of production and non-production labor, represent strategic complements. Moreover, he shows that production labor is the more flexible labor input factor and experiences more rapid adjustments accomplished in a year only while nonproduction labor adjustments are smoothed out over a couple of years.

And Nilsen et al. (2006), for a set of Norwegian firms in two Manufacturing industries and one Service industry for 1995 to 2003 find that man hours, as the labor input factor, and capital are strongly contemporaneously interrelated.

Nilsen et al. (2006) and Sakellaris (2004) also study the effect of investment or employment spikes on firm performance indicators like output or sales, labor productivity or total factor productivity. They stress that any positive or negative input spikes are accompanied by almost proportional changes in sales or output. In line with results found by Huggett and Ospina (2001), Sakellaris (2004) emphasizes that labor productivity temporarily falls in response to positive investment spikes while only minor and insignificant changes emerge in Nilsen et al. (2006). These results are indicative of temporary disruption costs associated with major technology upgrading. In terms of total factor productivity, results again point towards prevailing temporary disruption costs associated with major positive or negative employment or capital adjustments and highlight the importance of learning-by-doing dynamics associated with improvements in productivity preceding any drastic input adjustments. 


\section{III.1. Data and Descriptive Statistics}

Data on firm characteristics and behavior are taken from the Austrian Industry Statistics Survey (Industriestatistik), conducted by Statistics Austria for 37 industries in Industry covering the period 1982-91. The Industry Statistics survey is an annual survey collecting data on individual firm's economic structure and success and has been carried out since 1969. By EU-decree, the Business and Consumer Survey replaced the Industry Statistics Survey in 1996 and was first conducted in 1997. Given binding legal restrictions on data confidentiality, individual firm observations are unavailable, however. Instead, firm-groups were generated based on similar sizecharacteristics approximated by total employment. Specifically, all firms within each industry were ranked according to size in 1982 and grouped together to form firmgroups comprising at least 4 firms. A unique identification number was assigned to each firm-group in the database to facilitate tracing its evolution. A balanced set of 839 firm-groups is available.

The initial gross capital stock of equipment and investment was derived applying the Booked Depreciation Method (BDM) suggested by Broersma et al. (2003) instead of the conventional Perpetual Inventory Method (PIM). While PIM derives productive capital by summing past investment flows and correcting for loss of productive capacity due to aging, its major drawback rests in the need for long time series of investments that cover the entire period of the underlying service life. This is particularly problematic in studies on micro-level phenomena where investment series are normally available for a short period only, not fully covering service lives of individual capital assets ${ }^{6}$.

The BDM methodology results in zero or negative initial equipment capital stocks for 6 firm-groups. Said observations were eliminated from the analysis.

As a proxy for productivity enhancing investments in new and technologically sophisticated machinery and equipment, the investment rate is defined as the ratio of new investments in machinery and equipment over the total machinery and equipment capital stock $(I / K)_{i l}$. The labor related input variables - as potential strategic complements/substitutes for new equipment investments - are measured in terms of growth rates as $(\triangle L / L)_{i r},(\triangle N P L / N P L)_{i l}$ and $(\triangle P L / P L)_{i r}$ for employment, nonproduction and production labor, respectively. Table 18 in the appendix demonstrates that all factor inputs considered are contemporaneously correlated. Frequency distributions of the variables are depicted in Figure 18 in the appendix.

\footnotetext{
${ }^{6}$ For a detailed discussion refer to appendix $\mathrm{A}$.
} 


\section{III.2. Methodology}

This section aims to analyze the interrelatedness of large technology-related production input adjustments as well as associated dynamic adjustment patterns of different variables in response to such large adjustment episodes.

Specifically, light is shed on how firm-groups modify overall employment (L), non-production labor (NPL) and production labor (PL) in periods of investment spikes (I) in addition to non-production labor (respectively, production labor) in periods of production labor (respectively, non-production labor) spikes as well as in the preceding and subsequent periods. Furthermore, adjustment dynamics of overall output, labor productivity and total capital stock around and during episodes of large equipment investment, employment, production and non-production labor spikes are analyzed.

Depending on the factor analyzed, different definitions of spikes are considered and specified:

- In accordance with the definition suggested by Power (1998), relative investment spikes (REL) are observed if the firm-group investment rate exceeds its median investment rate over the entire time span by $75 \%$.

- A firm-group undergoes an absolute investment spike (ABSOL) if its investment rate exceeds $20 \%$ for a given year.

- Motivated by Sakellaris (2000), a positive employment spike (POS) is observed if the firm-group growth rate of overall employment is greater than $10 \%$ for a year in absolute terms. A negative employment spike (NEG) is identified if the growth rate of overall employment is lower than $10 \%$ for a given year in absolute terms.

- Likewise, positive and negative production and non-production labor spikes (POS and NEG, respectively) are defined accordingly with an annual growth rate of more than $10 \%$ indicating a positive spike and an annual growth rate of less than $10 \%$ specifying a negative spike, all in absolute terms.

Additionally, in order for an observation to qualify as a spike-event the firm-group has to have all relevant data for the time window around the event. Given the short time horizon available, only the year preceding and succeeding such an event as well as the year of the event are subject to the analysis that follows.

Exceptional outliers with investment ratios exceeding one for one or more periods were excluded from the analysis to avoid contamination of the results. Only 5 observations were subject to this cleansing strategy. 
Analogous to Sakellaris (2000) and Letterie et al. (2004), indicator variables are used to pin down the timing of lumpy adjustment periods. Per spike variable $V$ considered, three time-dependent indicator variables are specified as $V_{k}$ with $V=\{I, L, P L, N P L\}$ and $k=\{$ previous, current, next $\}$.

To identify the relationship between the timing of a spike event $V$ and the variable of interest $X_{11}$ for firm-group $i$ in year $t$, the following equation is estimated:

$X_{i l}=\mu_{i}+\sum_{k=-1}^{+1} \theta_{k} V_{1}^{\prime+k}+\alpha_{1} Y_{t}+\beta_{u} Z_{i l}+\varepsilon_{i l}$

where $\mu_{1}$ are firm-group fixed effects to account for unobserved firm-group heterogeneity, the vector $Y$, contains macroeconomic controls like real GDP growth and the growth rate of equipment investments, while the vector $Z_{\text {it }}$ includes firm-group specific characteristics like size, average personnel costs, the non-production labor share, the gender ratio as well as labor productivity, broken down into respective quartiles to also capture dynamic size-related effects ${ }^{7} . X_{\| \prime}$ specifies either the investment rate $(I / K)_{11}$, the employment growth rate $(\Delta L / L)_{11}$, the non-production $(\triangle N P L / N P L)_{i t}$ or the production labor growth rate $(\triangle P L / P L)_{i f}$. The indicator variable $V_{k}$ is equal to $I$ if the firm-group experienced a spike event in either the previous, current or next period. To control for unobserved (time invariant) firm heterogeneity, above equation is estimated using two standard panel data models, fixed effects and random effects models. As the Hausman test rejects the null hypothesis of no correlation between the right hand side variables and the random effects in the model, results for fixed effects estimations will be reported only. The sample summary statistics are reported in Table 19 in appendix C.

Table 8: Absolute Frequency of Spiky Input Adjustments

\begin{tabular}{|l|cccc|}
\hline & POS & NEG & ABSOL & REL \\
\hline Investment & - & - & $437(239)$ & $1378(628)$ \\
Employment & $896(727)$ & $872(553)$ & - & - \\
Non-Production Labor & $1175(813)$ & $1021(693)$ & - & - \\
Production Labor & $1069(834)$ & $1018(605)$ & - & - \\
\hline
\end{tabular}

Total mumber of year-group observations: 8260

POS and NEG refer to positive or negative employment, non-production or production labor spikes (as defined above), while ABSOL and REL denote absolute or relative equipment investment spikes (as defined above). The absolute number of spikes in the sample is reported first while the mumber of spikes of firm-groulps that have all relevant data in the three-year window around the spike event is given in parentheses.

\footnotetext{
${ }^{7}$ For more detailed information on the control variables refer to section IV.
} 
Table 8 reports the frequency of lumpy input adjustments for the 10-year sample according to above outlined definitions where the first number refers to the absolute number of spikes observable in the panel, while the number in parentheses refers to the number of firm-groups that have all relevant data in the three-year time window around the spike event.

Relative equipment investment spikes are three times as frequent as absolute equipment investments spikes. Generally, negative labor-related spikes are less frequent than positive ones. Compared to non-production or production labor, employment shows significantly less frequent positive as well as negative spikes which stress the importance of rich and dynamic adjustment processes at work in skillrelated subcategories. Additionally, non-production labor underwent significantly more expansionary adjustment episodes.

Table 9: Summary Statistics of Analyzed Input Spikes

\begin{tabular}{|l|cc|cc|cc|cc|}
\hline & \multicolumn{3}{|c|}{ POS } & \multicolumn{2}{c|}{ NEG } & \multicolumn{2}{c|}{ ABSOL } & \multicolumn{2}{c|}{ REL } \\
& Mean & Std. & Mean & Std. & Mean & Std. & Mean & Std. \\
\hline I & - & - & - & - & 0.307 & 0.121 & 0.179 & 0.115 \\
L & 0.239 & 0.269 & -0.195 & 0.124 & - & - & - & - \\
NPL & 0.268 & 0.308 & -0.215 & 0.136 & - & - & - & - \\
PL & 0.249 & 0.312 & -0.203 & 0.135 & - & - & - & - \\
\hline
\end{tabular}

Mean and standard deviation of all positive, negative, absolute or relative input spikes analyzed. I refers to investments, $L$ to employment, NPL to non-production labor and PL to production labor. POS and NEG refer to positive or negative employment, non-production or production labor spikes (as defined above), while ABSOL and REL denote absolute or relative equipment investment spikes (as defined above).

Table 9 shows summary statistics of all input spikes observed in the 10-year panel and highlights prevailing spike-asymmetries. Specifically, on average, positive laborrelated spikes are significantly higher and more dispersed compared to negative ones. Both, in terms of positive as well as negative spikes, non-production labor exhibits higher average adjustment rates than production labor. This observation points at a potential stronger role of labor market regulations in impeding major personnel cuts of non-production labor relative to production labor.

\section{III.3. Results}

Results for any effects of absolute or relative equipment investment spikes in previous, current or next periods on changes in employment growth and changes in nonproduction and production labor growth rates are presented in Panels A, B and C in Table 10 below.

All in all, the results point at a positive relationship between absolute investment spikes and the three employment variables considered. This supports the widely held view of capital-labor and equipment-skill complementarities with new technology embodied in new machinery and equipment as suggested by Bartel and Lichtenberg 
(1987) and Flug and Hercowitz (2000). Contrary to above analyses of aggregated data, firm-level dynamics points at equipment to strategically complement production and non-production labor - as proxies for unskilled and skilled labor, respectively. In line with Letterie et al. (2005), relative investments spikes are found to generate responses in close resemblance to those of absolute investment spikes.

\section{III.3.1. Effects of Investment Spikes}

The results in Panel A suggest that employment growth rates are significant and high during episodes of absolute investment spikes but only insignificantly related to spikes occurring in preceding or succeeding periods. This highlights that equipment investments and employment are contemporaneous strategic complements and strongly interrelated.

Panels B and C present results for different skill related types of labor.

Table 10: Effects of Previous, Current or Future Absolute or Relative Investment Spikes

\begin{tabular}{|c|c|c|}
\hline \multicolumn{3}{|c|}{ A. Effects on Employment } \\
\hline & Absolute & Relative \\
\hline Previous & $0.0072(0.57)$ & $0.0194(2.87)^{* * *}$ \\
\hline Current & $0.0312(2.81)^{* * *}$ & $0.0223(3.61)^{* * *}$ \\
\hline Next & $0.0086(0.75)$ & $0.0107(1.68)^{*}$ \\
\hline \multicolumn{3}{|c|}{ B. Effects on Non-production Labor } \\
\hline & Absolute & Relative \\
\hline Previous & $0.0235(1.46)$ & $0.0310(3.36)^{* * *}$ \\
\hline Current & $0.0341(2.39)^{* *}$ & $0.0202(2.42)^{* *}$ \\
\hline Next & $0.0248(1.69)^{*}$ & $0.0121(1.38)$ \\
\hline \multicolumn{3}{|c|}{ C. Effects on Production Labor } \\
\hline & Absolute & Relative \\
\hline Previous & $0.0297(2.07)^{* *}$ & $0.0215(2.81)^{* * *}$ \\
\hline Current & $0.0398(3.13)^{* * *}$ & $0.0170(2.44)^{* *}$ \\
\hline Next & $0.0309(2.36)^{* *}$ & $0.0184(2.55)^{* *}$ \\
\hline
\end{tabular}

The dependent variable is the grow'th rate of employment (Panel $A$ ), non-production labor (Panel $B$ ) or production labor (Panel C) while the independent variables are dummy variables to indicate whether an absolute or relative investment spike (as defined above) has occurred in the previous, current or next period as well as quartiles of size, personnel costs, non-production labor shares, gender-ratios and labor productivity and the growth rate of Alustrian real GDP and the equipment investment deflator to capture macroeconomic dynamics. To account for firm heterogeneity, i.e. unobservable and time-invariant firm characteristics, fixed as w'ell as random effects models w'ere calculated. The Hausman tests clearly reject suitability of the random effects specification so results are presented for the fixed effects specification only. Absolute values of t-statistics are in parentheses.

*Significant at $10 \%$ level.

** Significant at $5 \%$ level.

*** Significant at $1 \%$ level.

Panel B indicates that absolute investment spikes are associated with increases in non-production labor growth rates. More specifically, non-production labor growth 
significantly increases prior to but also in the period of an absolute investment spike, possibly for reasons of increased organizational and administrative complexity associated with firm expansion in terms of the capital stock and the production apparatus.

In contrast to effects on non-production labor growth rates, however, Panel C emphasizes that production labor growth rates experience increases prior to, after as well as in the year of investment spikes with stronger contemporaneous effects. Preparatory training activities ahead of investments as well as the realization of insufficient labor operating new machineries and equipment help explain the identified patterns.

Similar to inferences drawn by Letterie et al. (2004) for the Dutch manufacturing sector, the definition of investment spikes also hardly matters for adjustment patterns in Austrian manufacturing with comparable responses of employment, nonproduction and production labor growth rates to either absolute or relative investment spikes.

\section{III.3.2. Effects of Employment Spikes}

The relationship between previous, current and future positive or negative employment spikes and equipment investment rates is reported in Table 11 below.

Table 11: Effects of Previous, Current or Future Positive or Negative Employment Spikes

\begin{tabular}{|l|l|l|}
\hline \multicolumn{3}{|c|}{ A. Effects on Equipment Investments } \\
\hline & Positive & Negative \\
\hline Previous & $0.0105(3.39)^{* * *}$ & $-0.0057(1.57)$ \\
Current & $0.0175(5.57)^{* * *}$ & $-0.0032(0.85)$ \\
Next & $0.0051(1.55)$ & $0.0037(0.92)$ \\
\hline
\end{tabular}

The dependent variable is the equipment investment rate while the independent variables are dummy variables to indicate whether a positive or negative investment spike (as defined above) has occtirred in the previous, current or next period as well as quartiles of size, personnel costs, non-production labor shares, gender-ratios and labor productivity and the growth rate of Austrian real GDP and the equipment investment deflator to capture macroeconomic dynamics. To accoumt for firm heterogeneity, i.c. unobservable and time-invariant firm characteristics, fixed as well as random effects models were calculated. The Hausman tests clearly reject suitability of the random effects specification so results are presented for the fixed effects specification only.

Absolute values of 1 -statistics are in parentheses.

* Significant at $10 \%$ level.

* Significant at $5 \%$ level.

*** Significant at $1 \%$ level.

Equipment investment rates are significantly associated with positive employment spikes and turn out to be higher during as well as after episodes of rapid positive employment adjustments with stronger contemporaneous effects. Preparatory training measures help to explain the emerging picture where considerable employment 
growth precedes expansions of the stock of machinery and equipment. Additionally, the results indicate that equipment investment rates are insignificantly related to the occurrence of negative employment spikes. Overall, there is ample evidence that employment and equipment investments are considerably but asymmetrically interrelated.

\section{III.3.3. Effects of Non-Production Labor Spikes}

Panels A and B of Table 12 help shed light on the relationship between previous, current or future non-production labor spikes and equipment investment rates or production labor growth rates. Both, equipment investments and production labor are contemporaneous complements to positive non-production labor spikes. Moreover, production labor growth rates are also significantly higher in periods following a positive non-production labor spike.

Table 12: Effects of Previous, Current or Future Positive or Negative Non-production Labor Spikes

\begin{tabular}{|l|l|l|}
\hline \multicolumn{3}{|c|}{ A. Effects on Equipment Investments } \\
\hline & Positive & Negative \\
\hline Previous & $0.0047(1.57)$ & $-0.0002(0.05)$ \\
Current & $0.0087(2.90)^{* * *}$ & $-0.0025(0.72)$ \\
Next & $0.0034(1.09)$ & $0.0015(0.41)$ \\
\hline \multicolumn{3}{|c|}{ B. Effects on Production Labor } \\
\hline & Positive & Negative \\
\hline Previous & $0.0129(1.78)^{*}$ & $-0.0026(0.30)$ \\
Current & $0.0530(7.29)^{* * *}$ & $-0.0571(6.29)^{* * *}$ \\
Next & $0.0001(0.11)$ & $0.0090(0.94)$ \\
\hline
\end{tabular}

The dependent variable is the equipment investment rate (Panel $A$ ) or the production labor growth rate (Panel B) while the independent variables are dummy variables to indicate whether a positive or negative non-production labor spike (as defined above) has occurred in the previous, current or next period as well as quartiles of size, personnel costs, non-production labor shares, gender-ratios and labor productivity and the grouth rate of Austrian real GDP and the equipment investment deflator to capture macroeconomic dynamics. To account for firm heterogeneity, i.e. unobservable and time-invariant firm characteristics, fixed as well as random effects models were calculated. The Hansman tests clearly reject stitability of the random effects specification so resulls are presented for the fixed effects specification only.

Absolute values of t-statistics are in parentheses.

* Significant at $10 \%$ level.

** Significant at $5 \%$ level.

*** Significant at $1 \%$ level.

The results also suggest that only production labor exhibits significant adjustment dynamics associated with negative non-production labor spikes. Specifically, there are significantly lower production labor growth rates in periods of drastic reductions in non-production labor. The analysis further reveals that while production labor is significantly related to both types of non-production labor spikes, equipment invest- 
ment is only asymmetrically associated with non-production labor spikes and shows no significant relationship with negative spikes.

\section{III.3.4. Effects of Production Labor Spikes}

The relationship between previous, current and next period's positive or negative production labor spikes and equipment investment as well as non-production labor growth is presented in Panels A and B of Table 13. The results in Panel A indicate that equipment investment rates are significantly higher in the year of as well as in the year following a positive production labor spike but are unrelated to negative production labor spikes. Training activities in preparation for the efficient operation of new and more sophisticated machinery and equipment help to explain the lagged response of equipment investment rates to spikes in production labor.

Table 13: Effects of Previous, Current or Future Positive or Negative Production Labor Spikes

\begin{tabular}{|l|l|l|}
\hline \multicolumn{3}{|c|}{ A. Effects on Equipment Investments } \\
\hline & Positive & Negative \\
\hline Previous & $0.0101(3.44)^{* * *}$ & $-0.0033(0.93)$ \\
Current & $0.0178(6.01)^{* * *}$ & $-0.0050(1.38)$ \\
Next & $0.0046(1.49)$ & $0.0029(0.74)$ \\
\hline \multicolumn{3}{|c|}{ B. Effects on Non-production Labor } \\
\hline & Positive & Negative \\
\hline Previous & $0.0066(0.84)$ & $0.0022(0.24)$ \\
Current & $0.0789(9.93)^{* * *}$ & $-0.0578(5.92)^{* * *}$ \\
Next & $0.0067(0.81)$ & $0.0016(0.16)$ \\
\hline
\end{tabular}

The dependent variable is the equipment investment rate (Panel A) or the non-production labor grouth rate (Panel B) while the independent variables are dimmy variables to indicate whether a positive or negative production labor spike (as defined above) has occurred in the previous, current or next period as well as quartiles of size, personnel costs, non-prodiction labor shares, gender-ratios and labor prodictivity and the grow'th rate of Austrian real GDP and the equipment investment deflator to capture macroeconomic dynamics. To account for firm heterogeneity, i.e. unobservable and time-invariant firm characteristics. fixed as well as random effects models were calculated. The Hausman tests clearly reject suitability of the random effects specification so results are presented for the fixed effects specification only.

Absolute values of $t$-statistics are in parentheses.

*Significant at $10 \%$ level.

** Significant at $5 \%$ level.

*** Significant at $1 \%$ level.

As pointed out above, Panel B confirms that production and non-production labor are contemporaneous complements with significantly higher (lower) non-production labor growth rates in the year of a positive (negative) production labor spike. 


\section{III.4. Performance Spike Effects}

Light is also shed on the dynamic adjustment pattern of levels of output, labor productivity and profits in response to abrupt input adjustments. Output is defined as the value of production, labor productivity refers to the value of production per employee while profits are specified as value added minus taxes, interest payments on debt capital and overall wage costs.

As shown in Panel A of Table 14, the hypothesis of a temporary disruptive effect of newly implemented machinery and equipment on smooth and routinized production processes is consistently invalidated for both investment spike definitions. However, with consistently stronger effects on labor productivity in the period following an equipment investment spike, the importance of learning-by-doing becomes apparent. Additionally, profits appear to respond to absolute investment spikes only and are significantly higher in the year of the investment spike only.

Panels B to D in Table 14 also confirm that irrespective of the labor-related spike indicator considered, output is significantly higher (lower) in the period of and the period following a positive (negative) spike. Contemporaneous effects tend to be stronger in that respect. Furthermore, when comparing the two skill-related labor spikes asymmetric responses of output become apparent: increases in output are stronger in response to positive production labor spikes while declines in output are more significant in response to negative non-production labor.

More complex dynamics are apparent for labor productivity responses: once contrasted with the effects for output, any significant changes in labor productivity turn out to be driven by (either positive or negative) labor-related spikes. Furthermore, falling or rising labor productivities in response to positive or negative laborrelated spikes, respectively, are relatively temporary phenomena and are confined to the period of the spike only. Moreover, with respect to production labor, interesting asymmetries emerge. While positive non-production labor spikes result in an immediate and significant loss of labor productivity, positive production labor spikes on the other hand are devoid of any significant adverse labor productivity responses.

Finally, profit dynamics of labor-related input adjustments are considered in Panels B to D in Table 14 which confirms that, except for drastic reductions of production labor, profits are significantly higher (lower) in the year of and following any labor-related positive (negative) spikes. The results therefore suggest that major personnel cuts of production labor are not associated with any significant profit losses. 
Table 14: Results for Output, Labor Productivity and Profits

\begin{tabular}{|c|c|c|c|c|c|c|}
\hline \multicolumn{7}{|c|}{ A. Effects of Absolute or Relative Equipment Investment Spikes on } \\
\hline & \multicolumn{2}{|c|}{ Output } & \multicolumn{2}{|c|}{ Labor Productivity } & \multicolumn{2}{|c|}{ Profits } \\
\hline & Absolute & Relative & Absolute & Relative & Absolute & Relative \\
\hline $\begin{array}{l}\text { Previous } \\
\text { Current } \\
\text { Next }\end{array}$ & $\begin{array}{l}0.054 \\
(3.85)^{* * *} \\
0.072 \\
(5.79)^{* * *} \\
0.015 \\
(1.18)\end{array}$ & $\begin{array}{l}0.039 \\
(4.65)^{* * *} \\
0.034 \\
(4.38)^{* * *} \\
0.012 \\
(1.52)\end{array}$ & $\begin{array}{l}0.021 \\
(2.03)^{* *} \\
0.020 \\
(2.15)^{* *} \\
-0.005 \\
(0.55)\end{array}$ & $\begin{array}{c}0.015 \\
(2.31)^{* *} \\
0.006 \\
(0.96) \\
-0.001 \\
(0.04)\end{array}$ & $\begin{array}{l}-0.003 \\
(0.06) \\
0.110 \\
(2.97)^{* * *} \\
0.039 \\
(1.04) \\
\end{array}$ & $\begin{array}{l}0.083 \\
(1.56) \\
0.035 \\
(1.53) \\
0.032 \\
(1.37)\end{array}$ \\
\hline \multicolumn{7}{|c|}{ B. Effects of Positive or Negative Employment Spikes on } \\
\hline & \multicolumn{2}{|c|}{ Output } & \multicolumn{2}{|c|}{ Labor Productivity } & \multicolumn{2}{|c|}{ Profits } \\
\hline & Positive & Negative & Positive & Negative & Positive & Negative \\
\hline $\begin{array}{l}\text { Previous } \\
\text { Current } \\
\text { Next }\end{array}$ & $\begin{array}{l}0.056 \\
(7.93)^{* * *} \\
0.070 \\
(9.81)^{* * *} \\
-0.048 \\
(6.54)^{* * *} \\
\end{array}$ & $\begin{array}{l}-0.040 \\
(4.90)^{* * *} \\
-0.062 \\
(7.28)^{* * *} \\
0.065 \\
(7.15)^{* * *} \\
\end{array}$ & $\begin{array}{l}-0.008 \\
(1.26) \\
-0.025 \\
(4.12)^{* * *} \\
0.025 \\
(3.93)^{* * *} \\
\end{array}$ & $\begin{array}{l}0.012 \\
(1.75)^{*} \\
0.020 \\
(2.90)^{* * *} \\
-0.023 \\
(3.06)^{* * *} \\
\end{array}$ & $\begin{array}{l}0.101 \\
(4.43)^{* * *} \\
0.085 \\
(3.68)^{* * *} \\
-0.021 \\
(0.87) \\
\end{array}$ & $\begin{array}{l}-0.086 \\
(3.47)^{* * *} \\
-0.076 \\
(2.92)^{* * *} \\
0.073 \\
(2.64)^{* * *} \\
\end{array}$ \\
\hline \multicolumn{7}{|c|}{ C. Effects of Positive or Negative Non-production Labor Spikes on } \\
\hline & \multicolumn{2}{|c|}{ Output } & \multicolumn{2}{|c|}{ Labor Productivity } & \multicolumn{2}{|c|}{ Profits } \\
\hline & Positive & Negative & Positive & Negative & Positive & Negative \\
\hline $\begin{array}{l}\text { Previous } \\
\text { Current } \\
\text { Next }\end{array}$ & $\begin{array}{l}0.035 \\
(5.21)^{* * *} \\
0.032 \\
(4.85)^{* * *} \\
-0.039 \\
(5.59)^{* * *}\end{array}$ & $\begin{array}{l}-0.043 \\
(5.76)^{* * *} \\
-0.051 \\
(6.46)^{* * *} \\
0.039 \\
(4.68)^{* * *}\end{array}$ & $\begin{array}{l}0.001 \\
(0.02) \\
-0.023 \\
(4.14)^{* * *} \\
0.015 \\
(2.54)^{* *}\end{array}$ & $\begin{array}{l}0.007 \\
(1.16) \\
0.013 \\
(2.01)^{* *} \\
-0.012 \\
(1.74)^{*}\end{array}$ & $\begin{array}{l}0.083 \\
(3.85)^{* * *} \\
0.052 \\
(2.43)^{* *} \\
-0.024 \\
(1.08)\end{array}$ & $\begin{array}{l}-0.064 \\
(2.80)^{* * *} \\
-0.081 \\
(3.43)^{* * *} \\
0.086 \\
(3.42)^{* * *}\end{array}$ \\
\hline \multicolumn{7}{|c|}{ D. Effects of Positive or Negative Production Labor Spikes on } \\
\hline & \multicolumn{2}{|c|}{ Output } & \multicolumn{2}{|c|}{ Labor Productivity } & \multicolumn{2}{|c|}{ Profits } \\
\hline & Positive & Negative & Positive & Negative & Positive & Negative \\
\hline $\begin{array}{l}\text { Previous } \\
\text { Current }\end{array}$ & $\begin{array}{l}0.055 \\
(8.06)^{* * *} \\
0.067 \\
(10.22)^{* * *}\end{array}$ & $\begin{array}{l}-0.028 \\
(3.52)^{* * *} \\
-0.042 \\
(5.07)^{* * *}\end{array}$ & $\begin{array}{c}0.005 \\
(0.88) \\
-0.001 \\
(0.22)\end{array}$ & $\begin{array}{l}0.005 \\
(0.78) \\
0.020 \\
(3.02)^{* * *}\end{array}$ & $\begin{array}{l}0.065 \\
(3.11)^{* * *} \\
0.101 \\
(4.76)^{* * *}\end{array}$ & $\begin{array}{c}-0.024 \\
(0.99) \\
-0.027 \\
(1.06)\end{array}$ \\
\hline Next & $\begin{array}{l}-0.044 \\
(6.25)^{* * *}\end{array}$ & $\begin{array}{c}0.044 \\
(5.04)^{* * *}\end{array}$ & $\begin{array}{c}0.014 \\
(2.38)^{* *}\end{array}$ & $\begin{array}{l}-0.013 \\
(1.93)^{*}\end{array}$ & $\begin{array}{l}-0.028 \\
(1.27)\end{array}$ & $\begin{array}{c}0.082 \\
(3.04)^{* * *}\end{array}$ \\
\hline
\end{tabular}

The dependent variables are either overall oulpul, labor productivity or profits while the independent variables are dummy variables to indicate whether an absolute or relative equipment investment spike or a positive or negative employment, non-production or production labor spike (as defined above) has occurred in the previous, current or next period as well as quartiles of size, average labor costs, nonproduction labor shares and gender ralios, firm-grotp dummies and the growth rate of Austrian real GDP and the growth rate of the equipment investment deflator to account for firm heterogeneity and aggregate trends in variables. Labor productivity responses are calculated wilhout the respective labor productivity quartiles. The Hausman tes/s clearly reject suitability of the random effects specification so results are presented for the fixed effects specifications only.

Absolute values of t-statistics are in parentheses.

* Significant at $10 \%$ level.

** Significant at $5 \%$ level.

*** Significant at $1 \%$ level. 


\section{Firm Characteristics and Spike Occurrence}

\section{IV.1. Methodology}

This section aims to identify macroeconomic and firm specific characteristics that significantly affect the occurrence of absolute and relative equipment investment as well as positive and negative employment, non-production and production labor spikes for the 10-year firm group sample covered by the Industry Statistics Survey for the period 1982 to 1991 .

A logit model - as a binary response model - is applied to specify the effects of different variables on the probability of the occurrence of a spike, where the presence of a spike is modeled as $y=1$ and the absence of a spike is specified as $y=0$. In particular, the following specification is analyzed:

$g(x)=\ln \left[\frac{\pi(x)}{1-\pi(x)}\right]=\beta_{0}+\beta_{1} x_{1}+\ldots+\beta_{k} x_{k}$,

where $\pi(x)$ is the logistic function $\pi(x)=\frac{e^{\beta_{1}+x_{2} \beta_{2}+\ldots+x_{k} \beta_{k}}}{1+e^{\beta_{1}+x_{2} \beta_{2}+\ldots+x_{k} \beta_{k}}}$.

The specification is estimated via an iterative Maximum-Likelihood procedure. To control for unobserved firm heterogeneity, above equation is estimated using fixed effects and random effects models. Since the Hausman test rejects the null hypothesis of no correlation between the right hand side variables and the random effects in the model, results for fixed effects estimations will be reported only.

The vector of explanatory variables is restricted by data availability and comprises macroeconomic and firm-specific characteristics. The sample summary statistics are reported in Table 19 in appendix $\mathrm{C}$.

\section{Macroeconomic characteristics}

The annual growth rate of Austrian real GDP is used to measure the cyclical effect of business conditions on the probability of an input adjustment spike. It is expected to negatively affect the spike-probability since - according to the "pit-stop idea of recessions" (e.g. Caballero et al. (1994)) - productivity enhancing activities are undertaken in recessionary times of low opportunity costs. Any change in the level of inputs temporarily disrupts the smooth and routinized production process since workers' assignments need to be rearranged and tasks need to be reassigned and restructured. Hence, productivity and output decline during retooling and reorganization activities. Since the opportunity costs associated with those rearrangements are 
relatively low in economic downturns, retooling and reorganization should be countercyclical and hence concentrated in economic recessions.

On the contrary, Cooper et al. (1999) show that in case exogenous shocks are persistent and adjustment costs are predominantly fixed, input adjustment activities are procyclical while Klenow (1997) advocates the role of learning effects for the cyclical behavior of investment activities and technology upgrading. He emphasizes that due to higher production rates during economic booms, high learning rates emerge quickly giving rise to higher productivity levels. Additionally, with complementarities between capital and labor on the one hand, and capital and skills on the other, changes in the capital stock and changes in the employment level or the skillcomposition of the workforce should take place simultaneously within firms.

However, empirical results are still inconclusive. Cooper and Haltiwanger (1993) highlight countercyclical replacement in the context of a machine replacement problem since overall costs of replacement (i.e. lower labor productivity) are lowest during recessionary periods. Dunne et al. (1996) reveal countercyclical spikes in nonproduction labor shares. On the contrary, Doms and Dunne (1998) and Cooper et al. (1999) for the U.S. economy and Süssmuth (2003) for Germany all stress the procyclical pattern of large investment episodes for the post and pre World War II periods, respectively.

The growth rate of the equipment investment deflator is used to explicitly account for price changes in new equipment and machinery. Technological progress embodied in new machinery and equipment enhances productivity and profitability of investing firms. Rising prices render new machinery and equipment more expensive, depressing adoption activities of new embodied technology. Therefore, a negative relationship between an increasing equipment deflator and the spikeprobability is expected. Goolsbee (1998) in his study on the U.S. airline industry from 1972-84 finds that the costs of capital equipment negatively affect the realization of investment projects since costly investments are postponed to more favorable periods.

\section{Firm characteristics}

Additionally, average firm-group specific characteristics are included to capture firm-group heterogeneity. Specifically, for each dependent variable considered quartiles are calculated based on the variable's industry distribution to also account for industry effects and cross-industry heterogeneity.

Average firm-group size - as proxied by total employment over firm-group size - is included to capture the size-effect of input adjustments. Since size stems from expansion of employment by profitable firms, larger firm-groups are expected to be more established and have levels of output closer to the minimum efficient scale. Hence, a negative relationship between the probability of a spike and firm-group size is expected. Doms and Dunne (1998) in their study on the U.S. economy find a strong positive but decreasing relationship between plant size and episodes of in- 
vestment spikes. In contrast, Varajão and Portugal (2007) discover a strong and negative relationship between plant size and the probability of an employment spike for the Portuguese economy, defined as employment adjustment rates in excess of 10 percent in a year.

Average wages paid are defined as the ratio of overall personnel costs (comprising gross wages, and salaries as well as compulsory employers' contributions to the social security system and other social costs) to total employment and represent the average personnel costs per employee. The higher average labor costs the more expensive are employees and therefore the lower is the expected employment spikeoccurrence. On the other hand, higher average labor costs indicate higher investment in training and firm-specific human capital and a positive relationship between the probability of employment spikes and average labor costs is expected.

Endowment of firm specific human capital is aiso expected to affect the probability of an input spike. Based on observed complementarities between skills and technology (e.g. Bartel and Lichtenberg, 1987 or Golding and Katz, 1998), technology embodied in newly implemented machinery and equipment are typically operated by skilled laborers. So, a high level of the non-production labor share - proxied by the average ratio of non-production to production labor of the firm-group - is associated with high levels and adoption rates of sophisticated machinery and equipment. And since technologically advanced machinery and equipment is also more productive, a positive relationship between the level as well as the growth rate of the non-production labor share and the probability of a spike is expected. However. Varejão and Portugal (2007) in their study on employment spikes in the Portuguese labor force find a decreasing probability of either a positive or negative employment spike with higher skill shares, measured as the proportion of workers in managerial and technical occupations in total firm employment. This result is attributed to the potentially more demanding and expensive hiring procedures for skilled workers.

The average gender ratio - defined as the ratio of female over male employees per firm in the firm-group - is included in the analysis to take account of potential gender related effects on the occurrence probability of an input spike. Varejão and Portugal (2007) determine an asymmetric relationship between the gender ratio (defined as the ratio of male employees over total employment) and the probability of an employment spike in the Portuguese labor force. While there is a significant positive relationship between the gender ratio and a negative employment spike so that expansions of male employment result in higher probabilities of drastic employment reductions, no significant relationship exists between the gender ratio and a positive employment spike.

Finally, labor productivity as the ratio of the production value and the overall firm-group employment is included as a control variable to represent the average level of technological sophistication of individual firms. Since superior production technologies result in higher output, sales and potentially profits, the need for the implementation of new production technologies or restructuring of firm labor force is low so that a negative relationship between the level of productivity and the probability of any input spike is expected. 


\section{IV.2. Results}

Results for the occurrence-probabilities of absolute or relative equipment investment spikes (ABSOL or REL), positive or negative employment growth spikes (L-POS or L-NEG), positive or negative non-production labor growth spikes (NPL-POS or NPL-NEG) or positive or negative production labor growth spikes (PL-POS or PLNEG) are presented in Table 15. Independent variables are classified into respective quartiles to also capture the role of between-quartile or size effects on the probability of any spike occurring and expressed relative to the largest quartile as the category of reference. Additionally, focus on both, negative and positive spike behavior should help to identify asymmetric dynamics associated with different explanatory variables. For reasons of comparability to results of the previous section, estimated results are reported for any three-year window only, where all relevant firm-group specific data around any spike event are available. An overview of expected and actual results found is given in Table 16 and general results are presented in Table 20 in appendix C.

The procyclical adjustment behavior of investment spikes turns out to be supportive of either the significance of exogenous persistent shocks paired with fixed adjustment costs as advocated by Cooper et al. (1999) or Klenow's (1997) idea of learning effects driving adoption of superior production technologies. Positive laborrelated spikes predominantly occur in economic upturns while negative ones are bunched into economic downturns and recessions, with more pronounced effects found for production labor as the more flexible and less costly factor to adjust. This latter observation is in line with results found for the UK and the Netherlands (Pfann and Palm, 1993), Spain (Alonso-Borrego, 1998) and Mexico (Robertson and Dutkowsky, 2002), where non-production labor is more costly and hence less prone to experience downward adjustments. Furthermore, no evidence of labor hoarding is found.

Furthermore, price increases of equipment and machinery not only reduce the probability of any investment spike but also significantly lessen the probability of any positive labor-related spikes. This result is in perfect line with above inferences on prevailing investment-labor and investment-skill complementarities. Hence, if equipment becomes more expensive and therefore investment projects less attractive, complementary labor or skill adjustments also turn out to be less likely. A closer look also highlights that the probability of a negative non-production labor spike is independent of the price developments of equipment while, in contrast, the likelihood of a negative production labor spike significantly increases with growing prices of equipment. 


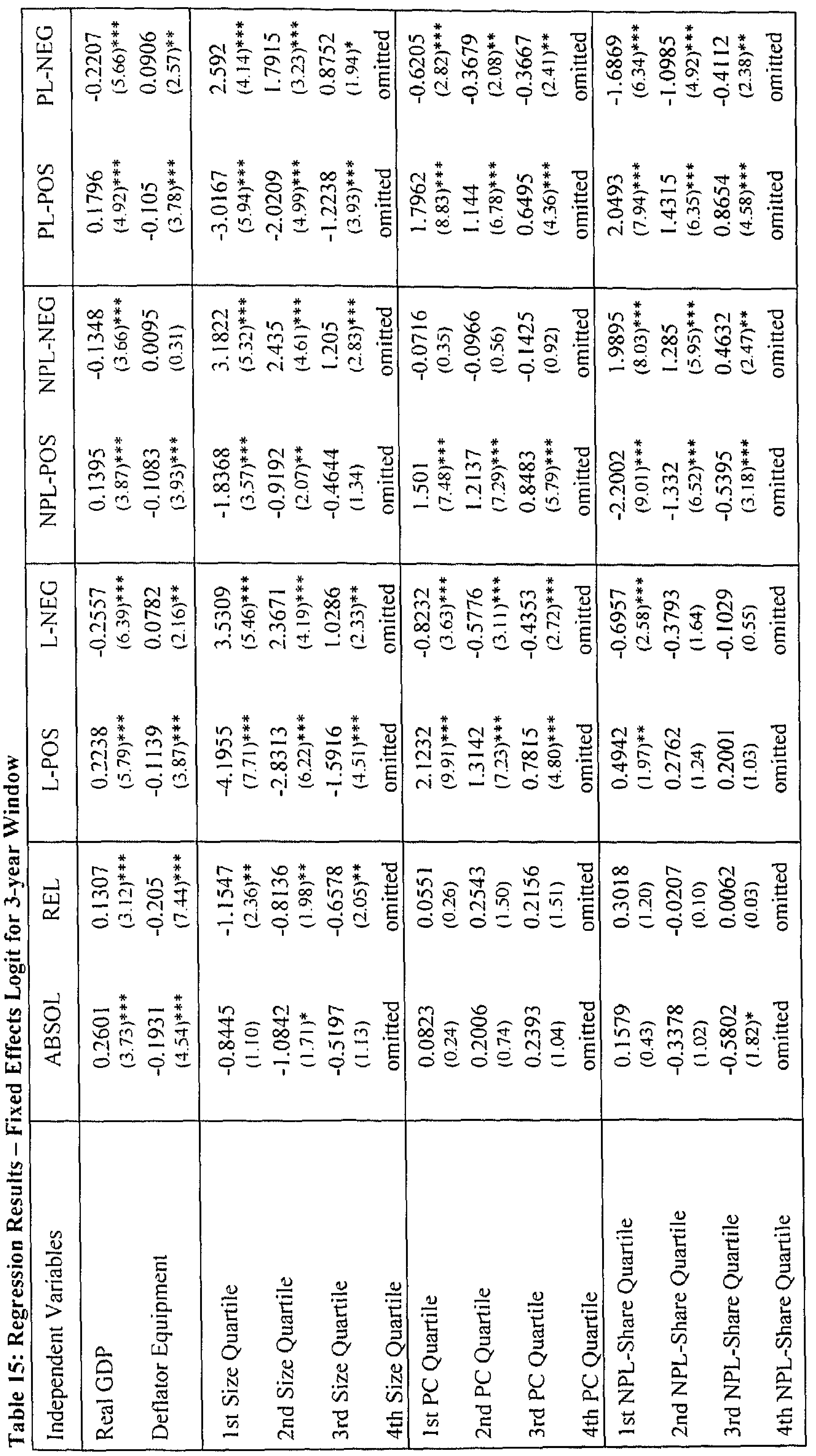




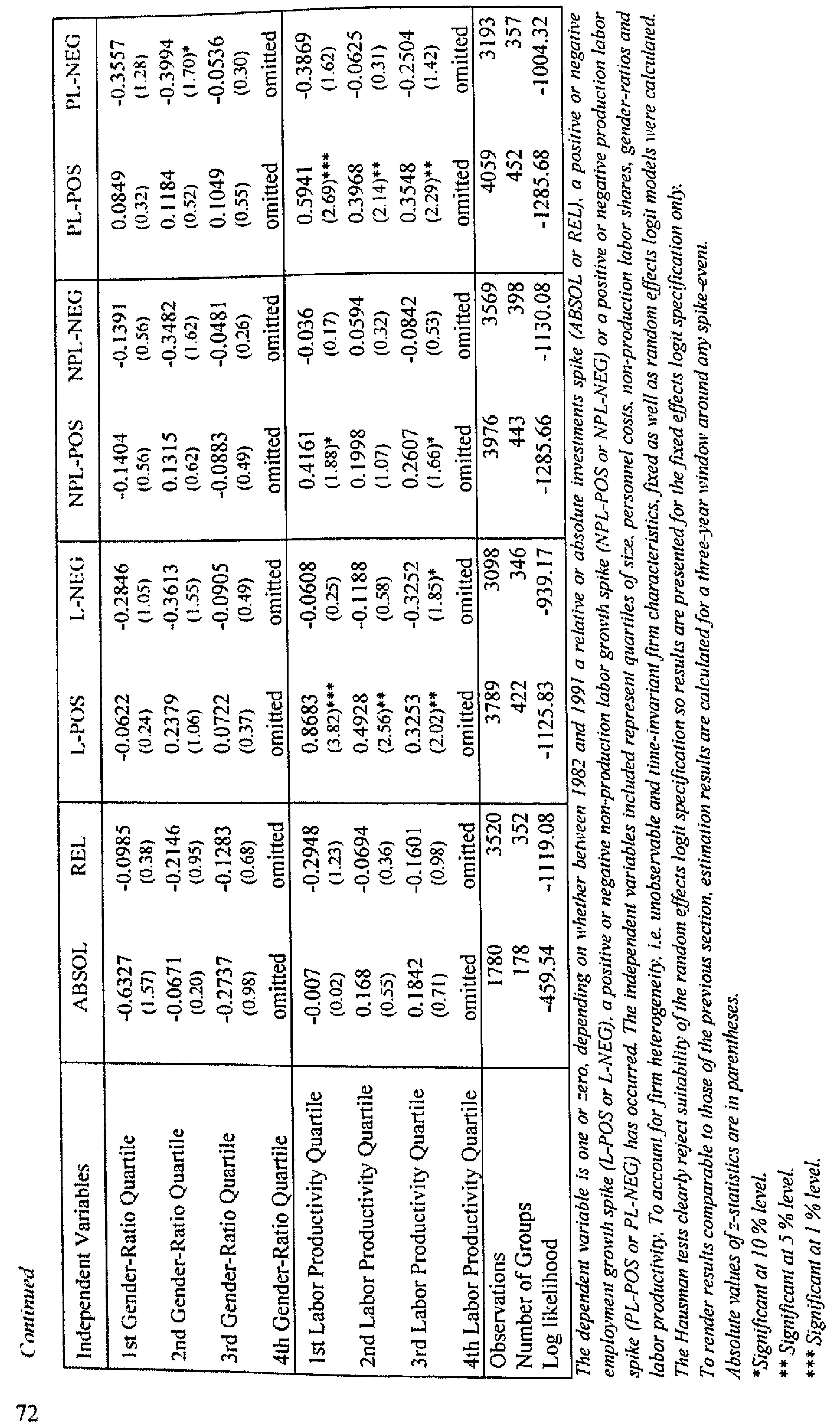


Comparable to conclusions drawn by Varajão and Portugal (2007), the results also emphasize the importance of firm size effects. Specifically, small firm groups are less likely to experience any positive investment or labor-related spikes but are more likely to go through negative input adjustments. Or put differently, relative to large firms, small firms are prone to shrink.

Additionally, increasing personnel costs renders labor more expensive and therefore decreases the probability of positive labor-related spikes, and vice versa. The results also highlight the absence of any significant cost-related effects on negative non-production labor spikes which probably points at the importance of asymmetric fixed labor adjustment costs associated with the reduction of non-production labor. Either asymmetric discriminatory institutional labor market conditions obstruct any flexible and inexpensive reduction of non-production labor. Or the loss of labor productivity or profitability associated with a drastic decline in firm-specific knowledge embodied in non-production labor renders a strong downward adjustment too expensive. The results in Table 14 in section III.4 highlight the lasting and significant negative response of firm profits to major reductions in non-production labor, lending support to the labor adjustment cost idea highlighted above. And despite prevailing investment-labor or investment-skill complementarities found above, rising personnel costs appear to have no significant effect on the probability of any equipment investment spikes occurring. So while, as outlined above, price developments of equipment significantly impinge on the realization of investment projects, labor cost considerations appear irrelevant and large investment projects are carried out irrespective of labor cost developments.

The results on the non-production labor share, defined as the ratio of nonproduction labor to production labor, show that the more abundant non-production labor becomes (relative to production labor) the lower the likelihood of a drastic employment expansion and vice versa.

All in all, the gender ratio hardly exhibits any significant effect on the occurrence of any input spike.

Finally, labor productivity appears unrelated to any equipment investment spike definition. And the higher a firm's labor productivity the less likely it will experience a positive employment or production labor spike.

Table 16: Expected and Actual Effects of Explanatory Variables

\begin{tabular}{|l|l|l|}
\hline Variable & $\begin{array}{c}\text { Expected effect on } \\
\text { spike occurrence }\end{array}$ & $\begin{array}{c}\text { Actual effect } \\
\text { found }\end{array}$ \\
\hline Real GDP growth rate & Positive or negative & Positive \\
Equipment investment deflator growth rate & Negative & Negative \\
Average firm-group size & Negative & Negative \\
Average personnel costs & Positive or negative & Negative \\
Non-production labor share & Positive & Negative (if any) \\
Gender ratio & Unclear & None \\
Labor productivity & Negative & None \\
\hline
\end{tabular}


Table 16 provides an overview and comparison of those effects expected and actual effects found in the analysis.

\section{Summary and Conclusion}

Lumpy adjustment of input factors is an empirical fact also for the small and open economy of Austria. The paper attempts to shed light on interrelatedness and dynamic responses of performance indicators associated with rapid input adjustments and seeks to identify firm characteristics related to the occurrence of absolute or relative equipment investment spikes and positive or negative labor-related spikes for a sample of manufacturing firms between 1982 and 1991 .

The results clearly reveal strong degrees of intertemporal interrelatedness between factors considered. More specifically, in the light of the implementation of new and technologically more sophisticated machinery and equipment, the significance of preparatory training activities and of potentially increased organizational and administrative complexity becomes apparent.

In terms of performance, output, labor productivity and profitability asymmetrically respond to observed spikes. With the exception of production labor, there is evidence of significant temporary productivity and profitability disruptions to drastic input adjustments. And while temporary disruptive effects of newly implemented machinery and equipment on labor productivity are consistently absent, timeconsuming productivity-enhancing learning-by-doing dynamics emerge. Furthermore, any significant productivity responses of either production or non-production labor are found to be temporary and are confined to the period of the spike only. Finally, in contrast to lasting profitability losses associated with extensive nonproduction labor reductions, major personnel cutbacks of production labor do not result in any significant profit losses.

Significant firm heterogeneity is also attested to Austrian Manufacturing. The size-related effect suggests that relative to larger firms smaller ones are more likely to shrink. Personnel costs also matter in that firm-groups facing higher average costs reveal a lower probability of positive labor-related input spikes, an effect that is stronger for production labor, identifying production labor as the more flexible input factor. This observation points at the potential importance of asymmetric fixed costs of labor adjustment associated with the reduction of non-production labor. This is compatible with both, relatively restrictive firing rules characteristic of the Austrian labor market and significant profitability losses found after non-production labor spikes. Furthermore, labor cost considerations appear irrelevant for large investment projects that are carried out irrespective of labor cost developments. The gender composition of the labor force hardly matters for input spike occurrence while, unexpectedly, labor productivity appears to hardly have any significant effect.

Finally, in terms of cyclicality of lumpy input adjustment activities, spike events are clearly procyclical since positive spikes are bunched in periods of economic recovery and growth while negative ones are concentrated in economic recessions. 
Furthermore, consistently procyclical absolute and relative equipment investment spikes debunk the pit-stop idea of recessions as advocated by Caballero et al. (1994).

The model-free empirical approach applied here helps to identify general patterns of adjustment dynamics and input interrelatedness. For further analysis, the results clearly stress that interrelatedness of input factors as well as firm heterogeneity explicitly needs to be taken into account. Furthermore, determining the structure of adjustment costs in terms of convexities and non-convexities in giving rise to and shaping spike-like input adjustment behavior is the natural path to follow next. This research thrust should also help to verify the differential adjustment cost structure found for non-production and production labor. 


\section{Appendix A}

The Booked Depreciation Method starts from the idea that provided firms' accounting practices are known to be subject to linear depreciation with equal deprecation per year over the service life of an asset and annual depreciation is available, booked depreciation contains information on investments undertaken in the past. Specifically, with a lifetime of $\mathrm{L}$ of an asset, booked depreciation is

$D_{1}=\sum_{p=1}^{L} \frac{1}{L} I_{1-p}$

and with the simple extension that $D_{t+1}-D_{t}=\frac{1}{L} I_{1}-\frac{1}{L} I_{t-1 .}$, investment in period $t-L$ and therefore past investment series can be derived by means of future investment and reported booked depreciations as

$I_{1-1}=I_{1}+L\left(D_{t}-D_{1+1}\right)$

The required service lifetimes $(\mathrm{L})$ of equipment and machinery in diverse industries are taken from OECD (1993), estimated on information supplied by enterprises, on estimates reported by other countries and on expert advice.

Investment and booked depreciation series are available for the period 1982-1991. Exemplified by the case of an industry with a service lifetime of 22 years reported for equipment and machinery, two subperiods are created covering 1960-1968 and 19691981. Hence, the nominal capital stock of the respective industry in 1982 - the initial year of the firm-group panel - is calculated as follows:

$n K_{82}=\sum_{t=60}^{81} \frac{(t-60+1)}{22} I_{t}=\sum_{t=60}^{68} \frac{(t-60+1)}{22} I_{t}+\sum_{t=69}^{81} \frac{(t-60+1)}{22} I_{t}$

It can be shown that the first term on the right hand side of above equation can be approximated by applying above intuition on the derivation of past investment series on the basis of available investment and depreciation series as

$$
I_{t}=22\left(D_{t+22}-D_{t+23}\right)+I_{t+22} \quad \text { with } t=(60, \ldots, 68)
$$

The second term can be approximated by

$$
\sum_{t=69}^{81} \frac{(t-60+1)}{22} I_{t} \approx\left(\frac{16}{22}\right) \sum_{t=69}^{81} I_{t} \quad \text { with } t=(69, \ldots, 81)
$$


With reference to $(A \mathrm{l})$, the sum of depreciation over the period equals

$$
\sum_{t=82}^{91} D_{l}=\left(\frac{1}{22}\right)\left(\sum_{t=69}^{90} I_{t}+\sum_{t=70}^{89} I_{t}+\sum_{t=71}^{88} I_{t}+\ldots+\sum_{t=60}^{81} I_{t}\right)
$$

and can be rewritten as the sum of the following three terms:

$$
\sum_{t=82}^{91} D_{t}=\left(\frac{10}{22}\right) \sum_{t=69}^{81} I_{t}+\sum_{t=82}^{90} \frac{(90+1-t)}{22} I_{t}+\sum_{t=60}^{68} \frac{(t-60+1)}{22} I_{t}
$$

And rewriting and rearranging gives the following expression that allows derivation of the equipment investment series needed to approximate (A5), where the first and second term can be observed from the data while the third one needs to be derived from (A4):

$$
\sum_{t=69}^{81} I_{t}=\left(\frac{22}{10}\right) \sum_{t=82}^{91} D_{t}-\sum_{t=82}^{90} \frac{(90+1-t)}{10} I_{t}-\sum_{t=60}^{68} \frac{(t-60+1)}{10} I_{t} .
$$

Finally, the real capital stock in 1981 in constant 1984 prices is derived by deflating the investment flows between 1982 and 1990 with the annual aggregate price index for gross fixed capital formation in equipment and machinery available for 1964 and 2005. Additionally, investment flows for the period 1960-1968 are deflated by the average annual price index for gross fixed capital formation for said period.

$$
K_{82}=\sum_{t=60}^{68} \frac{(t-60+1)}{22} I_{t}\left(\frac{P_{i, 84}}{P_{i, t}}\right)+\sum_{t=69}^{81} \frac{(t-60+1)}{22} I_{t}\left(\frac{P_{i, 84}}{a \nu P_{69,81}}\right)
$$

The overall series of real capital stocks of equipment and machinery is derived by adding real investments to depreciated last period's capital stock:

$$
K_{1}=K_{t-1}[1-\delta]+I_{1}
$$

where a linear and industry-specific depreciation of equipment and machinery specified as $\delta=1 / L$ is applied (see appendix B below for industry-specific service lifetimes and depreciation rates). 


\section{Appendix B}

Table 17: Industry Service Lives of Machinery and Equipment (excluding Vehicles)

\begin{tabular}{|c|c|c|c|c|c|}
\hline $\begin{array}{c}\text { Industry } \\
\text { code }\end{array}$ & Name & $\begin{array}{l}\text { No. of } \\
\text { firm- } \\
\text { groups }\end{array}$ & Match & $\begin{array}{c}\text { Service } \\
\text { lives for } \\
\text { machinery } \\
\text { and } \\
\text { equipment }\end{array}$ & $\begin{array}{c}\text { Depreciation } \\
\text { Rate } \\
\text { (1/Lifetime) }\end{array}$ \\
\hline 12 & Gas supply & 7 & Gas & 18 & 0.06 \\
\hline 13 & $\begin{array}{l}\text { Thermal energy } \\
\text { supply }\end{array}$ & 8 & Energy & 18 & 0.06 \\
\hline 14 & Water supply & 44 & Water & 18 & 0.06 \\
\hline 21 & Mining of coal & 1 & Coal Mining & 20 & 0.05 \\
\hline 22 & Mining of metal ores & 1 & Iron-ore mining & 20 & 0.05 \\
\hline 23 & $\begin{array}{l}\text { Mining of crude oil } \\
\text { and gas }\end{array}$ & 1 & Petroleum and Gas & 20 & 0.05 \\
\hline 24 & Mining of salt & 1 & Mining and Quarrying & 20 & 0.05 \\
\hline 25 & Mining of magnetite & 1 & Mining and Quarrying & 20 & 0.05 \\
\hline 26 & $\begin{array}{l}\text { Mining of graphite, } \\
\text { talc, gypsum and } \\
\text { other minerals }\end{array}$ & 3 & Mining and Quarrying & 20 & 0.05 \\
\hline 27 & $\begin{array}{l}\text { Quarrying of stones } \\
\text { and soil }\end{array}$ & 16 & Mining and Quarrying & 20 & 0.05 \\
\hline 31 & Food & 62 & Food and beverages & 22 & 0.05 \\
\hline 32 & $\begin{array}{l}\text { Beverages and } \\
\text { tobacco }\end{array}$ & 28 & Tobacco & 22 & 0.05 \\
\hline 33 & Textiles & 64 & Textiles & 17 & 0.06 \\
\hline 34 & Wearing apparel & 56 & Textiles & 17 & 0.06 \\
\hline 35 & Footwear & 8 & Clothing & 17 & 0.06 \\
\hline 36 & Leather & 5 & Leather & 17 & 0.06 \\
\hline 37 & $\begin{array}{l}\text { Processing of wood } \\
\text { and products of } \\
\text { wood }\end{array}$ & 9 & $\begin{array}{l}\text { Lumber and wood } \\
\text { products }\end{array}$ & 15 & 0.07 \\
\hline 38 & Furniture & 48 & Furniture & 15 & 0.07 \\
\hline 39 & $\begin{array}{l}\text { Musical instruments, } \\
\text { sports equipment } \\
\text { and toys }\end{array}$ & 5 & Other Manufacturing & 18 & 0.06 \\
\hline 41 & $\begin{array}{l}\text { Paper and paper } \\
\text { products }\end{array}$ & 28 & $\begin{array}{l}\text { Paper and paper } \\
\text { products }\end{array}$ & 18 & 0.06 \\
\hline 42 & $\begin{array}{l}\text { Printing and publis- } \\
\text { hing }\end{array}$ & 1 & $\begin{array}{l}\text { Printing and Publis- } \\
\text { hing } \\
\end{array}$ & 15 & 0.07 \\
\hline 44 & $\begin{array}{l}\text { Rubber and plastic } \\
\text { products }\end{array}$ & 24 & $\begin{array}{l}\text { Rubber, Plastic } \\
\text { Products } \\
\end{array}$ & 18 & 0.06 \\
\hline 45 & $\begin{array}{l}\text { Chemicals and allied } \\
\text { products }\end{array}$ & 54 & Chemicals & 18 & 0.06 \\
\hline 46 & $\begin{array}{l}\text { Other non-metallic } \\
\text { mineral products } \\
\end{array}$ & 4 & $\begin{array}{l}\text { Other non-metallic } \\
\text { mineral products }\end{array}$ & 17 & 0.06 \\
\hline 47 & $\begin{array}{l}\text { Products of stone } \\
\text { and soil }\end{array}$ & 63 & $\begin{array}{l}\text { Clay and stone } \\
\text { products }\end{array}$ & 17 & 0.06 \\
\hline
\end{tabular}




\begin{tabular}{|c|c|c|c|c|c|}
\hline \multicolumn{6}{|c|}{ Continned } \\
\hline$\overline{48}$ & Glass products & 9 & Glass & 17 & 0.06 \\
\hline 51 & $\begin{array}{l}\text { Iron and non-ferrous } \\
\text { metals }\end{array}$ & 27 & Basic metals & 20 & 0.05 \\
\hline 52 & $\begin{array}{l}\text { Manufacture of basic } \\
\text { metals }\end{array}$ & 22 & Basic metals & 20 & 0.05 \\
\hline 53 & $\begin{array}{l}\text { Manufacture of } \\
\text { fabricated metal } \\
\text { products }\end{array}$ & 46 & Metal Products & 20 & 0,05 \\
\hline $54 \_55$ & $\begin{array}{l}\text { Machinery and } \\
\text { equipment }\end{array}$ & 64 & $\begin{array}{l}\text { Machinery and } \\
\text { Equipment }\end{array}$ & 20 & 0.05 \\
\hline $56 \_57$ & $\begin{array}{l}\text { Electrical machinery } \\
\text { and apparatus }\end{array}$ & 43 & $\begin{array}{l}\text { Machinery and } \\
\text { Equipment }\end{array}$ & 20 & 0.05 \\
\hline 58 & Transport equipment & 37 & Transport & 25 & 0.04 \\
\hline 59 & $\begin{array}{l}\text { Medical, precision } \\
\text { and optical instru- } \\
\text { ments }\end{array}$ & 7 & Other Manufacturing & 18 & 0.06 \\
\hline 62 & $\begin{array}{l}\text { Conversion of } \\
\text { buildings and } \\
\text { auxiliary construc- } \\
\text { tion }\end{array}$ & $t$ & Construction & $\overline{8}$ & 0.13 \\
\hline 63 & Construction & 7 & Construction & 8 & 0.13 \\
\hline$\overline{94}$ & $\begin{array}{l}\text { Personal hygiene } \\
\text { and cleaning. } \\
\text { undertaking }\end{array}$ & 5 & Personal Services & $\overline{20}$ & 0.05 \\
\hline 95 & $\begin{array}{l}\text { Recreational. } \\
\text { cultural and sporting } \\
\text { activities }\end{array}$ & 29 & Health & 15 & 0.07 \\
\hline
\end{tabular}


Figure 18: Distributions of Relevant Input Variables
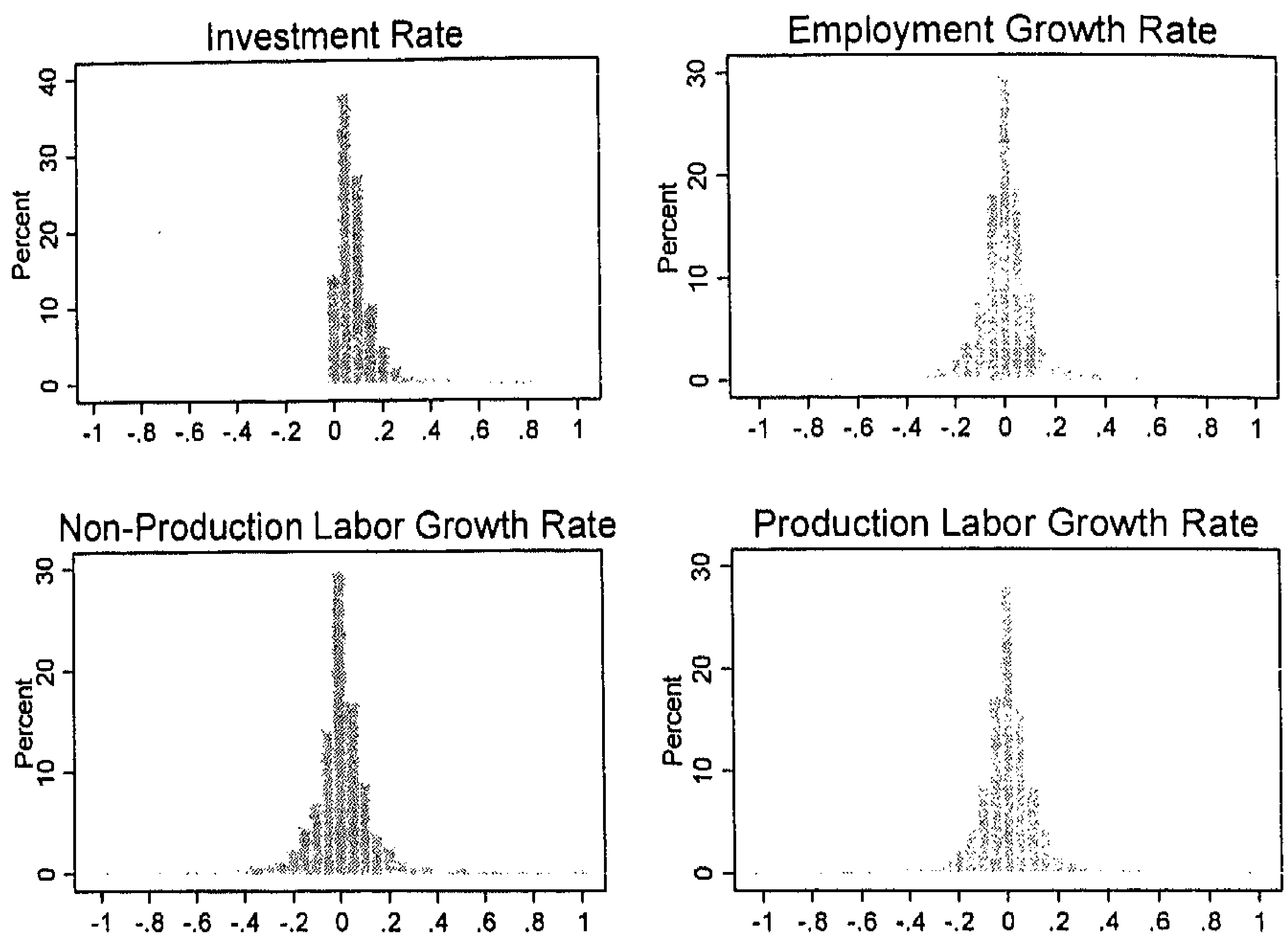


\section{Idix C}

18: Contemporaneous Correlation of Input Factors

\begin{tabular}{|c|c|c|c|c|}
\hline & $\begin{array}{c}\text { Investment } \\
\text { Rate }\end{array}$ & $\begin{array}{l}\text { Enuployment } \\
\text { Growth Rate }\end{array}$ & $\begin{array}{c}\text { Non-Production } \\
\text { Growth Rate }\end{array}$ & $\begin{array}{l}\text { Production } \\
\text { Growth Rate }\end{array}$ \\
\hline ment Rate & 1 & & & \\
\hline $\begin{array}{l}\text { syment } \\
\text { th Rate }\end{array}$ & $0.0888^{*}$ & 1 & & \\
\hline $\begin{array}{l}\text { roduction } \\
\text { Growth Rate }\end{array}$ & $0.0658^{*}$ & $0.6733^{*}$ & 1 & \\
\hline $\begin{array}{l}\text { ction Labor } \\
\text { th Rate }\end{array}$ & $0.0702^{*}$ & $0.8368^{*}$ & $0.2815^{*}$ & 1 \\
\hline
\end{tabular}

relations are significant at the l percent level.

\section{9: Summary Statistics}

\begin{tabular}{|l|c|c|}
\hline sle & Mean & Std. Dev. \\
\hline ment investment rate & 0.0848 & 0.0739 \\
syment growth rate & 0.0063 & 0.1537 \\
roduction labor growth rate & 0.0152 & 0.1922 \\
ction labor growth rate & 0.0074 & 0.1824 \\
rutput & 11.8708 & 1.4588 \\
abor productivity & 6.9813 & 0.6536 \\
rofits & 10.6536 & 1.7961 \\
JDP growth rate & 2.6493 & 1.2404 \\
ment investment deflator growth rate & 1.8764 & 1.5733 \\
verage lirm-group size & 3.7102 & 1.4869 \\
verage personnel costs & 5.5970 & 0.3584 \\
on-production labor share & -0.8355 & 0.7146 \\
ender ratio & -0.8150 & 1.2607 \\
\hline
\end{tabular}




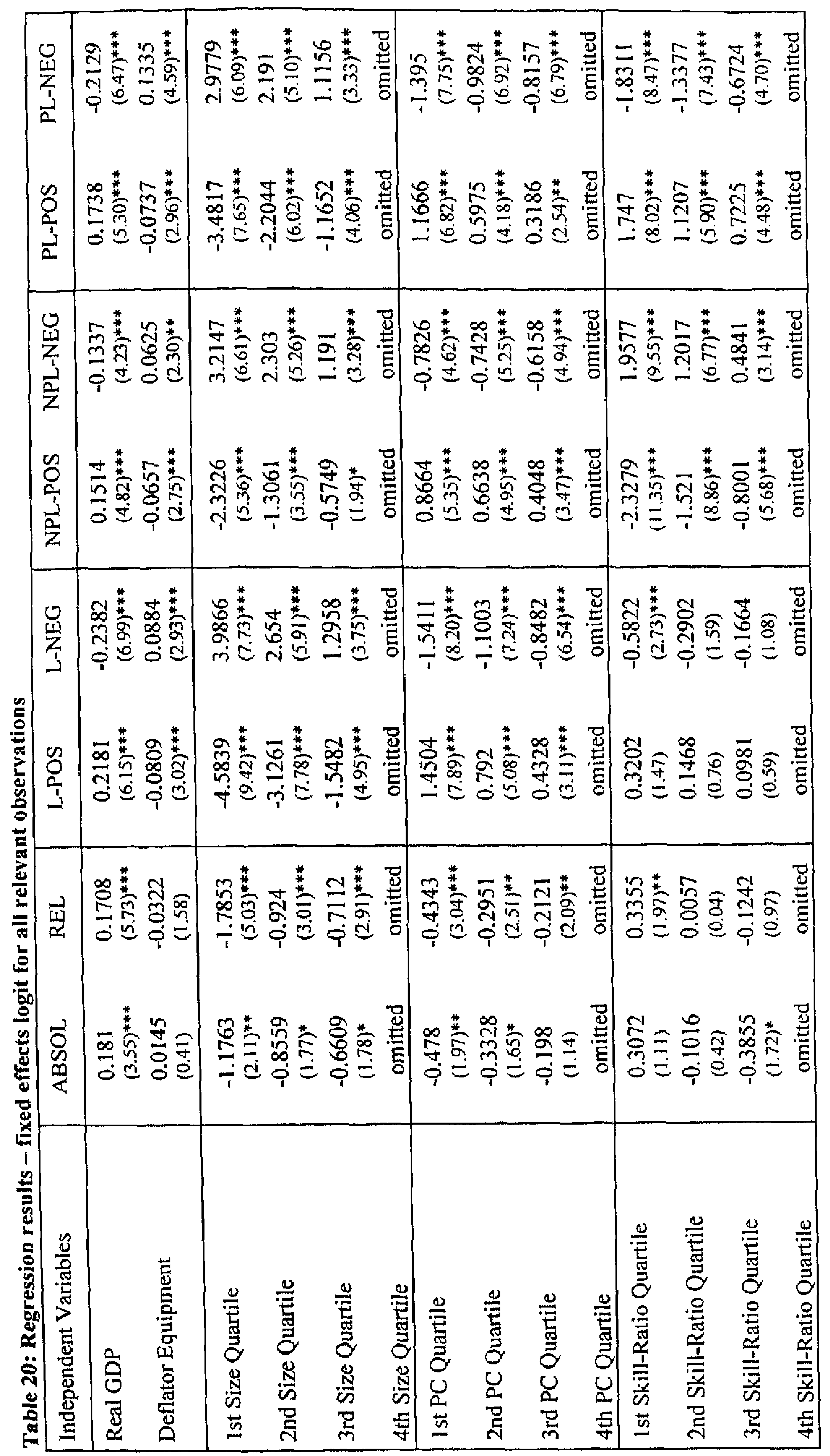

82 


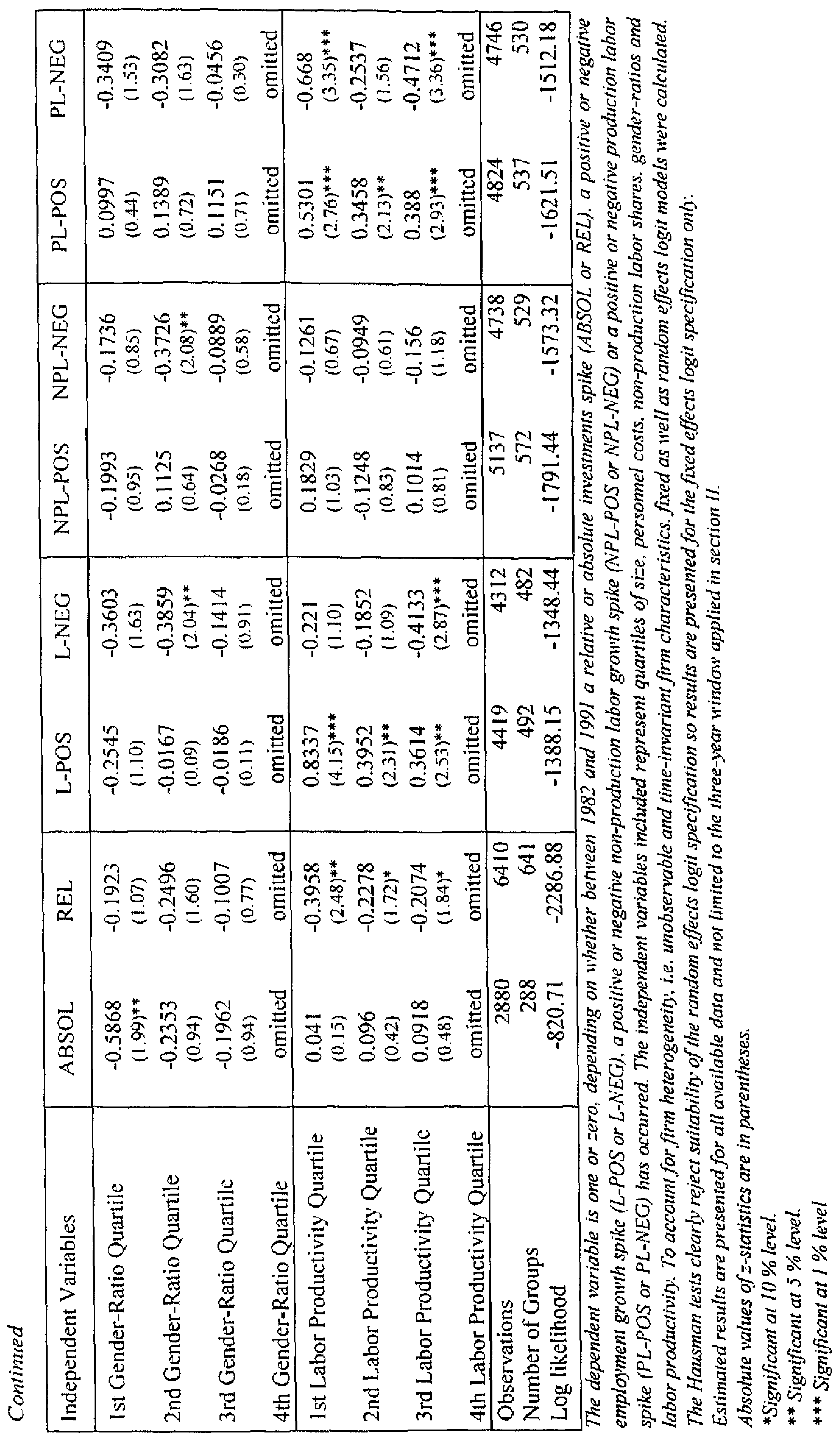




\section{The Nature of Capital Adjustment Costs in Austrian Manu- facturing}

\section{Introduction}

Input adjustments in response to aggregate or idjosyncratic shocks represent costly activities. In the course of input modifications, firm productivity temporarily declines $^{8}$, when routinized production processes are disrupted and firms incur fixed costs associated with plant or organizational restructuring or worker retraining.

Traditionally, deficient or altogether lacking appropriate firm-level data led to studying aggregate input adjustment patterns to gain viable insights into micro-level input adjustment behavior. Since aggregate patterns are typically found to be rather smooth, the representative firm was assumed to face strictly convex adjustment costs. Under convex adjustment costs, large input modifications entail large adjustment costs, prompting the firm to split and spread out the input adjustment project over several periods, leading to familiar smooth, frequent and small adjustments. However, aggregation tends to cushion and wash out any prevailing discontinuity and volatility, irregularity and heterogeneity in firm input adjustment strategies.

More recently, partly due to growing dissatisfaction with empirical results stemming from the underlying assumption of convex adjustment technologies, paired with increased availability of microeconomic data and statistic methodologies, the obvious becane apparent: input adjustment is highly erratic and proceeds in jumps. To reconcile empirical evidence with theoretical assumptions, adjustment frictions in the form of fixed adjustment costs are highlighted. Under fixed adjustment costs, firms resort to infrequent but lumpy input modifications to fully internalize prevailing sizeable fixed costs associated with any input changes. Theoretically, for investments, firm level input adjustment behavior under fixed adjustment costs is developed by Abel and Eberly (1994) who stress the discontinuous nature of investment activities to jump between zero, positive or negative values.

Furthermore, empirical evidence also highlights the strong and persistent asymmetry of input adjustment patterns and the role of irreversibilities of inputs in that respect. Under irreversibilities, maybe due to lacking second hand markets for capital or strongly regulated labor markets with binding or expensive firing rules for labor, costs associated with newly acquired inputs are sunk and cannot be recovered should the firm want to reverse any preceding increases in inputs. In their strongest form, irreversibilities fully prevent firms from cutting down previously acquired inputs and only zero or positive input adjustment strategies become feasible.

\footnotetext{
${ }^{8}$ Sakellaris (2004)
} 
Irrespective of input factor considered or country context chosen, the plentitude of empirical evidence of periods of more or less zero changes in inputs being superseded by periods of feverish changes and of highly asymmetric, predominantly positive changes strongly points at the importance of both, convex and nonconvex adjustment costs, as well as irreversibilities in determining observed input adjustment patterns ${ }^{9}$. Analyses of investment dynamics reveal the following: descriptive evidence, as provided by the seminal work of Dums and Dunne (1998), documents highly lumpy firm investment patterns which account for a significant fraction of overall firm investment and are undertaken within a short period of time only. The hazard approach, as applied by Cooper et al. (1995) for example, helps to identify the relevance of fixed adjustment costs compared to convex adjustment costs or irreversibilities. With upward sloping input hazards, or put differently, with an increasing probability of any input spike with the time that has elapsed since the last input spike, the significance of fixed adjustment costs becomes apparent. Finally, empirical tests of the q-theory model of investments with convex adjustment costs suggest a non-linear relationship between 'fundamentals' captured by $q$ and firm investment activities such that firms adjust substantially more to large input shortages than to small ones, providing support for the presence of nonconvex adjustment costs.

While extremely insightful and relevant for the development of a correct representation of firm-level input adjustment behaviors, outlined methodologies are unable to capture the exact magnitudes of both, convex and nonconvex adjustment costs as well as irreversibilities that are associated with any input modifications.

This paper attempts to contribute to the recent discussion on the exact nature of adjustment costs, initiated by Cooper and Haltiwanger (2006) for the U.S. and advanced by Contreras (2006) for Colombia. Specifically, firm-group level data for the small and open economy of Austria between 1982 and 1991 are applied to shed light on the size of convex and nonconvex adjustment costs in investments in machinery and equipment, subject to perfect irreversibility ${ }^{10}$.

From a vintage-model point of view, investments in equipment and machinery are of particular interest since newly implemented machinery and equipment embodies recent and productivity enhancing technological knowledge and acts as carrier of technology across industries and countries. Therefore, they represent key transmission mechanisms from technological change to productivity enhancement and output

\footnotetext{
${ }^{9}$ For capital adjustments see: Doms and Dunne (1998), Caballero, Engel and Haltiwanger (1995a), Cooper, Haltiwanger and Power (1995), Barnett and Sakellaris (1998) for the US, Carlsson and Laseen (2005) for Sweden, Nilsen and Schiantarelli (2003) for Norway, Attenasio, Pacelli and do Reis (2003) for the UK, Verick, Letterie and Pfann (2004) for West-Germany, Letteric and Pfann (2007) for the Netherlands, Licandro, Maroto and Puch (2005) for Spain, Gelos and Isgut (2001) for Columbia and Mexico and Fuentes, Gilchrist and Rysman (2004) for Chile.

For labor adjustments see: Hamermesh (1989), Caballero, Engel and Haltiwanger (1995b) for the US, Rota (2001) for Italy, Varejão and Portugal (2007) for Portugal and Nilsen, Salvanes and Schiantarelli (2003) for Norway.

${ }^{10}$ Information on disinvestment and capital scrapping is absent from the data, so the emerging structure of investment activities only captures zero or positive adjustments, which is perfectly in line with the presence of perfect Irreversibilitics.
} 
expansion. In that respect, investment specific technological change is found to be crucial for economic activities like business cycles, long-term economic growth or, given capital-labor complementarities, for labor market conditions and dynamics.

For the post World War II period, Fisher (2002, 2006), Gambetti (2005) and Greenwood et al. (2000) find that investment specific technological change explains much of U.S. business cycles while only a negligible role is found for the UK. Khan and Tsoukalas (2006) demonstrate that only up to 10 percent of fluctuations in output are accounted for by investment specific technological change. Moreover, these studies also shed light on labor market dynamics related to technological change and highlight that for the U.S. and the UK up to 54 or 15 percent of fluctuations in hours worked can be ascribed to investment specific technological change, respectively.

And in their studies on the U.S. economy, Greenwood et al. (1997) and Cummings and Violante (2002) emphasize that about 60 percent of U.S. per capita growth between 1954 and 2000 can be attributed to investment specific technological change.

With the decisive role of investment specific technological change for macroeconomic performance and labor market outcomes, the pattern of investment activities as well as its source becomes a central issue. And once capital modifications entail adjustment costs, their size and structure significantly affect investment behavior. Hence, studying the structure of capital adjustment costs not only sheds light on the factors determining the pattern and size of investment activities but also helps to spot impediments to investments as potential sources of poor growth performances or strongly disruptive labor market dynamics.

In order to estimate the structural capital cost parameters, the methodology of simulated method of moments as developed by McFadden (1989), among others, finds application. The approach rests on the idea that structural parameters can be identified by matching moments of data simulated on the basis of a combination of cost parameters with observed key moments of actual data. Simulations are based on dynamic optimization problems solved by firms facing both convex and non-convex capital adjustment costs.

Overall, the results highlight the prevalence of adjustment frictions in the course of investment in machinery and equipment and therefore debunk the neoclassical hypothesis of only convex adjustment costs governing input adjustment behavior. More specifically, firms operating in Austrian manufacturing face non-negligible fixed costs of adjustment of 10.5 percent of installed capital and convex adjustment costs of 18 percent of installed capital.

The results well compare to the Greek case studied by Lapatinas (2007a) for a similar scenario of perfect irreversibilities.

However, higher than estimated capital adjustment costs are expected to prevail in Austrian manufacturing since the analysis is restricted to a set of aggregated firmgroups instead of individual firm observations and aggregation is known to wash out strong irregularities.

The paper is structured as follows: section II reviews empirical evidence related to investment activities and patterns. The data are discussed in section III. Section IV 
discusses the methodology that is applied in terms of different underlying cost scenarios while section $V$ elaborates on the estimation procedure. The recovery of overall firm profitability shocks as well as aggregate and idiosyncratic profitability shocks are subject of section VI, section VII presents and discusses the estimation results while section VIII summarizes and concludes.

\section{Empirical Evidence}

In a competitive, frictionless environment, profit-maximizing firms' input adjustment activities are governed by the marginal equality concept so that firms alter their stocks of capital and labor instantaneously to perfectly internalize aggregate or idiosyncratic shocks. However, much of the empirical literature emphasizes the sluggish and spike-like nature of adjustments in response to observed shocks - a phenomenon typically assigned to the emergence of adjustment costs in the course of input modifications.

In that respect, Nickell (1986) points out that hiring and firing activities are costly and generate costs over and above wages since routinized production processes are disrupted when workers' assignments are rearranged in the course of expanding or shrinking workforces. Additionally, firms incur search costs in terms of advertising and screening for or training of new employees or firing costs affected by employment security regulations concerning unfair dismissal and redundancy payments.

Furthermore, Nickell (1978) stresses that the purchase and implementation of capital goods incur costs over and above their prices and Hamermesh and Pfann (1996) point out that the (net) costs of adjusting the level of capital goods are associated with disruptions of routines, reassignment and restructuring of tasks and temporary productivity and output losses.

Four potential structures of adjustment costs are conceivable:

- Convex adjustment costs are given when marginal adjustment costs increase with the size of input adjustment;

- Symmetric convex adjustment costs represent similar increases in marginal costs for positive and negative changes of equal size and create a symmetric and smooth adjustment path;

- Asymmetric convex costs are characterized by the possibility of differences in marginal costs to positive and negative changes in stocks and give rise to asymmetric and smooth adjustment paths;

- Linear adjustment costs are based on the idea that costs are proportional to input changes so that irrespective of the extend of change, marginal costs remain constant and adjustment paths exhibit some discontinuity since it pays for firms to delay adjustment until additional profits of adjustment offset incurred costs; 
- Lumpy or non-convex costs indicate that fixed costs are associated with any change in the stock of inputs and that this non-convexity gives rise to erratic, i.e. infrequent and large changes;

Partly inspired by the seminal work of Eisner and Strotz (1963) as well as smooth adjustment patterns observed at the aggregate level, the adjustment cost function was typically assumed to be strictly convex. However, more recent empirical studies invalidate said assumption but highlight its lumpiness, linearity or asymmetry.

For capital goods, Cooper et al. (1995) find for the U.S. that the probability of an investment spike increases with the time that has elapsed since the previous spike, giving support to underlying nonconvexities since changes are infrequent and large. In the same vein, positive investment hazards are found by Fennema et al. (2006) for a large sample of Dutch manufacturing firms. Caballero et al. (1995a) show for the U.S. that firms adjust more to large capital shortages than to small ones, which is consistent with nonlinear adjustment technologies. Lumpy investment behavior and the significance of trigger levels for the realization of investment projects are found by Doms and Dunne (1989) for the U.S. manufacturing. They also identify tremendous heterogeneity in capital adjustment patterns with smaller or older plants or plants that undergo ownership changes or switch industries undergoing lumpier investment episodes. The role of fixed adjustment costs for replacement as compared to expansion investment activities by West German establishments is studied by Verick et al. (2004). They conclude that given the dominance of large establishments in the sample, expansion investments are more continuous than lumpy. The presence of irreversibilities of investment activities, as characterized by predominantly nonnegative investment episodes, paired with lumpy investment episodes are found by Cooper and Haltiwanger (2000) for U.S. manufacturing plants and by Carlsson and Laséen (2001) for Swedish manufacturing plants.

Few studies on developing countries also highlight prevailing differences of adjustment cost technologies across development levels. While Bigsten et al. (2005) emphasize the significance of irreversibilities and the prevalence of lumpiness for a diverse set of African manufacturing firms, Gelos and Isgut (2001) show that nonconvexities are irrelevant for Mexican and Columbian manufacturing firms' investment activities. That investment patterns of Chilean manufacturing plants are lumpier than in U.S. counterparts and that lumpiness is more dominant in small plants is highlighted by Fuentes et al. (2004).

But investment technologies also differ across capital goods. Investment activities of Norwegian manufacturing plants are found to be subject to convex and nonconvex adjustment costs as well as irreversibilities and are found to be lumpier for Buildings compared to Machinery and Equipment (Nielsen and Schiantarelli, 2003). Similarly, Attanasio et al. (2003) for a set of UK plants conclude that Buildings and Land are the most rigid capital goods, Plant and Machinery the most flexible ones while Vehicles are rigid but reversible capital goods. 
The existence of convex as well as nonconvex adjustment costs in investment activities also emerges in industry studies of Goolsbee and Gross (1997) on the U.S. Airline Industry and of Asano (2002) on the U.S. Petroleum Refining Industry.

Recently, as inspired by the seminal work of Cooper and Haltiwanger (2006) for the U.S. attempts were made to specify the nature of adjustment costs and the relative roles convex and nonconvex adjustment costs as well as irreversibilities play for input adjustments in Colombia (Contreras, 2007), Spain (Sánchez-Mangas, 2002), Germany (Bayraktar et al., 2005) and Greece (Lapatinas, 2007). Despite different model assumptions, all studies agree that model specifications accounting for all adjustment cost components fit the data best.

For U.S. manufacturing firms, Cooper and Haltiwanger (2006) find mean disruption costs of 20.4 percent and mean fixed costs of 4 percent of installed capital and a small role for irreversibilities. Contreras (2006) extends the approach applied by Cooper and Haltiwanger (2006) to explicitly account for capital-labor complementarities discovered in Colombian manufacturing. The analysis highlights the prevalence of congestion effects for both convex as well as disruption costs such that joint adjustment activities are more expensive than the adjustment of only one of the two inputs. Moreover, congestion effects are stronger in terms of disruption costs as compared to convex costs. And in contrast to U.S. results, irreversibilities are considerable and a central feature of capital adjustment processes in Columbian manufacturing.

The relative roles of real frictions and financial frictions in the presence of financial market imperfections associated with capital investment activities in a small sample of relatively large German manufacturing firms are identified by Bayraktar et al. (2005). The results point at a relatively modest impact of financial frictions on firms' investment activities but highlight the importance of fixed costs in determining investment behavior in that at the mean investment rate, 16.3 percent of overall purchase costs are attributed to fixed costs while only 4.7 percent of overall purchase costs represent convex costs.

Finally, to account for the high degree of irreversibilities present in the data Sánchez-Mangas (2002) and Lapatinas (2007a) specify discrete models of capital investment for Spanish and Greek manufacturing, respectively. Sánchez-Mangas (2002) highlights the dominance of fixed costs associated with capital adjustments and emphasizes the significance of firm-size for capital adjustment costs. Specifically, he demonstrates that small firms face fixed capital adjustment costs of 23.3 percent of installed capital while medium sized or large firms only face fixed costs of 1.1 or 0.2 percent, respectively. Finally, Lapatinas $(2007 \mathrm{a})^{11}$ points out that firms face fixed costs of 15.57 percent of installed capital in case of capital adjustments, a result that is in stark contrast to the fixed costs found in the above-mentioned studies ( 4 percent for the U.S. and 0.02 percent for Colombia for capital alone).

\footnotetext{
1 Lapatinas (2007b) also studies the nature of labor adjustment costs and shows that firms face convex adjustment costs of 56.3 percent per worker hired or fired, negligible fixed costs and disruption losses of 2 percent of profits during adjustment.
} 


\section{Data}

Data on firm investment and labor adjustment behavior are taken from the Austrian Industry Statistics Survey (Industriestatistik), conducted by Statistics Austria for 37 industries in Industry for the period 1982 to 1991. The Industry Statistics survey is an annual survey collecting data on individual firm's economic structure and success and has been carried out since 1969 up to 1995. With Austria's EU-membership in 1995, the survey was replaced by the Business and Consumer Survey which was first conducted in 1997.

However, given strong binding legal restrictions on data confidentiality, individual firm observations are unavailable. Instead, to guarantee confidentiality on delicate individual firm information disclosed to the national statistical office, firmgroups were generated based on similar size-characteristics approximated by total employment. Specifically, all firms within each industry were ranked according to size in 1982 and grouped together to form firm-groups comprising at least 4 firms. A unique identification number was assigned to each firm-group in the database to facilitate tracing its development. All in all, a balanced set of 839 firm-groups is available for the analysis.

The initial gross capital stock of equipment and investment was derived applying the Booked Depreciation Method (BDM) suggested by Broersma et al. (2003) instead of the conventional Perpetual Inventory Method (PIM). While PIM derives productive capital by summing past investment flows and correcting for loss of productive capacity due to aging, its major drawback rests in the need for long time series of investments that cover the entire period of the underlying service life. This is particularly problematic in studies on micro-level phenomena where investment series are normally available for a short period only, not fully covering service lives of individual capital assets.

The overall firm-group level series of real capital stocks of equipment and machinery $K$ is derived by adding up real investments $I_{t}$ and the real depreciated capital stock:

$$
K_{t+1}=K_{l}(1-\delta)+I_{t}
$$

where linear and industry-specific time-invariant depreciation rates $\delta$ of equipment and investment are applied and, for lack of better deflators, investments are depreciated by the annual aggregate price index for gross fixed capital formation in equipment and machinery and expressed in 1984 prices.

Productivity enhancing investments in new and technologically sophisticated machinery and equipment are proxied by the investment rate. It is defined as the ratio of new investments in machinery and equipment to the capital stock of machinery and equipment $(I / K)_{i t}$. 
Table 21: Moments of Investment Rate

\begin{tabular}{|l|lllll|}
\hline & Mean & Std. & SK & K & C.V \\
\hline Investment Rate & 0.085 & 0.074 & 3.136 & 20.950 & 0.8706 \\
\hline
\end{tabular}

Tolal number of year-group observations: 8260

Mean, standard deviation, coefficient of variation, skewness and kurtosis of equipment imestment rates.

The variable's first four moments as well as the coefficient of variation are reported in Table 21. Positive skewness and excess kurtosis is apparent and the one-sided Kolmogorov-Smirnov test of normality is clearly and significantly rejected. Positive skewness is indicative of bunching of observations on the left of the mean and of a long tail on the right of the distribution and highlights that the majority of firms have low or zero input adjustment rates while some exhibit large ones ${ }^{12}$. With excess kurtosis, the distribution shows thicker tails and higher peaks than normal distributions. The coefficient of variation, an indicator that captures the dispersal around the mean, is low for investments due to the presence of non-negative rates only and the associated low standard deviation.

Table 22: Characterization of Input Adjustment Rates

\begin{tabular}{|l|c|}
\hline & Investments \\
\hline Average rate & $8.5 \%$ \\
Inaction rate* & $5.6 \%$ \\
Frequency of positive adjustments & $94.4 \%$ \\
Frequency of negative adjustments & $0 \%$ \\
Spike rate - in excess of $20 \%$ & $6.3 \%$ \\
Spike rate - in excess of -20\% & $0 \%$ \\
Spike rate - in excess of 30\% & $3 \%$ \\
Spike rate - in excess of -30\% & $0 \%$ \\
Correlation of investment rates and profit shocks & $0.055(0.00)$ \\
\hline
\end{tabular}

* Inaction rate defined as rates less than I percent in absolute terms.

The spike rate is defined as the frequency' of observed investment spikes in the sample.

Standard errors are provided in parentheses.

Table 22 provides additional information on distributional characteristics. Due to the lack of information on scrapping, the distribution of productive equipment and machinery adjustments is limited to zero or positive investment rates only, which is perfectly in line with the prevalence of perfect irreversibilities.

The mean investment rate is 8.5 percent which is about two thirds of the average investment rate reported for the U.S. by Cooper and Haltiwanger (2006). The frequency of zero adjustment rates is approximately 6 percent. Episodes of input adjustment rates in excess of 20 percent are relatively infrequent but twice as frequent as episodes in excess of 30 percent. Input adjustments exceeding 20 percent represent 6 percent of all observed investment activities and account for 11 percent of total

\footnotetext{
${ }^{12}$ In that respect, 71 percent of all investment activities which account for 54 percent of total investments are in the range between 0 and 10 percent.
} 
investments. A cross country comparison of characteristics of investment rates is given in Table 26 in the appendix.

Finally, Table 23 reports mean investment rates and investment shares of firms by rank in ascending order with the highest average investment rate attributed to rank 10 and the lowest to rank 1 . The investment share represents the mean proportion of overall firm-group 10-year investment that occurs in each year and is ranked from lowest to highest.

The results illustrate that during the 10 year span considered, firms experience many periods of relatively low average capital adjustment and a few periods of vivid capital adjustment with the highest average investment rate amounting to 20.4 percent.

Furthermore, the investment shares demonstrate that slightly more than 50 percent of firms' overall investments are carried out in just three years. This finding is comparable to capital adjustment patterns of U.S. manufacturing plants as highlighted by Doms and Dunne (1998). Moreover, despite the spiky realization of investment projects, firms still invest in every period.

Table 23: Mean Investment Adjustment Rates by Rank

\begin{tabular}{|c|cc|c|}
\hline (in ascending order) \\
\hline Rank & $\begin{array}{c}\text { Investment rate* } \\
\text { Mean }\end{array}$ & Std & Investment share** \\
\hline 1 & 0.027 & $(0.021)$ & 0.028 \\
2 & 0.037 & $(0.023)$ & 0.040 \\
3 & 0.046 & $(0.026)$ & 0.050 \\
4 & 0.055 & $(0.028)$ & 0.061 \\
5 & 0.064 & $(0.031)$ & 0.073 \\
6 & 0.076 & $(0.034)$ & 0.087 \\
7 & 0.090 & $(0.039)$ & 0.105 \\
8 & 0.109 & $(0.047)$ & 0.129 \\
9 & 0.140 & $(0.075)$ & 0.169 \\
10 & 0.204 & $(0.120)$ & 0.258 \\
\hline
\end{tabular}

*Mean investment rates by rank (in ascending order).

Standard deviations are in brackets.

**Defined as the ratio of a firm 's average investments to its total 10-year investments that occurs in each year.

All in all, the results on the tail behavior of the frequency distribution of the investment rate, the identified mass points around zero and the average annual investment rates and shares highlight the lumpiness in capital adjustment behavior, a pattern that is consistent with the prevalence of non-convex adjustment costs.

\section{Methodology}

Basically, to identify the structure of adjustment costs associated with capital adjustments, a stationary firm-level dynamic optimization problem is specified, explicitly 
accounting for the presence of both convex and non-convex adjustment costs. Specifically, the entrepreneur determines the optimal level of investment by maximizing the value of the firm, given costs associated with input adjustments and potential future profitability shocks:

$$
V(A, K)=\max _{I} \Pi(A, K)-C(I, A, K)+\beta E_{A^{\prime} \mid A} V\left(A^{\prime}, K^{\prime}\right) \quad \forall(A, K),
$$

where primed values refer to future values, $\Pi(A, K)$ represents the reduced form profits earned by the firm with a given capital stock $K$ and observed profitability shocks $A, \beta$ refers to the discount factor while $\beta E_{A{ }^{\prime} A} V\left(A^{\prime}, K^{\prime}\right)$ represents the present discounted future value of the firm.

The costs of adjustment are specified by the function $C(I, A, K)$ which encompasses both convex and nonconvex cost components as well as the purchase costs:

$$
C(I, A, K)=\left(\frac{\gamma}{2}\right)\left(\frac{I}{K}\right)^{2} K+F K+p I
$$

$I$ captures the equipment investment outlay which, together with today's depreciated equipment capital stock $K(1-\delta)$, determines tomorrow's capital stock $K^{\prime}=K(1-\delta)+I$. Hence, due to the complex and time-consuming nature of new capital good installation activities a time-to-build element is included so that today's new equipment investment is assumed to become operative and productive with a one-period lag.

Following Eisner and Strotz (1963) on the one hand and applying insights gained from smooth macro-level adjustment patterns on the other, micro-level input adjustment costs are specified as convex costs captured by the parameter $\gamma$ where increasing marginal costs result in continuous adjustment episodes characterized by small input modifications.

Fixed or synonymously nonconvex adjustment costs $F$ are typically associated with costs arising from the need for plant and organizational restructuring during episodes of installation of new machinery and equipment. These costs arise during each adjustment activity and are independent of the size of input adjustment, therefore render regular input changes expensive and infrequent and sizeable adjustment patterns emerge. 


\section{IV.1 Case 1: Convex Adjustment Costs only}

With a quadratic convex adjustment cost function as outlined above coupled with the uncertainty incorporated in the exogenous profitability shocks, the dynamic programming problem is specified as a stochastic problem as follows:

$V(A, K)=\max _{l} \Pi(A, K)-\left(\frac{\gamma}{2}\right)\left(\frac{I}{K}\right)^{2} K-p l+\beta E_{A^{\prime} \mid A} V\left(A^{\prime}, K^{\prime}\right) \quad \forall(A, K)$

To determine the optimal equipment capital investment strategy, the first-order condition of the maximization problem can be derived as:

$$
\left(\frac{I}{K}\right)=i=\left(\frac{1}{\gamma}\right)\left(\beta E V_{k}\left(A^{\prime}, K^{\prime}\right)-p\right)
$$

where $E V_{k}(\cdot)$ is the expected marginal value of capital and $p$ is the cost of capital. Hence, investments serve to close the gap between the cost of capital and the expected marginal value of capital with high or increasing convex adjustment costs depressing investment rates, leading to more frequent but low capital adjustments and low investment rates.

\section{IV.2 Case 2: Nonconvex Adjustment Costs only}

Once nonconvex adjustment costs are also accounted for, the dynamic programming problem becomes a stochastic discrete choice problem and the following discrete choices become conceivable: non-zero investment labeled adjustment ' $a$ ' or zeroinvestment labeled no-adjustment 'na':

$$
V(A, K)=\max \left\{V^{a}(A, K), V^{m a}(A, K)\right\} \quad \forall(A, K)
$$

$V^{\prime \prime}(A, K)$ and $V^{m a}(A, K)$ refer to the values of the firm in case of non-zero or of zero investments, respectively. Hence, the entrepreneur chooses to invest if, relative to inaction, investment leads to a higher value of the firm. In case of adjustment, the following dynamic optimization problem arises that helps to identify the optimal investment volume:

$$
V^{a}(A, K)=\max _{I} \Pi(A, K)-F K-p l+\beta E_{A \mid A^{\prime}} V\left(A^{\prime}, K^{\prime}\right) \quad \text { if } I \neq 0
$$


with $K^{\prime}=K(1-\delta)+I$.

And, in case of no-adjustment, no costs arise and the dynamic optimization problem can be represented as follows:

$V^{n a}(A, K)=\Pi(A, K)+\beta E_{A \mid A^{\prime}} V\left(A^{\prime}, K(1-\delta)\right) \quad$ if $I=0$

Hence, given observed exogenous profitability shocks, the entrepreneur invests if its capital stock is less than the optimal level or remains inactive otherwise, so there will be periods of inaction intermittent by periods of positive investment bursts.

\section{IV.3 Case 3: Convex and Nonconvex Adjustment Costs and Investment Irreversibilities}

Furthermore, accounting for perfect irreversibility that totally abolishes negative capital adjustments, the following choices become possible: positive investment labeled adjustment ' $a+$ ' or zero-investment labeled no-adjustment 'na':

$$
V(A, K)=\max \left\{V^{a+}(A, K), V^{n a}(A, K)\right\} \quad \forall(A, K) .
$$

$V^{a+}(A, K)$ and $V^{n a}(A, K)$ refer to the values of the firm in case of positive or of zero investments, respectively. Then, in case of positive adjustment, the following dynamic optimization problem arises:

$$
V^{a+}(A, K)=\max _{I} \Pi(A, K)-\left(\frac{\gamma}{2}\right)\left(\frac{I}{K}\right)^{2} K-F K-p I+\beta E_{A^{\prime \prime} A} V\left(A^{\prime}, K^{\prime}\right) \quad \text { if } I>0
$$

with $K^{\prime}=K(1-\delta)+I$.

And, in case of no-adjustment, the dynamic optimization problem is:

$$
V^{n a}(A, K)=\Pi(A, K)+\beta E_{A \mid A} V\left(A^{\prime}, K(1-\delta)\right) \quad \text { if } I=0
$$

Hence, just like in the case of nonconvex adjustment costs only, the entrepreneur invests if the firm's capital stock is less than the optimal level or remains inactive otherwise, so there will be periods of inaction intermittent by periods of positive investment bursts. This specification is subject to the empirical analysis. 
However, the latter two cases cannot be solved numerically since the presence of nonconvex adjustment costs generates discontinuous investment behavior. Instead, the numerical method of value function iteration will be utilized. Details are outlined in the next section.

\section{Estimation}

The set of structural parameters of interest $\Theta=[\gamma, F]$ is identified by applying the methodology of simulated method of moments as developed by McFadden (1989), among others. Specifically, structural parameters are chosen such that a set of moments calculated from simulated data matches the moments derived from the actual data.

For a set of arbitrary values of the parameters in $\Theta$, the underlying dynamic programming problem is solved by value function iteration. In each of the above functional equations describing the maximization behavior of entrepreneurs, the value function $V(A, K)$ itself is the unknown. This function needs to be identified to satisfy the maximization condition. Starting from an initial guess of the value function $V_{0}$, the optimization problem is solved and a new set of value functions $V_{j+1}$ is derived, initiating a reoptimization of the choice of the control variable. The iterative process is stopped when the desired value function is identified, that is once the difference between consecutive value functions satisfies a predetermined convergence criterion $\varepsilon$, i.e. $\left|V_{j+1}(\cdot)-V_{j}(\cdot)\right|<\varepsilon$ where $\varepsilon$ is a small number. Once the desired value function is known, the policy function as the optimal decision rule is derived which is used to simulate a panel of 500 firms over 100 periods. Underlying moments of the simulated panel are then estimated and compared to the respective moments from the actual data, where the moments of interest are chosen to best capture the specific characteristics of observed firm investment behavior: one, to allow for the observed lumpiness of investment activities, the moments of interest are adjustments below the $10^{\text {th }}$ percentile and above the $90^{\text {th }}$ percentile of the investment distribution; two, to account for the significance of profitability shocks for firm investment activities, as highlighted by the underlying theoretical model, the correlation between profitability shocks and capital adjustments is identified.

With $\psi^{\prime \prime}(\Theta)$ denoting the set of moments based on the simulated data given the set of parameters $\Theta$ and $\psi^{\prime \prime}$ as the set of moments calculated for the actual panel, the method of simulated moments then minimizes the weighted distance between the simulated and actual moments by solving the following specification:

$$
\Omega(\Theta)=\min _{\Theta}\left[\Psi^{\prime \prime}-\Psi^{s}(\Theta)\right]^{\prime} W\left[\Psi^{a}-\Psi^{s}(\Theta)\right]
$$


where $W$ is a weighting matrix set equal to the identity matrix. The optimization is then accomplished by applying the Nelder-Mead simplex algorithm.

\section{Profitability Shocks}

Above discussion of firm investment behavior stresses the importance of profitability shocks in determining whether and how much to invest per period. For the numerical analysis that follows, profitability shocks will be simulated based on characteristics of the actual distribution of shocks that need to be specified first.

The profitability shocks firms face can be identified directly from the data and estimated through the profit function, where profits of firm $i$ at time $t$ are a function of the profitability shocks $A_{i t}$ it faces and its capital stock $K_{\| l}$ specified as:

$\Pi\left(A_{i l}, K_{i t}\right)=A_{l i} K_{i t}^{\alpha}$

or in terms of logs

$\pi_{i t}=a_{i t}+\alpha k_{i t}$

Following Cooper and Haltiwanger (2006), profitability shocks $a_{i t}=\ln \left(A_{i t}\right)$ are assumed to have an aggregate $x_{t}$ and an idiosyncratic $\varepsilon_{i t}$ element so that: $a_{i t}=x_{t}+\varepsilon_{i l}$. Furthermore, idiosyncratic profitability shocks are assumed to follow an $\operatorname{AR}(1)$ lognormal process $\varepsilon_{i t}=\rho_{\varepsilon} \varepsilon_{i t-1}+v_{i t}$ with autocorrelation of shocks captured by $\rho_{\varepsilon}$ and $v_{i t}$ is i.i.d. Hence (5) becomes: $\pi_{i t}=\alpha k_{i t}+x_{t}+\rho_{\varepsilon} \varepsilon_{i t-1}+v_{i l}$.

Quasi-differencing this profit function yields:

$\pi_{i t}=\rho_{\varepsilon} \pi_{i t-1}+\left(\alpha k_{i t}-\rho_{\varepsilon} \alpha k_{i t-1}\right)+\left(x_{t}-\rho_{\varepsilon} x_{t-1}\right)+v_{i t}$.

Equation (6) is estimated by system GMM, where a set of time dummies is used to capture aggregate shocks $x_{t}$ and twice-lagged profits as well as lagged and twicelagged real capital stocks are used as instruments for lagged profits and current and lagged real capital stocks, respectively. The estimation result points at $\rho_{\varepsilon}$ to be 0.40 (s.e. 0.049 ) and $\alpha$ to be 0.55 (s.e. 0.0789 ) which can be used to identify the profitability shock series from equation (5). From the estimated profitability shock series, aggregate and idiosyncratic shocks can be recovered, where the aggregate shocks $x_{t}$ is captured by the annual mean of $a_{\|}$and the idiosyncratic shock $\varepsilon_{\|}$represents the deviation from the annual mean. 
For the numerical analysis and the estimation, the processes of simulated shocks are specified based on characteristics derived from estimated profitability shocks. Specifically, in the simulation, aggregate shocks are represented by two-state, first-order Markov processes with either low or high realizations $\Lambda_{t} \in\left\{\Lambda_{l}, \Lambda_{h}\right\}$ and the transition matrix between states given by $T_{A}$. The two aggregate shock realizations $\Lambda_{l}$ and $\Lambda_{h}$ as well as the between-states transition matrix $T_{A}$ are set to properly reproduce the variance and serial correlation of aggregate shocks recovered from the firm level analysis. With a standard deviation of $\sigma_{a}=0.036$, aggregate shocks are set 4 percent below and above the mean of 1 .

The transition matrix $T_{A}$ is an $n \times n$ dimensional matrix with elements $(i, j)$ that denote the probability of moving from state $i$ to state $j$. The estimated serial correlation as persistence parameter determines the probability of remaining either in state $i$ or in state $j$. With a serial correlation of $\rho_{a}=0.91$ the diagonal values of $T_{A}$ are specified.

Idiosyncratic shocks are approximated as discrete first-order Markov processes following Tauchen (1986) who demonstrates how an autoregressive process of order one can be approximated by a first-order Markov process. Said shocks are assumed to take 11 possible values with a transition matrix $T_{\varepsilon}$ and are specified to reproduce estimated characteristics of idiosyncratic shocks, i.e. a mean of 0 , a standard deviation of $\sigma_{\varepsilon}=0.88$ and a serial correlation of $\rho_{\varepsilon}=0.40$.

Table 24: Parameter Values used in the Simulation

\begin{tabular}{|c|c|c|c|c|c|c|}
\hline$\alpha$ & $\beta$ & $\delta$ & $\sigma_{a}$ & $\rho_{a}$ & $\sigma_{S}$ & $\rho_{S}$ \\
\hline 0.55 & 0.95 & 0.057 & 0.036 & 0.91 & 0.88 & 0.88 \\
\hline
\end{tabular}

The remaining parameters are as follows: the annual discount factor $\beta$ is equal to 0.95 , while the rate of capital depreciation $\delta$ is 5.7 percent calculated as the frequency weighted average depreciation rate of all two-digit industry specific depreciation rates. Table 24 provides an overview of all parameters used in the simulation exercise.

\section{Results}

The estimated structural cost parameters for fixed and convex costs, as captured by $F$ and $\gamma$, respectively, that generate the best fit between selective moments of actual and simulated investment data are reported in Table 25. With respect to the size of the parameters, convex costs dominate. Specifically, capital adjustment activities entail convex costs of 18 percent of installed capital and fixed costs of 10.5 percent of installed capital. 
The size of the fixed cost parameter well compares to the one found by Lapatinas (2007a) for Greece but is at odds with the ones identified for the U.S. by Cooper and Haltiwanger (2006) or for Columbia by Contreras (2006). However, the presence of perfect irreversibility in investment activities in Austrian manufacturing required the specification of a 'reduced' model of capital adjustment behavior to only encompass positive or zero investment activities given any external profitability shock. In that respect, Austrian results are not directly comparable to the ones derived for the U.S. or Columbia.

Table 25: Simulated Moments and Structural Cost Parameter Values

\begin{tabular}{|l|cccc|cc|}
\hline & \multicolumn{5}{|c|}{ Moments } & \multicolumn{2}{|c|}{ Parameters } \\
\hline & $\begin{array}{c}10^{\text {th }} \\
\text { Percentile }\end{array}$ & $\begin{array}{c}90^{\text {th }} \\
\text { Percentile }\end{array}$ & $\operatorname{Corr}(\mathrm{i}, \mathrm{A})$ & $\Omega(\Theta)$ & $\mathrm{F}$ & $\gamma$ \\
\cline { 2 - 7 } Actual Data & 0.0186 & 0.1616 & 0.0522 & & & \\
Simulated Data & 0.0320 & 0.0582 & 0.0125 & 0.1617 & 0.105 & 0.180 \\
& & & & & $(0.005)$ & $(0.005)$ \\
\hline
\end{tabular}

Siandard errors are reported in parenlheses.

Table 25 also reports the moments of the actual and simulated investment data that are associated with the identified structural cost parameters of interest. Obviously, none of the estimated moments perfectly resemblances the actual moments with the highest absolute deviation found for the $90^{\text {th }}$ percentile.

\section{Summary and Conclusion}

A lumpy adjustment pattern of equipment capital as characterized by periods of inaction being superseded by periods of feverish investments and a bunching of investment activities into a short period of time only also emerges for the small and open economy of Austria. This pattern is typically attributed to the existence of nonnegligible adjustment costs that arise in the course of the implementation of new equipment capital and result from the need for plant or organizational restructuring or worker retraining. Given the decisive role of investment specific technology in determining macroeconomic performance, understanding the determinants and patterns of investments in machinery and equipment that embodies recent and productivity enhancing technological knowledge becomes a critical concern.

This paper sheds light on the exact nature of capital adjustment costs in terms of convex and nonconvex components, subject to perfect irreversibility, prevailing in Austrian manufacturing between 1982 and 1991 . Methodologically, a discrete stochastic optimization problem of equipment investment with both convex and nonconvex adjustment costs governing investment behavior in the light of exogenous productivity shocks is specified and solved by means of value-function iterations. The methodology of the simulated method of moments is applied that rests on the idea that underlying structural cost parameters of interest can be identified by match- 
ing moments of data simulated on the basis of a combination of cost parameters with observed key moments of actual data.

The results show that firms in Austrian manufacturing face fixed costs of adjustment of 10.5 percent of installed capital and convex costs of 18 percent of installed capital in the course of the adjustment of machinery and equipment. The significance of fixed adjustment costs therefore invalidates the traditional neoclassical hypothesis of only convex adjustment costs affecting investment behavior but points at the vital role fixed costs play. Hence, adjustment frictions are key in determining investment patterns which are known to be decisive for macroeconomic performance and labor market dynamics.

Unfortunately, the results are not directly comparable with those available for the U.S. or Columbia since lacking disinvestment series made the specification of a discrete choice model under perfect irreversibilities necessary. With perfect irreversibility, however, Cooper and Haltiwanger (2006) implicitly demonstrate that a considerable part of the irreversibility effect is then absorbed by the fixed cost parameter. This also helps to explain the high cost parameters found for Austrian and Greek manufacturing. Overall, the results well compare to cost parameters found by Lapatinas (2007a) for Greek manufacturing who also applied a discrete choice model subject to perfect irreversibilities.

Furthermore, it is also worth noting that the above analysis is based on firmgroups instead of individual firms or establishments. And given the cushioning effect of aggregation, higher capital adjustment costs are expected to actually prevail in Austrian manufacturing. 


\section{Appendix}

Table 26: Cross Country Comparison of Investment Rate Characteristics

\begin{tabular}{|l|rrrr|}
\hline & Austria & U.S & Columbia & Greece \\
\hline Average Rate & $8.5 \%$ & $12.2 \%$ & - & $18.1 \%$ \\
Inaction Rate & $5.6 \%$ & $8.1 \%$ & $18.9 \%$ & $1 \%$ \\
Frequency of positive adjustments & $94.4 \%$ & $81.5 \%$ & - & - \\
Frequency of negative adjustments & $0 \%$ & $10.4 \%$ & - & - \\
Spike rate $>20 \%$ & $6.3 \%$ & $18.6 \%$ & $29.8 \%$ & $31.7 \%$ \\
Spike rate $<-20 \%$ & $0 \%$ & $1.8 \%$ & $1.8 \%$ & $0.6 \%$ \\
First order autocorrelation of investment & 0.136 & 0.058 & 0.025 & 0.17 \\
rates & & & & \\
Correlation of investment rates and profit & 0.055 & 0.143 & - & - \\
shocks & $(0.000)$ & $(0.003)$ & & \\
\hline
\end{tabular}

Table 27: Cross Country Comparison of Results

\begin{tabular}{|l|llll|}
\hline Cost parameters* & Austria & U.S & Columbia $^{i}$ & Greece \\
\hline Convex costs: $\gamma$ & 0.18 & 0.049 & 0.000006 & 0.5164 \\
Fixed costs: $F$ & 0.105 & 0.039 & 0.0002 & 0.1557 \\
Fixed costs: $\lambda$ & - & 0.796 & 0.0002 & - \\
lrreversibilities: $p_{\mathrm{s}}$ & - & 0.975 & $0.42 * \mathrm{pi}$ & - \\
\hline
\end{tabular}

* All cost parameters refer to the models including all parameters.

'Only the parameters for capital adjustment cosis are reported. 


\section{Summary and Conclusion}

The idea that much of technological progress is embodied in new capital equipment with streams of new and more efficient generations of capital vintages continuously replacing obsolete ones is an old and highly disputed one. However, it was not until more appropriate and reliable data became available in the early 1990's that the decisive role of embodied, or synonymously, investment specific technological change became evident: embodied technological change is a major driver of longterm economic growth and of short-term business cycles. In this regard, investment activities in new and more efficient leading-edge vintages act as carriers of embodied technology and become the key transmission mechanism from technological change to productivity and output growth. Hence, given the vital role of investments, identifying prevailing firm-level investment patterns and underlying determinants of investment activities turns out to be essential for understanding cross-country macroeconomic performance differences or labor market outcomes and dynamics in case of strong capital-labor complementarities.

The present thesis revolves around issues related to embodied technological change and firm-level investment patterns and takes the small and open economy of Austria as the empirical platform.

The significance of both neutral and investment specific technology for shaping Austrian business cycles between 1977 and 2005 is established in chapter two. Methodologically, a spectral analysis is applied to the dynamic correlation of actual and simulated variations in hours worked and output as the two business cycle proxies. It is a procedure that decomposes a time series into a spectrum of cycles of different lengths and therefore serves to identify periodicities inherent in time series. This particular approach is taken for two major reasons: one, to avoid the generation of spurious cycles during filtering aimed at extracting business cycle components from underlying data and, two, to also shed light on the roles of both technology shocks for other than business cycle frequencies. This alternative methodological approach is also the major contribution and strength of this chapter.

The results demonstrate that technology indeed plays a decisive role in explaining variations in output but is of moderate importance only for cyclical variations in hours worked. This overall strong effect of technology on variations in output stems from the substantial expansion of output in conjunction with the productivityenhancing effect of technological change. The relatively modest response of hours worked to technology shocks seems to suggest that either technology shocks do not necessitate substantial adjustments in hours worked to accompany changes in output or entrepreneurs also adjust total employment to satisfy new hours input requirements. And provided that average hours worked per employee remains fairly unaffected, employment adjustments would not translate into variations in hours. However, in the light of substantial costs of adjustment associated with hiring or firing 
activities of employees and the more flexible hours variable at hand, the latter scenario appears highly unlikely.

Furthermore, a decomposition of the overall effect on either business cycle proxy into a component explained by investment specific technology shocks and a component explained by neutral technology shocks emphasizes the dominant role neutral technology shocks play. This is probably due to two effects: the inferior proxy for investment specific technology shocks that is not explicitly adjusted to account for quality improvements of technological change in the tradition of Gordon (1990) as well as the relatively sluggish diffusion of leading-edge technologies as captured by the relatively stable ratio of equipment investments to GDP in Austria.

The alternative methodological approach pursued in this chapter also allows to look beyond business cycle frequencies and to determine different and changing roles of both technology shocks for the very short and long run. The results highlight that neutral technology shocks more strongly contribute to variations in hours or output in the medium to long run compared to the short run. On the other hand, investment specific technology shocks matter most for variations in output in the very short run. The stronger medium to long term role of neutral technology shocks appears to indicate that learning effects of how to efficiently exploit productivity-enhancing new technologies unfold over time and increasingly contribute to business cycle variations in hours worked and output.

And finally, in the very short run, the contribution of investment specific technology shocks to variations in hours and output is strongly hump-shaped like and only slowly rises thereafter. The presence of disruptive effects in the course of the implementation of new technologies embodied in new machinery and equipment that lead to temporary losses in productivity and output coupled with the swarming effect of investment activities help to explain this pattern. Once a large group of entrepreneurs implements the latest technology, productivity drops and only slowly recovers after the initial disruptive effects are overcome.

Since investment-specific technological change is found to matter for Austrian business cycles, investments in new capital vintages become the key carrier in translating technological change to growth in productivity and output. The third chapter is therefore devoted to identifying general patterns of equipment investment activities as carriers of embodied technology in a sample of Austrian manufacturing firms between 1982 and 1991. Specifically, the chapter draws a comprehensive, rich and coherent picture of micro-level input adjustment patterns and focuses on equipment investments as well as employment, production and non-production labor. Key issues of lumpiness, dynamic interrelatedness of factor inputs and of temporary disruptive effects of drastic input adjustments are addressed. It furthermore identifies macroeconomic and firm characteristics that are conducive for drastic input modifications.

The analysis demonstrates that input adjustments are highly erratic and lumpy and that equipment investments, employment and production and non-production labor all represent strategic complements. Moreover, lumpy investment activities are found to require preparatory training activities of production labor ahead of the 
implementation of new and technologically more sophisticated machinery and equipment and to necessitate the expansion of non-production labor due to increased organizational and administrative complexity.

In terms of performance, there is evidence of significant temporary productivity and profitability disruptions in the course of drastic input adjustments. Moreover, labor productivity and profitability asymmetrically respond to observed spikes.

Labor productivity disruptions are found to be temporary in nature only and are strictly confined to the period of the spike event only. The hypothesis of a potential temporary disruptive effect of newly implemented machinery and equipment on labor productivity during periods of retooling and reorganization is consistently invalidated while significant productivity-enhancing learning-by-doing dynamics surface.

Finally, major personnel cutbacks have asymmetric effects on firm profits: permanent losses in the course of non-production labor cuts and no significant effects in response to production labor reductions. This is probably due to the loss of a significant portion of firm-specific knowledge embodied in non-production labor and should induce entrepreneurs to less frequently or less substantially reduce non-production labor.

The analysis also identifies firm characteristics conducive for input adjustments and demonstrates that relative to larger firms smaller ones are more likely to shrink.

Personnel costs are found to matter in that higher average personnel costs lower the probability of positive labor-related input spikes and vice versa. Additionally, the results highlight the absence of any significant cost-related effects on negative nonproduction labor spikes which probably points at the importance of asymmetric fixed labor adjustment costs associated with the reduction of non-production labor. In general, substantial input adjustment spikes in Austrian manufacturing already stress the importance of fixed adjustment costs for firm input adjustment behavior. But the dissimilar response of non-production labor to rising personnel costs points at different underlying forces driving adjustment dynamics. Both, relatively restrictive firing rules characteristic of the Austrian labor market as well as identified significant productivity or profitability losses after drastic non-production labor cuts are compatible with this pattern. The Austrian labor market is known to be strongly regulated aimed at achieving a higher level of employment under socially acceptable and fair conditions. And relatively restrictive firing rules are in place to accomplish that goal. Probably, labor regulations work in favor of non-production labor making it harder and more expensive to adjust. Furthermore, the lasting and significant drop of firm profits after drastic non-production labor reductions highlighted above lends support to the hypothesis of asymmetric fixed costs of adjustment. Moreover, labor cost considerations appear irrelevant for the realization of large investment projects which are carried out irrespective of adverse labor cost developments.

Finally, spike events are clearly procyclical since positive spikes are bunched in periods of economic recovery and growth while negative ones are concentrated in economic recessions. Furthermore, consistently procyclical absolute and relative equipment investment spikes invalidate the pit-stop idea of recessions that highlights 
the implementation of disruptive leading-edge technologies embodied in machinery and equipment during recessionary periods of relatively low opportunity costs. However, empirical evidence points at the absence of any disruptive effects in conjunction with the adoption of new equipment and machinery but stresses the prevalence of learning effects and fixed costs as manifested in lumpy investment patterns. Consequently, procyclical investment behavior comes at no surprise.

Finally, the last chapter seeks to explain identified lumpy equipment investment patterns in terms of adjustment costs. Specifically, the exact nature of adjustment costs that govern equipment investment behavior in Austrian manufacturing between 1982 and 1991 is sought for. The analysis explicitly accounts for perfect irreversibility apparent in the data due to lacking disinvestment series and specifies a discrete stochastic dynamic programming problem of equipment capital adjustment which only accounts for non-zero investment activities. Methodologically, the simulated method of moments is applied to estimate underlying structural cost parameters. The approach rests on the idea that structural parameters of interest can be identified by matching moments of simulated data with observed key moments of actual data. The moments of interest are chosen to best capture the observed lumpy investment behavior.

The analysis emphasizes the prevalence of non-negligible adjustment frictions in Austrian manufacturing that emerge in the course of the adjustment of the stock of machinery and equipment. Results therefore invalidate the neoclassical assumption of only convex adjustment costs governing investment behavior. Specifically, on average, for each investment activity, a firm has to shoulder fixed costs of 10.5 percent of its installed capital and convex costs of 18 percent of its installed capital which renders a frequent and smooth capital adjustment pattern costly and inefficient but gives rise to infrequent and lumpy adjustment behavior instead.

However, the analysis is subject to two major limitations.

One, lacking disinvestment series and the arising necessity to specify a discrete choice model of perfect irreversibility that only accounts for non-negative investment activities, renders international comparability of results risky, if not impossible. Except for a similar study conducted by Lapatinas (2007a) for Greek manufacturing that also explicitly accounts of prevailing perfect irreversibility in investments and gives rise to a similar fixed cost parameter, Austrian results cannot be directly compared. Cooper and Haltiwanger (2006) implicitly demonstrate that the fixed cost parameter tends to absorb a significant fraction of the irreversibility effect if it is not explicitly accounted for. This probably explains the higher fixed cost parameters found in the Austrian and Greek cases.

And two, the analysis is based on a set of firm-groups instead of individual firm observations and given the cushioning effect of aggregation, higher than estimated adjustment costs are expected to actually exist in Austrian manufacturing. 


\section{References}

Abel, A. B. and J. C. Eberly, 1994, A Unified Model of Investment under Uncertainty, The American Economic Review 84(2), 1369-84

Abowd, J. M. and F. Kramarz, 1997, The Costs of Hiring and Separations, NBER Working Paper No. 6110

Alonso-Borrego, C., 1998, Demand for Labour Inputs and Adjustment Costs: Evidence from Spanish Manufacturing Firms, Labour Economics 5, 475-97

Arrow, K. J., 1968, Optimal Capital Policy with Irreversible Investment, in J. N. Wolfe (ed.), Value, Capital and Growth, Papers in Honour of Sir John Hicks, Edinburgh: Edinburgh University Press, $1-19$

Asano, H., 2002, An Empirical Analysis of Lumpy Investment: The Case of US Petroleum Refining Industry, Energy Economics 24(6), 629-45

Attanasio. O. P., Pacelli, L. and I. Reduto dos Reis, 2003, Investment Patterns in UK Manufacturing Establishments, Working Paper No. 67 del Dipartimento di Scienze Economiche e Finanziarie, Università di Torino

Barnett, S. A. and P. Sakellaris, 1998, Nonlinear Response of Firm Investment to Q: Testing a Model of Convex and Non-Convex Adjustment Costs, Journal of Monetary Economics 42, 261-88

Bartel, A. P and F. R. Lichtenberg, 1987, The Comparative Advantage of Educated Workers in Implementing New Technology, The Review of Economics and Statistics 69 (1) 1-11

Basu, S., Fernald, J, Kimball, M., 2006, Are Technology Improvements Contractionary?, The American Economic Review 96(5), 1418-48

Baumgartner, J., Glatzer, E., Rumler, F. and A. Stiglbauer, 2005, How Frequently Do Consumer Prices Change in Austria? Evidence from Micro CPI Data, OeNB Working Paper 101

Baxter, M. and R. G. King, 1999, Measuring Business Cycles: Approximate Band-Pass Filters for Economic Time Series. The Review of Economics and Statistics Vol. 81(4), 575-593

Bayraktar, N., Sakellaris, P. and P. Vermeulen, 2005, Real versus Financial Frictions to Capital Investment, Working Paper No. 566, European Central Bank

Bigsten, A., Collier, P., Dercon, S., Fafchamps, M., Gauthier,B., Funning, J. W., Oostendorp, R., Pattillo, C., Söderbom, M. and F. Teal, 2005, Adjustment Costs and Irreversibility as Determinants of Investment: Evidence from $\Lambda$ frican Manufacturing,

Blanchard, O. J. and D. Qual,, 1989, The Dynamic Effects of Aggregate Demand and Supply Disturbances, American Economic Review Vol. 79(4), 655-73

Broersma, L., McGuckin, R. H. and M. P. Timmer, 2003, The Impact of Computers on Productivit in the Trade Sector: Explorations with Dutch Microdata. De Economist 151, No. 1, 53-79

Caballero, R. J. Engel, E. and J. Haltiwanger, 1995a, Plant-Level Adjustment and Aggregate Investment Dynamics, Brookings Papers on Economic Activity 1995(2), 1-54

Caballero, R. J. Engel, E. and J. Haltiwanger, 1995b, Aggregate Employment Dynamics: Building From Microeconomic Evidence, NBER Working Paper No. 5042

Caballero, R. J and M. L. Hamour, 1994, The Cleansing Effect of Recessions, American Economic Review 84(2), 1350-68

Carlsson, M. and S. Laséen, 2001, Capital Adjustment Patterns in Swedish Manufacturing Firms: What Model Do They Suggest?, Economic Journal 115, 969-86

Christiano, L. J., Eichenbaum, M. and R. Vigfusson, 2003, What Happens After A Technology Shock?, Board of Governors of the Federal Reserve System, International Finance Discussion Paper No. 768

Cogley, T. and J. M. Nason, 1995, Effects of Hodrick-Prescott Filter on Trend and Difference Stationary Time Series: Implications for Business Cycle Research, Journal of Economic Dynamics and Control $19,253-78$

Collard, F. and H. Dellas, 2002, Technology Shocks and Employment, University of Bern Diskussionsschriften $02-17$ 
Contreras, J. M., 2006, An Empirical Model of Factor Adjustment Dynamics, Working Paper Series No. 2006-13, Congressional Budget Office

Cooper, R. W. and J. C. Haltiwanger, 2006, On the Nature of Capital Adjustment Costs, Review of Economic Studies 73, 611-33

Cooper, R. W. and J. C. Haltiwanger, 1993, The Aggregate Implications of Machine Replacement: Theory and Evidence, American Economic Review 83(3), 360-82

Cooper, R. W., Haltiwanger, J. C. and L. Power, 1995, Machine Replacenent and the Business Cycle: Lumps and Bumps, NBER Working Paper No. 5260

Croux, C., Forni, M. and L. Reichlin, 2001, A Measure of Comovement for Economic Variables: Theory and Empirics, The Review of Economics and Statistics 83(2), 232-41

Cummins, J. and G. L. Violante, 2002, Investment-Specific Technical Change in the United States (19472000): Measurement and Macroeconomic Consequences, Review of Economic Dynamics 5 (2), 243-284

Doms, M. and T. Dunne, 1998, Capital Adjustment Patterns in Manufacturing Plants, Review of Economic Dynamics 1, 409-29

Dunne, T., Haltiwanger, J. and K. R. Troske (1996):'Teclunology and Jobs: Secular changes and Cyclical Dynamics', NBER Working Paper Series No 5656

Eisner, R, and R. H. Strolz, Determinants of Business Investment, in Commission on Money and Credit. Impacts of Monetary Policy, Englewood Cliffs, NJ: Prentice Hall, 1963, 59-337

Evans, C. L., 1992, Productivity Shocks and Real Business Cycles, Journal of Monetary Economics 29(2), $191-208$

Fennema, J., Letterie, W. and G. Pfann, 2006, The Timing of Investment Episodes in the Netherlands, De Economist $154,373-88$

Fisher, J. D. M., 2006, The Dynamic Effects of Neutral and Investment-Specific Technology Shocks, Journal of Political Economy 114(3), 413-51

Fisher, J. D. M., 2002, Technology Shocks Matter, mimeo, Federal Reserve Bank of Chicago

Flug, K. and Z. Hercowitz, 2000, Equipment Investment and the Relative Demand for Skilled Labor: International Evidence, The Review of Economic Dynamics 3, 461-85

Francis, N. and V. A. Ramey, 2005, Is the Technology-Driven Real Business Cycle Hypothesis Dead? Shocks and Aggregate Fluctuations Revisited, Journal of Monetary Economics 52, $1379-99$

Fuentes, O., Gilchrist, S. and M. Rysman, 2004, Discrete Adjustment Costs and Investment Dynamics for Chilean Manufacturing Firms: A Maximum Likelihood Approach, Working Paper

Gali, J., 1999, Technology, Employment, and the Business Cycle: Do Technology Shocks Explain Aggregate Fluctuations?, The American Economic Review 89(1), 249-71

Gambetti, L, 2005, Technology Shocks and the Response of Hours Worked: Time-Varying Dynamics Matter, mimeo, Job Market Paper, Univeristat Pompu Fabra

Gelos, G, and A. Isgut, 2001, Fixed Capital Adjustment: Is Latin America Different?, The Review of Economics and Statistics 83(4), 717-26

Goolsbee, A., 1998, The Business Cycle, Financial Performance, and the Retirement of Capital Goods, NBER Working Paper No 6392

Goolsbee, A. and D. B. Gross, 1997, Estimating Adjustment Costs with Data on Heterogeneous Capital Goods, NBER Working Paper No. 6342

Gordon, R. J., 1996, Can Technology Improvements Cause Productivity Slowdowns? Comment, in NBER Macroeconomics Annual 1996, (eds.) Rotemberg J. J. and B. S. Bernanke. Cambridge, MA: MIT Press

Gordon, R. J., 1990, The Measurement of Durable Goods Prices. Chicago: University of Chicago Press

Gort, M. and R. Wall, 1998, Obsolescence, Input Augmentation, and Growth Accounting. European Economic Review, 42, 1653-65

Greenwood, J, Hercowitz Z. and P. Krusell, 2000, The Role of Investment-Specific Technological Change in the Business Cycle, European Economic Review 44, 91-115

Greenwood, J, Hercowitz Z. and P. Krusell, 1997, Long-Run Implications of Investment-Specific Technological Change, The American Economic Review 87(3), 342-62

Hahn, F. and I. Schmoranz, 1984, Estimates of Capital Stock by Industries for Austria, Review of Income and Wealth $30,289-307$ 
Hall, R., 1989, The Relation between Prices and Marginal Cost in U.S. Industry, Journal of Political Economy 96(5), 921-47

Hamermesh, D. S., 1992, A General Model of Dynamic Labor Demand. Review of Economics and Statistics 74(4), 733-37

Hamermesh, D. S., 1989, Labor Demand and the Structure of Adjustment Costs, American Economic Review 79(4), 674-89

Hamermesh, D. S. and G. A. Pfann, 1996, Adjustment Costs in Factor Demand, Journal of Economic Literature 34, 1264-92

Hamermesh. D. S. and G. A. Pfann, 1992. Turnover and the Dynamics of Labor Demand. NBER Working Paper No. 4204

Harvey, A. and A. Jaeger, 1993, Detrending, Stylized Facts and the Business Cycle, Journal of Applied Econometrics 8, 231-47

Hercowitz, Z.. 1998, The 'Embodiement' Controversy: A Review Essay, Journal of Monetary Economics $41.217-24$

Hobijn. B., 2000, Identifying Sources of Growth, mimeo, Federal Reserve Bank of New York

Hobijn, B., Oviedo A. M. and A. Vasan, 2002, Embodied Technological Change in US Manufacturing, mimeo, Federal Reserve Bank of New York

Hoover, K. D. and S. J. Perez, 1994, Post hoc ergo procter once more: An Evaluation of 'Does Monetary Policy Matler?' in the Spirit of James Tobin, Journal of Monetary Economics 34, 47.74

Huggett, M. and S. Ospina, 2001, Does Productivity Growth Fall after the Adoption of New Technology? Journal of Monctary Economics 48(1), 173-95

Hylleberg, S., Engle, R. F., Granger, C. W. and B. S. Yoo, 1990, Seasonal Integration and Cointegration, Journal of Econometrics 44, 215-38

Khan, H. and J. Tsoukalas, 2006, Technology Shocks and UK Business Cycles, Macroeconomics Working Paper No. 0512006

Klenow, P. J., 1998, Learning Curves and the Cyclical Behavior of Manufacturing Industries, Review of Economic Dynamics 1, $531-50$

Kwiatkowski, D. P.. Phillips, C. B., Schmidt, P. and Y. Shin, 1992, Testing the Null Hypothesis of Stationarity Against the Alternative of a Unit Root, Journal of Econometrics Vol. 54, 159-78

Lapatinas, A., 2007a, Investment Decisions and Capital Adjustment Costs: Estimation of a Dynamic Discrete Choice Model Using Panel Data for Greek Manufacturing Firms, Department of Economics Working Paper Series

Lapatinas, A., 2007b, On the Structure of Labour Adjustment Costs, Department of Economics Working Paper Series

Letterie, W. A. and G. A. Pfann, 2007, Structural Identification of High and Low Investment Regimes, Journal of Monetary Economics 54, 797-819

Letterie, W. A., Pfann, G. A. and J. M. Polder, 2004, Factor Adjustment Spikes and Interrelation: An Empirical Investigation, Economics Letters 85, 145-50

Licandro. O., Maroto, R. and L. A. Puch, 2005, Innovation, Machine Replacement and Productivity, CEPR Discussion Paper No. 5422

Lätkepohl, HI., 2005, New Introduction to Multiple Time Series Analysis, Springer-Verlag: Berlin Heidelberg

McFadden, D., 1989, A Method of Simulated Moments for Estimation of Discrete Response Models without Numerical Integration, Econometrica 57, 995-1026

Nickell, S. J., 1986, Dynamic Models of Labour Demand, in Ashenfelter, Orley and David Layared (eds.) Handbook of Labor Economics, Volume I, Amsterdam. North Holland

Nickell, S. J., 1978, The Investment Decisions of Firms, James Nisbet \& Co Lid., Cambridge University Press

Nilsen, O. A., Raknerud, A.. Rybalka, M. and T. Skjerpen, 2006, Lumpy Investment, Factor Adjustments and Productivity, Norwegian School of Economics and Business Administration Working Paper

Nilsen, O. A., Salvanes, K. G. and F. Schiantarelli, 2007, Employment Changes, the Structure of Adjustment Costs, and Plant Size, European Economic Review 51, 577-98

Nilsen, O. A. and F. Schiantarelli, 2003, Zeros and Lumps in Investment: Empirical Evidence on Irreversibilities and Nonconvexities, The Review of Economics and Statistics 85(4), 1021-37 
OECD. 1993. Methods Used by OECD Countries to Measure Stocks of Fixed Capital. National Accounts: Sources and Methods No. 2

Pfann, G. A. and F. C. Palm, 1993, Asymmetric Adjustment Costs in Non-linear Labour Demand Models fort he Netherlands and U.K. Manufacturing Sectors, Review of Economic Studies 60, 397-412

Pfann, G. A. and B. Verspagen, 1989, The Structure of Adjustment Costs for Labor in the Dutch Manufacturing Sector, Economic Letters 29,365-71

Portugal, P. and J. Varejäo, 2007. Employment Dynamics and the Structure of Labor Adjustment Costs, Journal of Labor Economics 25(1), 137-65

Power, L., 1998, The Missing Link: Technology, Investment, and Productivity, Review of Economics and Statistics 80, 300-13

Robertson, R, and D. H. Dutkowsky, 2002, Labor Adjustment Costs in a Destination Country: The Case of Mexico, Journal of Development Economics 67, 29-54

Rota. P., 2001, Dynamic Labour Demand with Lumpy and Kinked Adjustment Costs, ETA - Economic Theory and Application, Fondazione Eni Enrico Mattei

Sakellaris, P., 2004, Patterns of Plant Adjustment, Journal of Monetary Economies 5 I (2), 425-50

Sakellaris, P. and D. J. Wilson, 2004, Quantifying embodied technological change, Review of Economic Dynamics $7,1-26$

Sánchez-Mangas, R., 2002, Estimation of a Dynamic Discrete Choice Model of Irreversible Investment, Statistics and Econometrics Working Paper No.01-56 (28), Universidad Carlos IIl de Madrid

Schenk, W. and G. Fink, 1976, Das Brutto-Sachanlagevermogen der osterreichischen Industrie 1955 bis 1973, WIFO-Monatsbericht 10/76

Schumpeter, J. A. (1934) The Theory of Economic Development. Cambridge: Harvard University Press

Shapiro, M. D. and M. W. Watson, 1988, Sources of Business Cycle Fluctuations, Cowles Foundation Discussion Paper No. 870

Shea, J., 1998, What Do Technology Shocks Do?, NBER Macrocconomics Annual, 275-310

Sussmuth, B., 2003, Are Procyclical Lumpiness and Asymmetry in Capital Adjustment Dateless Phenomena? The Case of Firms in German Industrialization: 1880-1913, Applied Economics Letters 10. 575-79

Tauchen, G., 1986, Finite State Markov-Chain Approximations to Univariate and Vector Autoregressions, Economics Letters 20, 177-81

Varejaxo. J. and P. Portugal, 2007, Employment Dynamics and the Structure of Labor Adjustment Costs, Journal of Labor Economics 25(1), 137-65

Verick, S., Letterie, W. and G. Pfann, 2004, Non-Linearities in the Expansion of Capital Stock, IZA Discussion Paper No. 1132 


\section{Nederlandse samenvatting}

Pas in de jaren negentig, met het baanbrekende werk van Gordon (1990), werd het tot dan toe zeer omstreden idee van technologische verandering belichaamd in nieuwe generaties van kapitaalgoederen, waarbij nieuwe investeringen continu oude kapitaalgoederen overbodig maken, algemeen aanvaard en werd zijn beslissende rol duidelijk: belichaamde technologische verandering is een belangrijke oorzaak van economische groei op lange termijn en van economische conjunctuur op korte termijn. De vraag welk aandeel van de naoorlogse conjunctuur van de kleine en zeer open Oostenrijkse economie kan worden toegeschreven aan de belichaamde, of synoniem, generatiespecifieke technologische verandering en welk deel aan neutrale technologische verandering, is het onderwerp van de analyse in het tweede hoofdstuk. Recentelijke productiviteitsverbeteringen, samengaand met een extreme oriëntatie naar buiten toe en de dominantie van hoogtechnologische producten in zijn handelsportfolio, geven de indruk dat technologie van grote invloed is op de macroeconomische prestaties en daarom is Oostenrijk een interessante casus om te bestuderen. Om tegengestelde en misleidende effecten van filtering tegen te gaan en tevens om verder te kijken dan de frequenties van conjunctuurcycli, is een dichtheidsanalyse van de dynamische correlatie van werkelijke en aan technologische schokken gerelateerde gesimuleerde variatie in productie en gewerkte uren verricht. De resultaten bevestigen de doorslaggevende, maar afwijkende rol van technologie en benadrukken zijn sterkere significantie voor productie in vergelijking tot gewerkte uren. De resultaten benadrukken ook de dominantie van neutrale technologische schokken in het vormen van de Oostenrijkse conjunctuurcycli, welke deels kan worden herleid tot een imperfecte benadering van investeringspecifieke technologische schokken en tot een relatief langzame diffusie van de nieuwste technologieën in Oostenrijk. Tenslotte spelen specifieke en neutrale technologische schokken verschillende rollen afhankelijk van de tijdsfrequentie. Een sterkere rol voor technologische schokken op de middellange tot lange termijn geeft aan dat leereffecten betreffende hoe het efficiënt te exploiteren van productiviteitsverhogende nieuwe technologieën in toenemende mate bijdraagt aan variaties in conjunctuurcycli.

In het licht van de geïdentificeerde cruciale rol van investeringspecifieke technologische verandering voor macro-economische prestaties, worden investeringen als dragers van belichaamde technologie het belangrijkste transitiemechanisme van technologie naar productiviteit en productieveranderingen en wordt een diepgaand begrip van investeringstrategieën van vitaal belang. Het derde hoofdstuk identificeert daarom de algemene patronen van investeringsactiviteiten voor kapitaalgoederen in een steekproef van Oostenrijkse bedrijven in de maakindustrie gedurende de periode 1982 tot 1991 en van complementaire, arbeidsgerelateerde factoren zoals de werkgelegenheid van productie- en niet-productiewerknemers. De analyse laat zien dat inputaanpassingen in hoge mate onregelmatig en discreet zijn en dat alle inputs sterk 
inter-temporeel gerelateerd zijn. Discrete investeringsactiviteiten vereisen trainingsactiviteiten voor productiewerkers voorafgaand aan de implementatie van technologisch geavanceerde machines en resulteert in uitbreiding van niet-productie arbeid door toenemende organisatie- en administratiecomplexiteit. Er is ook bewijs voor een significante, tijdelijke en asymmetrische productiviteit- en winstgevendheidverstoringen in de loop van drastische inputaanpassingen. Er is geen steun gevonden voor de hypothese dat een potentieel tijdelijk verstorend effect van nieuw geïnstalleerde machines op arbeidsproductiviteit tijdens perioden van reorganisatie. Wel komen belangrijke productiviteitsbevorderende dynamische leereffecten aan de oppervlakte. De analyse identificeert ook bedrijfskarakteristieken dienstig aan inputaanpassingen en demonstreert dat loontoename niet leidt tot grote afnamen in de werkgelegenheid van niet-productie werkers. Zowel de restrictieve ontslagregulering van de Oostenrijkse arbeidsmarkt als het significante verlies van winstgevendheid in de nasleep van drastisch werkgelegenheidsverlies voor niet-productie werkers komen overeen met dit patroon. Ten slotte blijken discrete inputaanpassingen procyclisch te zijn, wat tegenstrijdig is met het idee dat recessies optimale tijden zijn om inefficiënte, gedateerde of slecht functionerende machines te vervangen.

Hoofdstuk vier tenslotte gaat uit van de veronderstelling dat de discrete en onregelmatige investeringspatronen in de Oostenrijkse maakindustrie, benadrukt in hoofdstuk drie, voortkomen uit niet-verwaarloosbare aanpassingsfricties. Het tracht te identificeren wat de natuur is van de onderliggende aanpassingskosten in termen van convexe en niet-convexe aanpassingskosten in het licht van onomkeerbare investeringen. Om de onderliggende structurele kostenparameters te schatten is de gesimuleerde methode van momenten toegepast, welke gebaseerd is op het idee dat de relevante structurele parameters geïdentificeerd kunnen worden door de momenten van gesimuleerde data aan te passen aan de belangrijkste geobserveerde momenten van de werkelijke data. De relevante werkelijke momenten zijn zo gekozen dat ze het beste de zeer specifieke karakteristieken van het geobserveerde investeringsgedrag meten. De analyse laat zien dat in de Oostenrijkse maakindustrie voor machines niet-verwaarloosbare aanpassingsfricties bestaan, omdat voor elke investeringsactiviteit een bedrijf vaste kosten moet dragen ter grootte van 10,5 procent van zijn geïnstalleerde kapitaal en convexe kosten heeft ter grootte van 18 procent van zijn geïnstalleerde kapitaal. 


\title{
Curriculum Vitae
}

Sandra M. Leitner

\author{
Date of birth January 30,1974 \\ Place of birth Linz, Austria
}

\section{Education}

$2008-2009$ MA Contemporary Asian Studies

University of Amsterdam, The Netherlands

2002 - 2009 PhD Candidate

Maastricht Economic and Social Research and Training Centre on Innovation and Technology (UNU-MERIT), University of Maastricht, The Netherlands

1999/2000 Erasmus Exchange Student University of Cambridge, UK

$1995-2001 \quad$ Master Studies in Economics

Johannes Kepler University Linz, Austria

\section{Professional experience}

2006 - 2008 Researcher, Vienna Institute for International Economic Studies (wiiw), Austria

2006-2008 Assistant Professor, Department of Economics, Johannes Kepler University Linz, Austria

2005 - 2006 Researcher, Institute for Technology and Regional Policy, InTeReg, Joanneum Research Graz, Austria

2004 Visiting Researcher, Philippine Institute for Development Studies (PIDS), Philippines

Summer 2004 Lecturer for "Economics of Technology and Technical Change", Ateneo de Manila University, Philippines

2002 - 2004 Lecturer, Public Finance, Johannes Kepler University Linz, Austria

2001 - 2002 Project Assistant, Johannes Kepler University Linz, Austria

2000-2001 Project Assistant, Vienna Institute for International Economic Studies (wiiw), Austria

1998 - 1999 Project Assistant, Johannes Kepler University Linz, Austria 